UNIVERSIDADE DE SÃO PAULO

FACULDADE DE SAÚDE PÚBLICA

DEPARTAMENTO DE SAÚDE MATERNO-INFANTIL

\title{
CONDIÇÕES DE NASCIMENTO \\ E DESIGUALDADE SOCIAL
}

ROBERTO TEIXEIRA LIMA

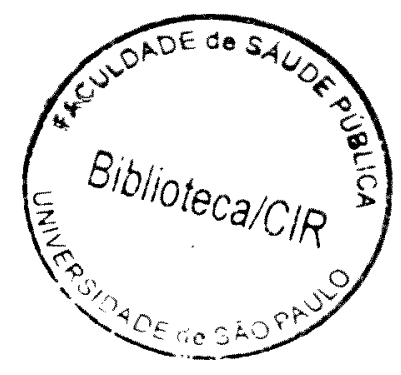




\section{FICHA CATALOGRÁFICA}

\section{M289v \\ TEIXEIRA-LIMA R. Condições de nascimento e desigualdade social/Roberto Teixeira Lima. São Paulo/SP, 2001; p.200. \\ Orientadora: Profa Dra Augusta Thereza de Alvarenga Tese (Doutorado) Faculdade de Saúde Pública da USP. \\ 1. Baixo peso ao nascer. 2. Mortalidade neonatal precoce.}

3. Assistência pré-natal. 4. Assistência ao parto. 5. Classe Social.

I. Augusta Thereza de Alvarenga. II. Faculdade de Saúde Pública da USP. III. Título.

Autorizo, exclusivamente para fins de pesquisa acadêmica, a reprodução parcial ou total desta tese, por processos fotocopiadores:

Assinatura do autor:

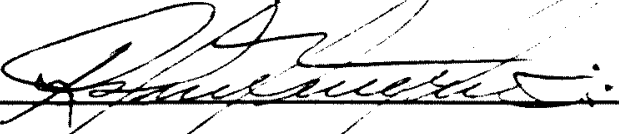

Data: $05 / 00 / 04$ 
"Até que ponto devem ser reconhecidos como determinantes os fatores "simples" à qualidade de vida urbana contemporânea? Existiria um conjunto de fatores responsáveis pela generalização, particularmente desigual, de certos fenômenos que se manifestam, com especial intensidade, nos contextos urbano-metropolitano, tal como as condições de nascimento e de morte?" 
DEDICATÓRIA:

A um casal de trabalhadores que vendeu sua gleba de terra para que seus filhos pudessem freqüentar a escola - meus pais: José Teixeira chaves Filho e María Espirito Teixeira.

In Memoriam:

Ao 'Sr. Teixeira", meu pai, a quem agradeço todo o esforço e dedicação para a minha formação. 
Agradecimentos:

Em nome das realizaçöes, sonhos e sofrimentos das parturientes e dos seus neonatos, ao possíbilitarem a realização deste estudo.

'Foi minha primeira gestação; planejei, fiquei um pouco perturbada pelo excesso de trabalho. além de ter apresentado crise renal, precisando de repouso, mas trabalhei até dez dias antes do parto. Fiz pré-natal nesta maternidade $e$ assisti a palestras sobre aleitamento materno. já tínha marcado a cesárea. A criança está em boas condiçôes de vida."

"Estou na minha segunda gravidez; não foi planejada. Engravidei quando fiz as pazes com men marido e ele foi embora novamente. Não foi uma gravidez tranqüila, houve muitos problemas emocionaís devido à separação. Só comecei a fazer o pré-natal no sexto mês de gestação. Estou muito triste pois minha filha nasceu com problema na boca."

"Eu desejava um outro filho, um homem, mas não agora. Pois meu último filho vai fazer um ano; e também tinha mês que tive muito choro, raiva, brigas, até tapas. Acesso ao serviço não foi fácil, pois não havia vagas. No momento me sinto bem, mas não muito feliz, porque o menino tem problema de cansaço." 


\section{AGRADECIMENTOS ESPECIAIS:}

À Prof Dra. Augusta Thereza de Alvarenga, orientadora, exemplar dedicação ao trabalho de minha orientação em todo o período do curso e imprescindivel contribuição para o êxito deste trabalho e para minha aprendizagem.

Aos componentes da banca, Prof. Dr. Jair Licio Ferreira santos, Prof. Dr. Arnaldo Angusto Franco de Siqueira; Prof. Dr. José da Rocha Carvalheiro, Prof Dre Elisabeth Meloni Vieira e Profa. Dra. Marilisa Berti de Azevedo Barros que, com responsabilidade e empenho, contribuíram para o aperfeiçoamento científico deste trabalho.

Ao Prof. Dr. Arnaldo Angusto Franco de Siqueira, pelas valiosas sugestões que, ao longo do trabalho, permitiu-me apreender com melhor clareza as concepçöes da perinatología.

À Profe Dra. Ana cristina D'Andretta Tanaka, especiais agradecimentos, pelas contribuições que tem dado na melhoría e aprofundamento na análise dos dados.

À Prof Ana Maria Elías, Prof Assistente do Departamento de ciências da Educação da Faculdade de ciências e Letras da UNESP-Araraquara/SP, por sua contribuição no delineamento e análise estatística dos dados, com uma dedicação primorosa.

À Prof Rebeca de Sousa e silva, do Departamento de Medicina Preventiva da UNIFESP, por sua contribuição no aperfeiçoamento do banco de dados para a definição de variáveis epidemiológicas.

Ao corpo técnico-administrativo do Departamento de Saúde Mateno-Infantil/FSP-USP, em particular, a Elba Barreto Carvalho e Nilson Silva Soares, pelo agradável clima de amizade e companheirismo do desenrolar durante minha estadia na faculdade de saúde Pública.

À amiga Anna Rita Pederneiras, Médica Sanitarista, pelo apoío e incentivo para seguir "sempre em frente.

\section{AGRADECIMENTOS INSTITUCIONAIS:}

Ao Núcleo de Estudos em Saúde Coletiva da universidade Federal da Paraíba, por minha líberação para dedicação exclusiva ao desenvolvimento deste trabalho.

Ao Conselho Nacional de Desenvolvimento científico e Tecnológico(CNPq) e, do mesmo modo, à coordenação de Aperféçoamento de Pessoal de Nível Superior (CAPES), pela concessão de Bolsa de Estudos, que possibiliton a dedicação integral ao trabalho de pesquisa.

Às instituições que permitiram o acesso aos seus pacientes que, direta ou indiretamente", contribuíram para o exito deste trabalho. 


\section{RESUMO}

TEIXEIRA-LIMA R. Condições de nascimento e desigualdade social. São Paulo, 2001. [Tese de Doutorado - Faculdade de Saúde Pública - USP].

O presente trabalho toma como objeto de estudo as relações existentes entre condições de nascimento de crianças de baixo peso e não baixo peso ao nascer, condições de assistência e condições de classe. Busca reter as possibilidades e os limites para o emprego do conceito de classes sociais em pesquisas empíricas no campo da Saúde Pública e Coletiva tendo em vista as mudanças operadas no capitalismo atual pelo processo de globalização. A população estudada constitui-se de 137 recém-nascidos de baixo peso e 372 recém-nascidos de não baixo peso, pertencentes ao municipio de João Pessoa/PB. Os dados foram obtidos através de entrevista individual com parturientes que deram à luz nos hospitais públicos e privados da cidade, no período de abril a setembro de 2000 . Foram observadas elevadas taxas de cesáreas, com predominância nos serviços privados, o que poderia estar determinando uma maior mortalidade neonatal precoce justamente para os neonatos de não baixo peso pertencentes à "burguesia". Em relação ao pré-natal pode-se observar que o maior risco materno-fetal coube aos neonatos de baixo peso e não baixo peso pertencentes ao "proletariado", cujas taxas estimadas de ausência de pré-natal foram de $33,4 \%$ e $27,1 \%$, respectivamente, acima da média nacional. Quanto aos óbitos neonatais precoces uma descrição qualitativa dos mesmos permitiu identificar as estreitas relações existentes entre as condições de assistência ao pré-natal, ao parto e ao recém-nascido e as mediações que as condições de classe oferece. A despeito das limitações observadas no emprego do conceito de classes sociais, dada a redução teórico-metodológica operada para sua aplicação e as mudanças atualmente existentes nos processos de trabalho, podese considerar que a interpretação dos eventos perinatais como as condições de peso ao nascer e a mortalidade neonatal precoce são fenômenos complexos, de natureza tanto biológica quanto social, o que exige para sua melhor compreensão não só o conhecimento gerado pela Epidemiologia mas, igualmente, aquele gerado pelas Ciências Sociais.

Descritores: baixo peso ao nascer, mortalidade neonatal precoce, assistência prénatal, assistência ao parto, classe social. 


\section{SUMMARY}

TEIXEIRA-LIMA R. Birth conditions and social inequalities. São Paulo, 2001. [Doctorate thesis - School of Public Health - USP].

The present work focuses on the existing relations between the birth conditions of low birth weight infants and infants weighing 2,500g and more, assistance conditions and class conditions. It attempts to analyse the possibilities and limits of the use of the concept of social classes in empirical research in the field of Public and Collective Health, in the light of the changes in the current form of capitalism brought about by the globalisation process. The studied population is composed of 137 low weight newborns and 372 newborns weighing 2,500g and more from the municipality of João Pessoa, state of Paraiba. The data were obtained by means of an individual interview with women who gave birth in the city's public and private hospitals, between April and September 2000. The study observed that there were high rates of cesarean sections, predominantly in the private health services, which could be determining a higher rate of early neonatal mortality for the neonates weighing $2,500 \mathrm{~g}$ and more belonging to the 'bourgeoisie'. With regard to prenatal care, the study observed that the low weight neonates and the neonates weighing 2,500g and more belonging to the "working class" had the highest mother and fetus risk, and the estimated rates of absence of prenatal care were $33.4 \%$ and $27.1 \%$, respectively, higher than the national average. With regard to early neonatal deaths, a qualitative description allowed the identification of close relationships between the conditions of assistance given to prenatal care, to delivery and to the newborn and the mediations offered by class conditions. Despite the limitations of the use of the concept of social classes, due to the theoretical-methodological reduction that was operated in order to proceed to its application and the changes existing today in the labour processes, it is possible to consider that the interpretation of perinatal events such as birth weight conditions and early neonatal mortality are complex phenomena, that nature is both biological and social. Therefore, their understanding requires not only the knowledge generated by Epidemiology, but also that generated by the Social Sciences.

Descriptors: low birth weight, early neonatal mortality, prenatal care, assistance to delivery, social class. 


\section{Relação das tabelas, quadros e figuras descritas no estudo:}

\begin{tabular}{|c|c|c|}
\hline $\begin{array}{l}\text { No da } \\
\text { Tabela }\end{array}$ & Descrição das tabelas & $\begin{array}{l}\text { No da } \\
\text { página }\end{array}$ \\
\hline 1 & Distribuição da ocorréncia de partos na cidade de Jojao Pessaj/PB. 1996 & 36 \\
\hline 2 & $\begin{array}{l}\text { Distribuiçäo de nascidos vivos segundo os serviços investigados e as estimativas paras as } \\
\text { amostras. }\end{array}$ & 37 \\
\hline 3 & $\begin{array}{l}\text { Distribuiçăo das estimativas de casos e controles de neonatos de baixo peso e não baixo peso } \\
\text { segundo os servicos investigados. }\end{array}$ & 39 \\
\hline 4 & Distribuicão dos neonatos de baixo peso e não baixo peso segundo o tjpo de familia. & 54 \\
\hline 5 & $\begin{array}{l}\text { Distribuição dos neonatos de baixo peso e não baixo peso segundo o estado civil e tipo de união } \\
\text { conjugal das parturientes. }\end{array}$ & 55 \\
\hline 6 & Distribuição dos neonatos de baixo peso e não baixo peso segundo os responsáveis pelas famillas. & 56 \\
\hline 7 & $\begin{array}{l}\text { Distribuição dos neonatos de baixo peso e não baixo peso segundo a idade das parturientes no } \\
\text { momento do parto. }\end{array}$ & 57 \\
\hline 8 & $\begin{array}{l}\text { Distribuição dos neonatos de baixo peso e não babxo peso segundo a idade das parturientes na } \\
\text { ocasiäo da primeira relaçao sexual. }\end{array}$ & 58 \\
\hline 9 & Distribuicão dos neonatos de baixo peso e não baixo peso sequndo a paridade das mulheres. & 59 \\
\hline 10 & $\begin{array}{l}\text { Distribuição dos neonatos de baixo peso e não baixo peso segundo o pré-natal e o número de } \\
\text { consultas. }\end{array}$ & 61 \\
\hline 11 & $\begin{array}{l}\text { Distribuição dos neonatos de baixo peso e não baixo peso segundo o inicio do pré-natal em } \\
\text { relação ao trimestre da gravidez. }\end{array}$ & 62 \\
\hline 12 & Distribuição dos neonatos de baixo peso e não baixo peso segundo o sexo. & 65 \\
\hline 13 & $\begin{array}{l}\text { Distribuição dos neonatos de baixo peso e não baixo peso segundo sua condição de sobrevida } \\
\text { pós-nascimento. }\end{array}$ & 66 \\
\hline 14 & $\begin{array}{l}\text { Distribuição dos neonatos de baixo peso e não baixo peso segundo o tipo de parto e de serviço } \\
\text { utilizado no parto. }\end{array}$ & 67 \\
\hline 15 & Distribuicão dos neonatos de baixo peso e não baixo peso segundo as indicaçóes de cesáreas. & 68 \\
\hline 16 & $\begin{array}{l}\text { Distribuição dos neonatos de baixo peso e não baixo peso segundo as morbidades referidas pelas } \\
\text { parturientes e as registradas nos prontutrios. }\end{array}$ & 69 \\
\hline 17 & $\begin{array}{l}\text { Distribuição dos neonatos de babo peso e não baixo peso segundo a adequação peso/idade } \\
\text { gestacional. }\end{array}$ & 71 \\
\hline 18 & Distribuicão dos neonatos de baixo peso e não baixo peso sequndo a situacão de intemacão. & 72 \\
\hline 19 & $\begin{array}{l}\text { Distribuição dos neonatos de baixo peso e não baixo peso segundo as categorias de classes } \\
\text { sociais dos responsáveis pelas familias. }\end{array}$ & 74 \\
\hline 20 & $\begin{array}{l}\text { Distribuição dos neonatos de baixo peso e não baixo peso segundo as categorias de classes } \\
\text { sociais e o tipo de mercado de trabalho. }\end{array}$ & 75 \\
\hline 21 & $\begin{array}{l}\text { Distribuição dos neonatos de baixo peso e não babxo peso segundo a renda per capita das } \\
\text { familias. }\end{array}$ & 77 \\
\hline 22 & $\begin{array}{l}\text { Distribuição dos neonatos de baixo peso e não baixo peso segundo a escolaridade materna no } \\
\text { momento do parto. }\end{array}$ & 78 \\
\hline 23 & $\begin{array}{l}\text { Distribuição dos neonatos de baixo peso e não baixo peso segundo as categorias de classes } \\
\text { sociais e a idade das parturientes. }\end{array}$ & 80 \\
\hline 24 & $\begin{array}{l}\text { Distribuição dos neonatos de baixo peso e não baixo peso segundo as categorias de classes } \\
\text { sociais e a paridade das mulheres. }\end{array}$ & 82 \\
\hline 25 & $\begin{array}{l}\text { Distribuição dos neonatos de baixo peso e não baixo peso segundo as categorias de classes } \\
\text { sociais e o tjpo de uniäo conjugal das parturientes. }\end{array}$ & 83 \\
\hline 26 & $\begin{array}{l}\text { Distribuição dos neonatos de baixo peso e não baixo peso segundo as categorias de classes } \\
\text { sociais e o hábito de fumar das parturientes. }\end{array}$ & 85 \\
\hline 27 & $\begin{array}{l}\text { Distribulção dos neonatos de baixo peso e não baixo peso segundo as categorias de classes } \\
\text { sociais e o consumo de álcool das parturientes. }\end{array}$ & 87 \\
\hline 28 & $\begin{array}{l}\text { Distribuicáa dos neonatos de baixo peso e não baixo peso segundo as categorias de classes } \\
\text { sociais e o tipo de servico utilizado no parto. }\end{array}$ & 89 \\
\hline 29 & $\begin{array}{l}\text { Distribuição dos neonatos de baixo peso e não baixo peso segundo as categorias de classes } \\
\text { sociais e o tppo de parto. }\end{array}$ & 91 \\
\hline 30 & $\begin{array}{l}\text { Distribuiçäo dos neonatos de baixo peso e não baixo peso segundo as categorias de classes } \\
\text { sociais e a adequaçäo peso/idade gestacional. }\end{array}$ & 93 \\
\hline 31 & $\begin{array}{l}\text { Distribuição dos neonatos de baixo peso e não baixo peso segundo as categorias de classes } \\
\text { sociais e sua sobrevida pós-nascimento. }\end{array}$ & 94 \\
\hline 32 & $\begin{array}{l}\text { Distribuiçáo dos neonatos de baixo peso e não baixo peso segundo as categorias de classes } \\
\text { sociais, consultas de pré-natal e número de óbitos. }\end{array}$ & 96 \\
\hline \multicolumn{3}{|c|}{ Descrição dos quadros e figuras } \\
\hline F1 & Classificacão de mortalidade fetal, perinatal e infantil. & 42 \\
\hline $\mathrm{F}-2$ & Classificacão de recém-nascido sequndo o peso ao nascer e idade gestacional. & 43 \\
\hline$Q-1$ & Demonstrativo do cálculo da amostra dos casos de recém-nascido de não baixo peso ao nascer. & 38 \\
\hline$Q-2$ & Parâmetros para definição de linha de pobreza e de indigência segundo regiōes brasileiras. & 107 \\
\hline
\end{tabular}




\section{S U M Á R I O}

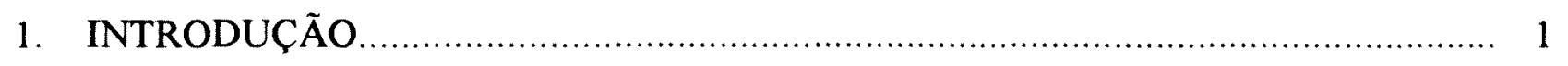

1.1 A relevância da perinatologia como objeto de investigação no campo da saúde pública............................................................... 7

1.2 Um balanço da literatura: a especificidade do baixo peso ao nascer nas condições de nascimento.

1.3 A explicação do baixo peso ao nascer: uma abordagem epidemiológica clássica.

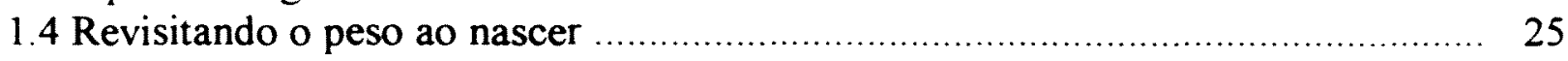

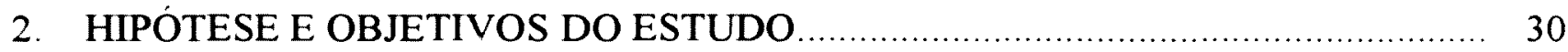

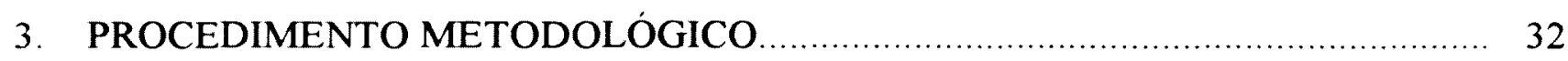

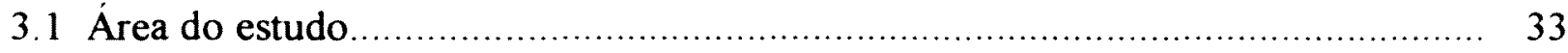

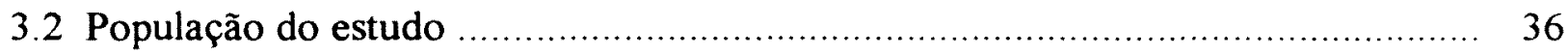

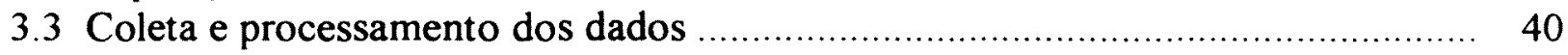

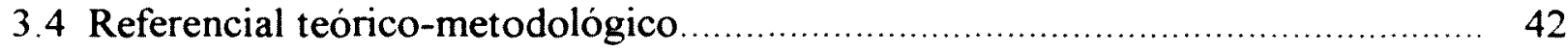

3.4.1 Aspectos conceituais e operacionais da perinatologia ........................ 42

3.4.2 Aspectos teórico-metodológicos sobre o conceito de classe social ........... 45

3.4.3 Aspectos operacionais do conceito de classe social .......................... 48

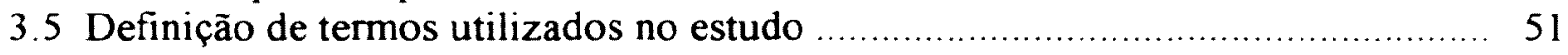

4. APRESENTAÇÃO E DESCRIÇÃO DOS RESULTADOS ............................... 53

4. 1 Caracterização sócio-demográfica familiar ............................................ 54

4.2 Caracterização da assistência pré-natal ................................................... 61

4.3 Caracterização da assistência ao parto e ao recém-nascido ............................... 65

4.4 Caracterização das relações existentes entre condições de nascimento e desigualdade social

5. DISCUSSÃO E ANÁLISE DOS RESULTADOS ......................................... 104

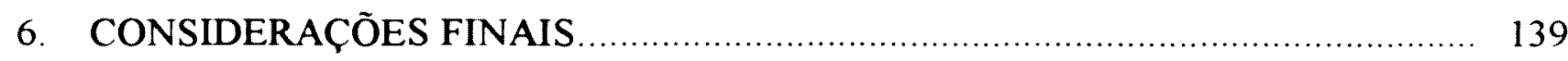

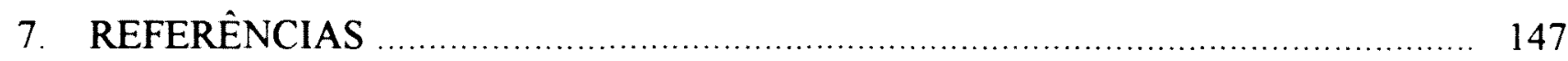

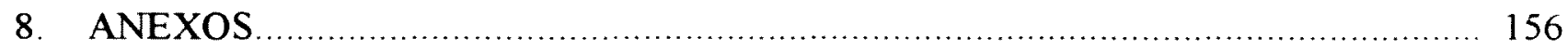


1. INTRODUÇÃO 
Temos muito a comemorar neste século passado, particularmente no Brasil, em função dos 500 anos de sua história. No entanto, paradoxalmente, esta comemoração não é uma festa em seu sentido pleno. Existem múltiplas formas de interpretar este marco do quinto centenário brasileiro. Um aspecto parece-nos pertinente ser mencionado. Fomos construídos como uma sociedade excludente desde o seu início. Do negligenciamento dos nativos in loco até mesmo à destituição à distância dos negros africanos, foi gerida uma sociedade assimétrica hierárquica, discriminatória, social, étnica e culturalmente. A miscegenação, se nos fez multiculturais, não nos permitiu desenvolver um processo de uma cultura peculiar, tendo por base um país democrático. Uma marca evidente é a forma de colonização de nosso nascimento como nação brasileira, o monopólio da terra, a concepção e a prática patrimonialista de poder, configurando o Estado metropolitano. As elites dirigentes da colônia determinaram uma estruturação de poder marcada, desde seu cerne, pelo empreguismo, a troca de favores e a corrupção, instaurando uma dada cultura política que até hoje não foi alterada. Essa leitura é claramente verificada quando se analisa a conformação das capitanias hereditárias.

Seguindo esta conformação política, o poder público também se estabeleceu nesta mesma linha. Assumiu-se um vasto leque de transações entre burguesia portuguesa e sua esmagadora administração, caracterizada pelo mandonismo, 
deixando uma herança de burocratismo excessivo, normatização exagerada e um pacto de dominação da massa de índios, negros escravos e mestiços das camadas destituídas, cujos projetos alternativos de sociedade foram drasticamente destituídos, a exemplo da Conferedação dos Cariris e os Quilombos. Lutou-se bravamente pela autonomia política ao preço de dois milhões de libras de ouro. No entanto, a essência da estruturação social não foi alterada: a ausência de junção entre as elites e o povo, articulado através de um projeto de sociedade democrática. Segundo ADORNO (Apud SILVEIRA, 2000), foi neste momento que liberalismo e democracia se desquitaram, seguindo trilhas bem distintas. É certo que houve movimentos de iniciativas no sentido de autonomia, a exemplo dos projetos populares dos cabanos, balaios, malês, sabinos, e até mesmo por parte da própria elite como o movimento dos farroupilhas.

Houve uma resistência duramente definida pela não autonomia da tradição libertadora do norte, atualmente Nordeste brasileiro, particularmente Paraíba, Pernambuco, Ceará, caracterizando a revolução de 1817 na Confederação do Equador, a chamada Revolução Praieira. O resultado desses eventos gerou um projeto de sociedade unitarista, centralizadora, regionalmente desigual, viabilizando e consolidando a hegemonia das elites centradas em outras regiões. Sob a égide de uma nação indivisa, reiterou-se a estruturação colonial. 0 liberalismo e a democracia à brasileira, baseados em modelos ingleses e franceses no que thes convinha e depurando as iniciativas emancipatórias que não thes convinham, conformaram uma estrutura social hierarquizada, evidenciando a discriminação político-eleitoral através da defesa de cidadãos ativos; estes com 
direitos políticos e cidadãos simplesmente, com direitos civis simplesmente, se bem que de maneira discutíveis, pois que está contextualizado por uma massa de analfabetos e de trabalhadores escravos.

A construção do Estado nacional foi uma das maiores engenharias políticas de exclusão de cidadania. Como diz MATOS (apud SILVEIRA, 2000), em seu processo de conformação definiu uma centralização política, organizando e estratificando o controle dos chamados "três mundos: o mundo da casa, representado pelo privativismo da elite agrária, podando-lhe a autonomia; o mundo da rua ou da plebe, cerceando as expressões populares; e o mundo do trabalho, caracterizado pela repressão normativa pura e simples".

A abolição dos escravos renovou o abismo entre liberalismo e democracia, pois que não permitiu, em sua essência, uma iniciativa de integração dos libertos à sociedade econômica, social e politicamente falando. Definindo uma situação de preconceitos e discriminação que até hoje ainda não se evaporou na sociedade. Mais uma vez o receio das elites recriminava uma alternativa de democracia forjada pela união de esforços na luta escrava com as aspirações das camadas médias urbanas por direitos políticos e acesso a condições de trabalho.

O que mudou dali até os dias de hoje? O que há de novo? A sedução pelo mercado globalizado da elite e de uma classe média alta afluente aos fluxos cibernéticos e internéticos internacionais permite não transparecer uma sociedade com movimentos perversos de expropriação de direitos da cidadania, a despeito 
de tudo de bom que se propaga sobre esta questão, particularmente pelos poucos beneficiados. Continuamos ainda hoje com enormes massas de analfabetos; pessoas morrem, cotidianamente, por causas preveniveis; milhões estão na miséria e outros morrem de epidemias tecnicamente resolvidas ha décadas e até mesmo ha séculos. O desemprego e o sub-emprego se exacerbaram; embora o poder de compra venha aumentando, vem aumentando, também, em maior grau as diferenças sociais.

A despeito das mudanças que vem ocorrendo no país, uma realidade crucial não é alterada: o país continua sendo conformado por uma distribuição desigual de seus produtos e serviços e mais acentuadamente de sua renda (SINGER, 2000). É conhecido que os dez porcento mais ricos da população absorvem uma renda quarenta e três vezes maior que os dez porcento de renda mais baixa. É certo que o impacto do rápido crescimento econômico tem propiciado uma regressão da população pobre; ainda assim persiste um grande contigente em condições de pobreza. Este aspecto permite levantar um questionamento: que implicações a desigualdade tem gerado numa época de crescimento na perspectiva de analises das condições de vida das pessoas?

Diversos estudos internacionais apontam para o aspecto de que 0 grau de desigualdade em grupos sociais está diretamente relacionado às taxas de mortalidade e de morbidade, independente do nível de renda. O Banco Mundial afirma que o Brasil com um produto interno bruto ultrapassando os cinco mil dólares per capita, está passando por uma fase difícil, mas que se esta fase não 
for acompanhada de outras transformações, esse aumento de renda dificilmente, por si só, conduzirá a grandes melhorias. Nota-se que nestas duas últimas décadas tem-se produzido inúmeros estudos de vanguarda sobre a interface pobreza-saúde. Contudo a atual "transição epidemiológica" também evidenciada por vários outros estudos (LAURENTI, 1990; MONTEIRO, 1995) sugere a adoção de novas abordagens teórico-metodológicas para melhor explicar esta realidade. As discussões apontam para uma direção de se investigar as interfaces que condicionam os processos sociais e de que maneira os distintos grupos se expõem a diferentes fatores de morbidade e mortalidade, definidores do processo saúde-doença.

É sob esta última perspectiva que desenvolvemos esta investigação de modo a configurar a realidade social de uma população e de como os aspectos definidores, característicos dessa sociedade, interferem nas condições de vida dos indivíduos, até mesmo antes de nascerem, evidenciando a importância do estudo do peso ao nascer como fator determinante dessa condição de nascimento. 


\subsection{A relevância da perinatologia como objeto de}

investigação no campo da saúde pública

Em diferentes paises, têm-se verificado grande número de investigações em torno da morbidade e mortalidade materno-infantil e sua relação com as condições de nascimento das crianças, em função do nível sócio-econômico. Nesses estudos, autores buscam caracterizar as condições de nascimento através de variáveis que, utilizando o conceito de risco, tentam identificar os fatores causais que definem as condiçoes favoráveis ou desfavoráveis para o nascimento. (URA, 1994; HIRVE, 1994; WALLACE, 1994; MONTEIRO, 1995; RODRIGUEZ, 1995; SPINILLO, 1995; WILCOX, 1995; HEMMINK, 1996). Nesse sentido, é que ALVARENGA, já em 1984, identificava nos fenômenos da prematuridade e da insuficiência ponderal, definidos na primeira metade do século de maneira indiferenciada como baixo peso ao nascer, os elementos básicos que articularão as condições maternas às condições de nascimento, de maneira específica.

O conceito de baixo peso ao nascer, a exemplo dos estudos de BARROS e VICTORA (1996), aparece nas investigações sobre o tema como elemento estreitamente relacionado e articulador das condições de morbidade, que implicará em sérios danos ao processo de crescimento e desenvolvimento da criança, bem como da mortalidade perinatal, expressando desse modo grande relevâiıcia em termos de saúde pública (BARTLEY, 1994). 
A demonstração dessa relevância está presente não somente nos livros e periódicos da literatura especializada mas, inclusive, nas propostas de organismos internacionais preocupados com o problema. Exemplo típico foi o Encontro Mundial de Cúpula Pela Criança, promovido pelo Fundo das Nações Unidas para a Infância (UNICEF, 1991), caracterizando-se como a maior reunião de Presidentes e Primeiros Ministros de Estado que culminou numa promessa pública de reduzir de maneira expressiva, até o ano 2000, as mortes de crianças e a desnutrição infantil, através de intervenções voltadas para melhoria das condições de saúde da mãe e da criança. Também a Organização Mundial da Saúde (OMS), desde 1988, juntamente com a Organização Pan-Americana da Saúde (OPAS) e o Centro Latino Americano de Perinatologia (CLAP), têm realizado amplos estudos sobre esse problema, inclusive apontando medidas para sua solução (CLAP, 1988).

Diante disso, considera-se relevante a temática do baixo peso ao nascer, na sua expressão de prematuridade e insuficiência ponderal, que progressivamente assume lugar de destaque nos estudos da perinatologia não somente pela elevada participação na mortalidade infantil, mas por encerrar questões teóricometodológicas importantes nos processos de investigações (BARROS e VICTORA, 1996; BELLZI, 1997). Este fato se dá pela diferenciação interna na evolução do conceito do baixo peso ao nascer evidenciado nos estudos quando se faz a distinção entre 0 baixo peso decorrente da prematuridade e 0 baixo peso decorrente do retardo de crescimento intra-uterino, conhecido como insuficiência ponderal. 
Esses conceitos apresentam grande importância por expressarem o risco gravídico tanto da mãe, quanto para o concepto. Essa preocupação está presente nos documentos das organizações médicas, a exemplo da OMS, CLAP, e Academia Americana de Pediatria, nos quais estes encontram-se descritos como indicadores de risco para mortalidade perinatal. Nesse contexto é que o peso ao nascer destaca-se como um dos mais importantes indicadores das condições de nascimento e de sobrevivência de menores de um ano de idade, assim como do crescimento e desenvolvimento infantil. (WALLACE, 1994; DELGADO, 1995; NCHS, 1995).

O tratamento do tema permite melhor exemplificar tal relevância quando abordado em termos da própria assistência à saúde. Estudiosos como BARROS e VICTORA (1996), dentre outros, elegem o peso ao nascer como indicador importante da condição de saúde de uma população porque, por meio deste, consideram ser possivel avaliar os programas assistenciais visto refletir, o resultado do processo gravídico e as condições sociais da gestante/puérpera e da assistência à saúde recebida. Já em estudos bem anteriores, BERTAGNON (1991) e BARVAZIAN e BEHAR (1978), ampliavam a consideração do tema ao relacionarem o peso ao nascer com o desenvolvimento social dos países e a questão da qualidade de assistência à saúde. Estes autores afirmam ainda que as condições de vida determinam o nivel de saúde da população. Por conseguinte, o processo saúde-doença-morte ganha várias dimensões não se constituindo a carga biológica, portanto, no único determinante do desenvolvimento do fetn. O meio 
ambiente, caracterizado pelos processos sociais, responde por boa parte de seu desenvolvimento.

Nesse particular, o número de crianças com baixo peso ao nascer é proporcional à prevalência de desnutrição materna, indicando que o retardo de crescimento fetal é uma constante nesta condição do baixo peso ao nascer, notadamente nos países e regiões menos desenvolvidas, onde responde por $70,0 \%$, dentre os nascidos nessa condição. Esta tendência diminui na medida em que os países alcançam maior nível de desenvolvimento. Diante do exposto, pode-se observar não somente o lugar de destaque ocupado pelo baixo peso ao nascer no interior da área de saúde materno-infantil, mas igualmente apontar para a relevância que assume como objeto de investigação no campo da saúde pública, dadas as várias possibilidades de abordagens que seu estudo encerra. 


\subsection{Um balanço da literatura: a especificidade do baixo}

peso ao nascer nas condições de nascimento

A literatura internacional e nacional apresentam diversos estudos sobre condições de nascimento da população infantil em que se evidenciam o lugar de destaque assumido pelo peso ao nascer, dada a sua contribuição sobretudo nas taxas de mortalidade perinatal. Assim, uma revisão da literatura a respeito de tal contribuição permite melhor delinear o âmbito no qual os problemas relativos ao objeto desse estudo se apresentam. (ALMEIDA, 1994; SUNG, 1994; ARNTZEN, 1995; STRACHAN, 1996; WIDSCHUT, 1997).

A Organização Mundial de Saúde, já em 1980, investigava as condições de nascimento no mundo, quando constatou que de 125 milhões de recém-nascidos, 20 milhões (16,0\%) apresentam BPN e que desses mais de 90,0\% são provenientes dos paises considerados como subdesenvolvidos. Em países como o Brasil, Indonésia e Ilhas do Caribe, considerados de nível intermediário de desenvolvimento, foram identificadas prevalências de baixo peso em torno de $10,7 \%$ a $15,0 \%$. Noutros paises, de condições sócio-econômicas mais baixas, a exemplo de Birmânia e Índia, foi encontrada uma prevalência de 22,0\% e 30,0\% respectivamente, em crianças de baixo peso (HIRVE, 1994). Em contrapartida, paises como Estados Unidos, Nova Zelândia e Suécia, altamente desenvolvidos, apresentaram uma incidência média de 4,7\% (HILLE, 1994; KLIEGMAN, 1995; 
COHEN, 1995; FAWER, 1995). Essa diversidade de resultados é explicada pelos diferentes níveis de desenvolvimento sócio-econômico desses países o que representa uma das formas tradicionais dos estudos epidemiológicos apontarem para a questão da desigualdade social presente na determinação do problema.

Nesta linha de preocupação, tomando como referência o peso ao nascer e a mortalidade perinatal, outras pesquisas foram realizadas em países com níveis diferenciados de desenvolvimento econômico e social, verificando igualmente uma distribuição distinta desse indicador (BRUGHA, 1994; PECK, 1994; PARKER, 1994). Condições específicas foram encontradas em países como Costa Rica, México, Uruguai, Chile e Cuba. O que se ressalta nesses países é que, a despeito de não se caracterizarem como desenvolvidos do ponto de vista econômico, mas em vias de desenvolvimento, foram implementadas políticas públicas e programas sociais que, de uma maneira geral, modificaram as condições de sobrevivência da população, resultando em taxas de baixo peso ao nascer inferiores a $10,0 \%$ (SCHLAEPFER, 1995). Tais resultados permitem indicar que nem sempre existe uma relação estreita entre desenvolvimento econômico e desenvolvimento social, o que aponta para a relevância das políticas sociais e de saúde no interior das quais a questão da qualidade de assistência à saúde perinatal adquire significado especial (LAURELL, 1993).

O significado social, no âmbito da saúde pública, determinado pelas diferentes taxas de baixo peso ao nascer recebe destaque nos estudos epidemiológicos por evidenciarem relações estreitas entre condições sócio-econômicas e condições de 
nascimento que, entre outros aspectos, são permeadas pela questão da qualidade de assistência à saúde (MONTEIRO, 1995).

No Brasil, em 1988 uma ampla investigação, desenvolvida pelo CLAP, envolvendo áreas urbanas das capitais brasileiras, identificou uma incidência média do baixo peso ao nascer para o país de $14,8 \%$. Mais tarde, NÓBREGA em 1995, utilizando a mesma metodologia observou uma taxa de $8,3 \%$, o que, a despeito do tempo que passou, sugere dificuldades para o conhecimento da real magnitude do problema no pais como um todo, dada a deficiência, ou mesmo ausência de registros de dados vitais (TEIXEIRA-LIMA, 1995).

Sustentando o pressuposto de que a questão das condições de nascimento, sobretudo o peso ao nascer, encontra-se estreitamente vinculada a diferentes ordens de determinantes sociais, alguns estudos no país apresentam evidências típicas quando trabalham com dados regionais. Nesse particular, a colaboração de MONTEIRO (1995) é relevante quando analisa os dados da Pesquisa Nacional de Saúde e Nutrição - PNSN/1989, por contrapor realidades regionais bastante distintas, indicando que o baixo peso ao nascer da Região Nordeste do país, que é de $12,0 \%$, se assemelha a da região rural do país como um todo. Reafirma, igualmente, tal diferenciação regional ao traçar a evolução da desnutrição infantil. Embora observe um recrudescimento da mesma no Brasil como um todo, nas regiões Norte e Nordeste esse fenômeno não ocorre. Para o mesmo, tal fato devese a que nestas regiões a desnutrição infantil "assume proporções endêmicas, a exemplo das sociedades mais pobres do mundo" (MONTEIRO, 1995, p. 110). Tal 
constatação indica a relevância de seus estudos para a consideração das relações existentes entre condição de vida, desigualdade social e condição de saúde. Esta diferenciação é explicada pela melhoria das condições sócio-econômicas que analisa a partir de indicadores como a renda familiar, a cobertura de serviços de saneamento, a saúde e educação para as regiões do país, com exceção das Regiões Norte e Nordeste.

Este aspecto foi também evidenciado no Estado do Maranhão em investigação realizada por VICTORA e colaboradores em 1991, nas cidades de Timbiras e São Luís, onde verificaram que as taxas do baixo peso ao nascer se apresentam diferenciadas em função da existência de serviços assistenciais de saúde. Colocam em destaque o caso da assistência da Pastoral da Criança evidenciando que em Timbiras, onde esta entidade atuava, o baixo peso ao nascer era de 10,1\%. Já em São Luís, onde a população não conta com tal tipo de assistência, o baixo peso ao nascer é de $14,8 \%$. Tal fato sugere, segundo os autores, a existência de uma desigualdade das condições de nascimento entre as duas populações estudadas, caracterizada pelo acesso diferenciado a serviços de saúde.

Estudos bem anteriores desenvolvidos por LAURENTI, em 1985, corroboraram tal pressuposto. Na Região Sudeste, de melhores condições sócio-econômicas, envolvendo nove maternidades das cidades dos Estados de São Paulo, Rio de Janeiro e Santa Catarina, identificaram uma incidência de $11,1 \%$ de BPN, valor inferior à média do país $(14,8 \%)$. O Rio Grande do Sul, representando um dos Estados mais desenvolvidos do país, sobretudo do ponto de vista do 
desenvolvimento social, apresentou taxas ainda menores, como evidenciam os estudos empíricos de BARROS e VICTORA (1996) na cidade de Pelotas/RS que identificaram uma taxa de $9,0 \%$.

Segundo dados do Ministério da Saúde, obtidos pelo Sistema Nacional de Nascidos Vivos - SINASC, o Estado do Rio Grande do Sul apresentou uma média de 8,0\% de crianças com baixo peso ao nascer (MS, 1995). Vale registrar ainda, que OLINTO dois anos antes, investigando nascidos vivos da periferia urbana da cidade e Pelotas/RS, caracterizada como área de população de baixa renda, encontrou uma taxa de $12,9 \%$, demonstrando assim a existência da desigualdade social nas condições de nascimento numa mesma região. Em outros estudos, os resultados encontrados reforçam a relevância de se diferenciar, em investigações sobre o tema, as condições sociais sob as quais as famílias de recém-nascidos de baixo peso ao nascer estão submetidas (VALÉRIO e cols. 1997). 


\subsection{A explicação do baixo peso ao nascer: uma abordagem epidemiológica clássica}

Mesmo excluindo dos estudos os casos de baixo peso ao nascer provenientes exclusivamente dos fatores biológicos (genéticos, gemelaridade), tem-se verificado que o déficit do peso continua presente na população com grandes implicações para a morbidade e mortalidade infantil (SCHAEPFER, 1995; HEMMINKI, 1996; WILCOX, 1995; TEIXEIRA-LIMA, 1998).

Buscando explicações acerca do fenômeno, diversos autores, através de investigações epidemiológicas clássicas, tomam isoladamente diversas variáveis, notadamente a idade, a paridade, o intervalo interpartal, o hábito de fumar, a ingestão de álcool, entre outras. Do ponto de vista clínico-epidemiológico enfatizam os antecedentes maternos, como também as intercorrências da própria gestação, além da questão nutricional, visando a identificar a determinação do baixo peso ao nascer presente na relação materno-perinatal.

Neste contexto, a busca da "relação causal" entre ganho ponderal na gestação e desenvolvimento fetal, a exemplo dos trabalhos de CONTER (1995) que ganha destaque na literatura por representar uma das modalidades de baixo peso ao nascer, caracterizada pelo retardo de crescimento intra-uterino. A idéia básica 
defendida é a de que a gestante com desnutrição crônica, ou mesmo déficit nutricional durante a gravidez, apresenta, do ponto de vista clínico-epidemiológico, condições desfavoráveis para o desenvolvimento fetal. Sustentam, igualmente, tal assertiva trabalhos como os de MENEZES (1995) e AERTS (1995). Vale ressaltar, no entanto, que tal relação nem sempre é observada, como indicam estudos de NARAYAN (1992) e SEIDMAN (1991), onde referem a necessidade de cautela para análise de variáveis isoladas neste tipo de investigação.

Tal fato aponta para questões metodológicas relevantes por permitir observar que a análise de variáveis isoladas pode sugerir tanto sua condição de fator causal, como de variável de confusão, ou ainda que outros fatores possam ser determinantes ou mediadores de tal "relação causal". Dessa forma, do ponto de vista teórico coloca-se em questão a relação entre o fenômeno e as prováveis causas associadas quando tomadas isoladamente sem um contexto histórico e social na qual estejam inscritas, do ponto de vista teórico.

Exemplificando esta discussão, a variável idade da mulher é exemplar. Esta apresenta-se, em geral, nos estudos, como importante fator de risco fetal. 0 critério básico é o de que a ocorrência de gestação nos dois extremos da idade fértil da mulher ( $<20$ e $>35$ anos de idade) é associada ao baixo peso ao nascer do concepto. Exemplos de tais associações são demonstradas em estudo realizado por PUFFER em 1974, sobre a mortalidade infantil na cidade de Recife/PE. Enfatizando a questão da idade precoce como fator de risco da gravidez na adolescência destacam-se pesquisas de autores como GUIMARÃES (1995), VERAS 
(1995) realizadas também na cidade do Recife/PE. Estudo de TEIXEIRA-LIMA (1995), na cidade de João Pessoa/PB, observa igualmente este fenômeno. Contrapondo-se a essa constatação, estudo feito por SPINILLO (1995) afirma, por exemplo, que se as mães adolescentes tiverem suas necessidades nutricionais atendidas no período gestacional, a idade materna repercute pouco no resultado da gravidez. Esse aspecto pode ser observado em estudos recentes a exemplo de CEESAY (1997).

Nessa perspectiva os autores questionam, portanto, o emprego da variável idade materna tomada isoladamente como determinante do baixo peso ao nascer. Defendem a necessidade de se considerar outros niveis de abordagens na medida em que tal associação pode ocorrer em função de patologias prevalentes, sobretudo no grupo etário com mais de 35 anos de idade (RODRIGUEZ, 1995). Acresce-se a isso o fato de a gravidez na adolescência incidir com maior freqüência nas camadas populares. Nesse sentido é que se coloca a afirmação de ALVARENGA, que já em 1978, considerava a dupla natureza social e biológica dessa variável por representar uma interseção entre essas duas dimensões, fato esse ignorado nos estudos epidemiológicos.

Ao lado da idade, a paridade se apresenta igualmente como variável considerada como fator de risco de morbidade e mortalidade perinatal, conforme EVER (1994) e AERTS (1995). Assim como a idade, a paridade apresenta-se, igualmente, como variável de natureza biológico-social, dada as relações intrínsecas existentes entre as mesmas no processo reprodutivo, o que implicaria cuidados teórico- 
metodológicos especificos para a busca investigativa do fenômeno. O hábito de fumar da gestante tem sido classicamente descrito na literatura como variável estreitamente relacionada ao baixo peso ao nascer, particularmente nos casos de retardo de crescimento fetal. Diversos estudos ilustram esta afirmação (TERUEL 1995; HIRVE 1994; CONTER 1995; TEIXEIRA-LIMA 1995).

Outra variável considerada estreitamente relacionada ao baixo peso ao nascer é o tempo da gestação. Estudiosos, a exemplo de ALMEIDA (1994), GUERRA (1995), AERTS (1995), analisando a relação desta com o fenômeno, descrevem que quanto menor a idade gestacional maior é a probabilidade da criança nascer com baixo peso. A relevância de tal variável, dada a sua natureza biológica, prende-se a fato de que o nascimento precoce (menor de 37 semanas) caracteriza a prematuridade, que se apresenta como uma das modalidades de baixo peso ao nascer. Nesse sentido BARVAZIAN e BEHAR (1978) afirmam que esta associação peso ao nascer/idade gestacional é importante para distinguir os neonatos prematuros, mais freqüentes nas populações de países desenvolvidos, dos neonatos com déficit ponderal ao nascer, condição esta encontrada com maior freqüência nas populações de paises menos desenvolvidos, o que aponta para a importância de se diferenciar esses dois grupos quando da análise do problema.

Ao lado desse conjunto de variáveis tradicionalmente consideradas como determinantes do risco de ocorrência do baixo peso ao nascer, outras igualmente se apresentam na literatura especializada ampliando o elenco de fatores passiveis de serem incorporados nessa modalidade de estudo, tais como: intervalo 
interpartal, ocorrência de aborto anterior à gravidez, patologias durante a gravidez, além de outras especificamente de natureza social, como o nível de escolaridade, a condição de moradia, a assistência à saúde, dentre outras (BESSA, 1995; CAETANO, 1997).

Na perspectiva adotada pelo paradigma ${ }^{1}$ clássico de investigação epidemiológica, aspecto característico é o de que toda "relação causal" é buscada na associação de variáveis isoladas. Assim, cada investigador se utiliza dessas variáveis de maneira individualizada, seja pela tradição no reconhecimento do poder explicativo identificado, seja pelo "interesse" em explorar determinado tipo de causa. No entanto, longe de garantir certezas tal paradigma investigativo tem, na atualidade, sido contestado por não assegurar uma abordagem contextualizada do objeto, do ponto de vista histórico-estrutural. Nesse sentido é que cabe, por exemplo, indagar se será possível interpretar e conhecer o fenômeno do baixo peso ao nascer, e seus nexos causais, através do estudo de fatores considerados de forma isolada, fundado tão somente em cálculos estatísticos de correlações e a eles reduzidos.

Vale considerar que estes estudos têm o seu mérito, como análise descritiva, para identificar variáveis relacionadas com o fenômeno. Mas, conforme já em 1995 (p.11), KOIFMAN afirmava que tal estratégia metodológica têm limites, pois com ela "... estaremos simplesmente observando a aparência do fenômeno, sem investigar na sua essência, o conjunto de condições que permitem que a patologia

\footnotetext{
'Entende-se por Paradigma a conoppăo de KUHN (1975) que atribut, em dado periodo da evolução do conhecimento cientifico, a adoģa. por comunidades cientificas. de como investigar e explicar, do ponto de vista teórico-maodologico, determinado problema
} 
se desenvolva de forma diferenciada em determinados grupos populacionais." 0 que se verifica, portanto, neste paradigma de investigação é que cada pesquisador emprega as variáveis de maneira fragmentada, sem um dado contexto teórico que justifique sua relevância e relações existentes. Nesta linha de interpretação SOLLA (1996, p. 208) enuncia, por exemplo, que "as alternativas clássicas da epidemiologia para o tratamento das variáveis sócio-econômicas nos coletivos humanos, sofrem as limitações referentes ao processo de redução/simplificação impostas pela construção de variáveis a partir dos conceitos estabelecidos na epidemiologia clássica", trazendo a idéia de redução do social ao modelo biológico. Como os processos saúde-doença ocorrem na sociedade, inseridos em processos gerais e particulares, o recurso ao instrumental da sociologia amplia as possibilidades de interpretação do mesmo. (ALVARENGA, 1992; FIGUEIREDO, 1995).

Tendo em vista tais considerações, outra questão que se apresenta é: se as condições de nascimento, tomando como parâmetro o peso ao nascer, refletem o resultado da gravidez de uma mulher e responde por formas diferenciadas de sua inserção social. Por outro lado, em que níveis tais relações sociais que se estabelecem estariam definindo o perfil do recém-nascido em função da inserção diferenciada da mulher parturiente em categorias de classes sociais definidas? Justificando tais indagações, apresentam-se alguns trabalhos que, mesmo tendo sido elaborados dentro da abordagem da epidemiologia clássica, trazem indicações de que a simples descrição dos números não explicam o fenômeno. No entanto, 
são particularmente importantes por procurarem introduzir a dimensão social como relevante no estudo das condições de nascimento.

Nesse particular colocam-se as análises que comparam a incidência ou prevalência do baixo peso ao nascer em sociedades desenvolvidas, subdesenvolvidas ou em vias de desenvolvimento, além da busca de identificação das diferenças regionais no interior do mesmo pais, conforme análise apresentada no item anterior de diferentes estudos (SILVA e ALVARENGA, 1995).

Outra modalidade de estudos que analisam relações entre baixo peso ao nascer e variáveis sociais como renda, ocupação, escolaridade, acesso a serviços públicos e privados relacionados à condição de "previdenciário" e "não previdenciário", "favelados" e "não favelados", apresentam fortes indícios da relevância da consideração da questão da desigualdade social no estudo das condições de nascimento, contexto no qual o baixo peso ao nascer adquire sentido. Nesse particular apresentam-se como exemplos típicos algumas pesquisas.

MONTEIRO, já em 1980, realizando estudos, tomando como critério de diferenciação os setores público e privado observou em maternidades de São Paulo/SP, diferentes incidências de BPN, respectivamente, 12,2\% e 8,9\%. ZISMAN em estudos de 1987 em Pernambuco, desenvolvendo estudo populacional segundo níveis de poder aquisitivo no uso de serviços de saúde, definidos como "previdenciário" e "não previdenciário", verificou que o baixo peso ao nascer apresentou uma maior taxa (duas vezes maior) no grupo "previdenciário". 
Resultado semelhante foi observado por SANTANA em estudo realizado em 1990, usando o mesmo critério para investigar a magnitude do BPN na cidade de João Pessoa/Paraíba, demonstrou a acentuada diferença existente entre as duas categorias (público e privado), respectivamente $10,0 \%$ e $3,8 \%$. Além de outras investigações (SOUZA 1995; AERTS 1995; ALMEIDA e cols. 1997) que a condição social diferenciada nos distintos grupos foi "determinante" para definir as condições de nascimento das crianças. Nesse sentido o CLAP elaborou, igualmente, análises de risco perinatal considerando os fatores sócio-econômicos como "risco potencial' para morbidade e mortalidade infantil, os quais se apresentaram distintos nos diferentes grupos sociais. Outros trabalhos apontam para esse mesmo aspecto (ALMEIDA, 1992; SLIWIANY, 1997).

Estes dados indicam que a questão das condições de nascimento, no interior das quais o baixo peso ao nascer adquire significado especial, se dá pela sua associação com outras variáveis epidemiológicas relacionadas aos determinantes sociais. Tais evidências são descritas por BARROS e VICTORA (1996) quando analisam a população infantil de Pelotas/RS e verificam que o parto cesáreo (cirúrgico) esteve diretamente relacionado com a inserção social da mãe. Nesse particular vale lembrar, igualmente, as estreitas relações entre a incidência de cesáreas e do baixo peso ao nascer que passam a representar importante questão em relação ao risco para a morbidade e mortalidade perinatal (VERAS 1995).

Diante do exposto observa-se, de um lado, a complexidade do fenômeno pelas múltiplas relações biológicas e sociais que encerra e, por outro, indica a relevância 
da consideração da questão da desigualdade social a partir do conceito de classe social como estratégia teórica para melhor apontar as possibilidades de identificar a presença de determinações sociais nesse tipo de investigação. 


\subsection{Revisitando o peso ao nascer}

No Brasil e na América Latina são poucos os estudos que procuram investigar a incidência do baixo peso ao nascer considerando as condições estruturais da sociedade e atribuindo aos processos histórico-sociais peso de determinação do processo saúde-doença-morte (FIGUEIREDO 1995).

Dentre as investigações específicas de baixo peso ao nascer, destacam-se as realizadas na cidade de Ribeirão Preto/SP, onde se investigou as condições de nascimento, observando que o baixo peso ao nascer apresentou uma diferença significativa entre as categorias de classes sociais, notadamente na categoria "proletariado". Para FIGUEIREDO (1995), tal diferenciação da condição de nascimento reflete o resultado dos processos de produção a que a sociedade brasileira está sujeita e aponta para a identificação das desigualdades sociais presente nas populações em função de inserções de classe diferenciais características do sistema capitalista vigente.

Buscando aprofundar a análise de dados dessa natureza SILVA e cols. (1992) identificaram as condições das parturientes segundo sua inserção nos estratos de classes sociais, relacionando-as a outras variáveis presentes nos grupos populacionais. Os resultados obtidos demonstraram que o maior percentual de recém-nascidos com baixo peso ao nascer ocorreu entre mães jovens, fumantes, e 
pertencentes a "classes trabalhadoras", corroborando o pressuposto da relação existente entre situação de classe social e outras variáveis sociais e biológicas com a condição de nascimento. Nesta mesma linha de preocupação BARBIERI (1985) e SILVA (1997) realizaram análises sobre a morbidade e mortalidade perinatal, investigando os nascidos vivos da população da cidade Ribeirão Preto/SP e relacionando-os às condições de inscrição de classes sociais das respectivas famílias. Constataram, igualmente, que a incidência de morbidade e de mortalidade perinatal esteve mais presente nas classes trabalhadoras.

Em outra investigação, nessa mesma cidade, ALMEIDA (1992) demonstrou a distribuição desigual da mortalidade infantil verificando que às classes sociais mais baixas corresponderam as taxas maiores de mortalidade infantil. SILVA (1991, p. 190) na cidade de São Luís/MA, caracterizando a população estudada segundo a adscrição de classe social da família de parturientes, demonstrou uma maior incidência de baixo peso ao nascer na classe social "subproletariado", concluindo que "o emprego do conceito de classes sociais, no estudo do processo saúdedoença-morte no período perinatal, apresenta-se como importante instrumental teórico-metodológico, na medida em que trata de incorporar a reflexão sociológica na explicação do fenômeno".

O que se depreende desses trabalhos é que a explicação das relações entre condições da mulher parturiente e do peso ao nascer não se restringe a relações causais de natureza estritamente biológica. Pelos trabalhos apresentados pode se observar que a questão da morbimortalidade perpassa outros níveis de 
determinação no interior das quais o social adquire significado especial. (SILVA e ALVARENGA, 1995).

As investigações que procuram ampliar a compreensão do objeto, incorporando o conceito de classes sociais, permitem demonstrar que o entendimento do problema implica na consideração de diferentes níveis de determinação e na busca de explicação da forma como atuam (BARBIERI 1989, MONTEIRO 2000). Dessa forma, segundo relata SILVA (1991, p. 143) "...com a incorporação de determinantes de natureza sócio-econômica e cultural poderíamos ampliar, em muito, a compreensão do problema, por permitirem resgatar o grau de participação que a dimensão biológica e social, entendida em seu sentido amplo, teriam na explicação da morbidade e mortalidade perinatal...".

Devido a especificidade e complexidade do objeto de estudo, ALVARENGA (1992, p. 189) afirma que "essa modalidade de investigação é particularmente enriquecedora para o progresso de conhecimento nas áreas de saúde da mulher e da criança, por permitir demonstrar os modos pelos quais condições de saúde e de doença se articulam, de maneira diferenciada, a condições sociais, numa relação reciproca."

No entanto, SOLLA (1996) aponta problemas e limites ao emprego do conceito de classe social em pesquisas específicas, pela necessidade de aprofundamento da análise dos processos de trabalho e de consumo em cada classe social. Na sua abordagem, o autor afirma que se torna necessário realizar adequações na 
operacionalização do conceito de classe social que sejam coerentes com as características da formação econômico-social investigada e de sua estrutura social.

Afirma ainda que, nesse particular, o emprego do conceito e classe social estuda fenômenos dinâmicos como se fossem situações definidas e pontuais, contrariando a dinâmica dos processos sociais e suas interfaces intraclasses esperando, dessa forma, ser possivel compreender as suas determinações. Participando dessa preocupação BRONFMAN e TUIRÁN já em 1984 (p.53) alertavam que estas investigações não permitem "apreender as classes como totalidades, isto é, em suas mutações internas e em suas inter-relações e com a estrutura social em seu conjunto."

Também considerando algumas dessas limitações, mas mostrando as possibilidades de enriquecimento da análise, BREILH, em 1989, afirmava que "a aproximação marxista da epidemiologia rebaixa o plano dos fenômenos empíricos e amplia o princípio de causalidade porque assume uma aproximação dialética." É, pois, esta concepção dialética que amplia o conhecimento sobre os fenômenos de saúde e de doença dos grupos sociais. E é nesse sentido que, a despeito dos limites, investigações buscando empregar o conceito de classes sociais permitem ampliar o tradicional tratamento de variáveis sociais isoladas, ou sistemas de estratificação ahistóricos, enriquecendo as abordagens do processo saúde-doençamorte em relação a problemas específicos como instrumental importante para o estudo das desigualdades sociais em saúde. 
A despeito das críticas quanto as dificuldades e limites teórico-metodológicos presentes na operacionalização do conceito de classe social em estudos epidemiológicos, entende-se que a análise empírica dos processos sociais particulares no interior das quais o objeto desta investigação, o baixo peso ao nascer se inscreve, permite enriquecer a explicação do fenômeno, sendo relevante para o investigador do campo da saúde trazer à tona discussões sobre processos estruturais característicos de uma dada realidade social.

Pressupondo esse contexto de possibilidades é que se busca considerar as relações existentes entre condições de nascimento e desigualdade social, tendo em vista reter as especificidades do baixo peso ao nascer num contexto em que condições clínico-epidemiológicas e sociais articuladas sejam passiveis de desvelarem a dupla natureza, biológica e social, do objeto sob investigação. 
2. HIPÓTESE E OBJETIVOS DO ESTUDO 
Partindo da hipótese básica de que as condições de nascimento das crianças encontram-se relacionadas a dadas condições de classe, no interior das quais se inscrevem as familias dos recém-nascidos, o presente trabalho objetiva:

- Caracterizar as condições de nascimento dos recém-nascidos de baixo peso e não baixo peso pesquisados, do ponto de vista clínicoepidemiológico, buscando reter peculiaridades do processo saúdedoença-morte neonatal precoce;

- Caracterizar a inserção dos grupos de mulheres parturientes investigadas num dado conjunto de categorias sociais;

- Identificar e analisar as especificidades assumidas pelo baixo peso e não baixo peso ao nascer no contexto das relações observadas entre condições clínico-epidemiológicas de nascimento das crianças, condições assistenciais e inserção de classe das parturientes investigadas;

- Identificar e analisar as especificidades assumidas pelo baixo peso e não baixo peso em relação à morte neonatal precoce. 
3. PROCEDIMENTO METODOLÓGICO 


\section{1 Área do Estudo}

Dada a importância das investigações na área da saúde materno-infantil com vista a diagnósticos e planejamento da assistência para esse grupo; e considerando a necessidade de estudos mais abrangentes nesta área, de grande interesse em saúde pública para a região Nordeste, em especial para o Estado da Paraiba, o presente estudo coloca-se como uma oportunidade para aprofundar, dentro de uma perspectiva interdisciplinar, o conhecimento sobre as condições de nascimento, saúde e assistência da população materno-infantil.

Para tanto, foi desenvolvida uma investigação na cidade de João Pessoa, Capital do Estado da Paraiba, região Nordeste do Brasil na qual, segundo dados censitários e sócio-econômicos, reside uma população de 576.116 habitantes, sendo $46,2 \%$ homens e $53,8 \%$ mulheres. Conta com uma população favelada de 138.477 habitantes que representa $24,0 \%$ da população geral residente em 31.285 domicilios. Desse total $65.908(11,4 \%)$ são menores de 6 anos de idade e, destes, $11.877(18,0 \%)$ menores de 1 ano de idade. Segundo o IBGE, a cidade apresenta 100,0\% da área urbanizada, com 109.956 domicilios particulares apresentado uma média de 4,49 pessoas por domicilio. A população economicamente ativa é de $73,0 \%$ com uma média de renda individual em torno de dois salários mínimos, sendo que dos chefes de familias $34,3 \%$ tem renda de 
até um salário mínimo. No extremo superior, conta $2,10 \%$ da população com renda familiar acima de 10 salários mínimos. A taxa de analfabetismo é de $16,4 \%$ na população jovem e de $18,4 \%$ nos adultos. Em relação aos aspectos econômicos, o setor industrial e de comércio apresenta um modesto parque industrial com 863 indústrias, gerando 27.000 empregos diretos e indiretos, com destaque na área de construção civil $(25,0 \%)$ e de alimentos $(22,1 \%)$, além de 12.000 microempresas, responsáveis por 60.000 empregos, numa proporção de 1 microempresa para cinco familias empregadas.

Quanto ao saneamento básico, existem 123. 135 (85,0\%) ligações de canalizações residenciais d'água, sendo $15,0 \%$ dos domicilios com tratamento d'água inadequado. O lixo é coletado em $84,0 \%$ dos domicílios, com deposição a céu aberto e o Sistema de Esgoto Sanitário atende apenas a 40,0\% da população (43.316 ligações prediais). Em termos de assistência médica, a população materno-infantil conta com 39 unidades básicas de saúde, 22 hospitais, sendo destes 11 maternidades distribuidas em setor público (5) e privado/conveniado (6), as quais oferecem uma cobertura de $96,0 \%$ de partos hospitalares. Quanto à taxa de mortalidade infantil, segundo o dados da PNADS o IBGE estima para o municipio de João Pessoa, para o ano 2000, uma taxa de mortalidade infantil de 63,85 por 1.000 nascidos vivos, e destas 169 casos foram de mortalidade neonatal precoce referente ao total de 17.027 nascidos vivos. Sobre o peso ao nascer, os dados indicam uma média de $9,0 \%$ de crianças nascendo com baixo peso ao nascer.(IDEME, 1995; SMS/JP, 1997; MS, 2001). 
A esta situação sócio-econômica caracterizadora da cidade, fruto do modelo de desenvolvimento econômico do pais, soma-se as condições climáticas da região, imprimindo um elevado custo social para a população, o que faz da Paraíba um dos Estados mais pobres do país. 


\subsection{População do estudo}

Foram selecionadas duas amostras, uma de neonatos de baixo peso ao nascer e outra de neonatos de não baixo peso. Para a definição das amostras tomou-se como referência o universo de partos ocorridos na cidade de João Pessoa/PB, previamente conhecido, que corresponde a 18.773 partos, conforme indicado na tabela 1 , a seguir.

Tabela 1 - Distribuição da ocorrência conhecida de partos na cidade de João Pessoa/PB, segundo as maternidades públicas e privadas.

\begin{tabular}{c|r|r|r|r|r|r|r|r|r|r|r}
\hline Ano 1998 & $\begin{array}{c}\text { Candida } \\
\text { Vargas }\end{array}$ & $\begin{array}{c}\text { Santa } \\
\text { Isabel }\end{array}$ & $\begin{array}{c}\text { Edson } \\
\text { Ramalho }\end{array}$ & $\begin{array}{c}\text { Frei } \\
\text { Damiäo }\end{array}$ & $\begin{array}{c}\text { Hosp. } \\
\text { Univer. }\end{array}$ & $\begin{array}{c}\text { Säo } \\
\text { Vicente }\end{array}$ & $\begin{array}{c}\text { H.Guar } \\
\text { niçäo }\end{array}$ & $\begin{array}{r}\text { H.Valen } \\
\text { tina }\end{array}$ & $\begin{array}{c}\text { Santa } \\
\text { Maria }\end{array}$ & $\begin{array}{c}\text { Lady } \\
\text { Center }\end{array}$ & Total \\
\hline Janeiro & 472 & 244 & 242 & 130 & 133 & 106 & 97 & 24 & 35 & 26 & 1509 \\
\hline Fevereiro & 432 & 223 & 193 & 48 & 151 & 106 & 88 & 36 & 38 & 35 & 1350 \\
\hline Março & 514 & 232 & 215 & 139 & 148 & 129 & 104 & 38 & 30 & 27 & 1576 \\
\hline Abril & 500 & 244 & 209 & 184 & 85 & 111 & 112 & 36 & 28 & 38 & 1547 \\
\hline Maio & 458 & 259 & 254 & 184 & 199 & 132 & 137 & 50 & 47 & 21 & 1741 \\
\hline Junho & 481 & 249 & 228 & 159 & 172 & 106 & 90 & 59 & 23 & 25 & 1592 \\
\hline Julho & 573 & 240 & 220 & 183 & 178 & 139 & 36 & 45 & 31 & 28 & 1673 \\
\hline Agosto & 530 & 241 & 211 & 212 & 174 & 106 & 31 & 41 & 22 & 30 & 1598 \\
\hline Setembro & 582 & 244 & 241 & 185 & 186 & 68 & 32 & 39 & 34 & 37 & 1648 \\
\hline Outubro & 585 & 241 & 211 & 175 & 154 & 87 & 35 & 53 & 47 & 26 & 1614 \\
\hline Novembro & 503 & 193 & 189 & 167 & 120 & 74 & 31 & 40 & 22 & 45 & 1384 \\
\hline Dezembro & 538 & 193 & 224 & 186 & 163 & 84 & 39 & 55 & 30 & 29 & 1541 \\
\hline T o ta I & 6168 & 2803 & 2637 & 1952 & 1863 & 1248 & 832 & 516 & 387 & 367 & 18773 \\
\hline Distribulça (\%a & 33 & 15 & 14 & 10 & 10 & 7 & 4 & 3 & 2 & 2 & 100 \\
\hline
\end{tabular}

Para o cálculo do tamanho das amostras dos neonatos de baixo peso ao nascer, considera-se que o evento baixo não apresenta sazonalidade em sua ocorrência sendo estimada as freqüências do fenômeno para o setor público em 9,0\% e $5,0 \%$ para o setor privado/conveniado. A partir da média mensal de naccimentos 
ocorridos em cada maternidade, obteve-se os valores esperados de baixo peso, conforme demonstrado na tabela 2 , a seguir.

Baseado na natureza do evento, escolheu-se, a princípio, um período de sessenta dias, especificamente para a coleta dos dados, em que seriam observados todos os casos de baixo peso (aproximadamente 235 casos) e uma amostra de não baixo peso, constituída de 363 casos, conforme cálculo apresentado no quadro 1, a seguir.

Entretanto, em função de dificuldades operacionais surgidas no momento de coleta dos dados, não acesso a prontuários, não autorização de entrevistas junto a algumas parturientes, ausência da mãe, foi necessário a redução da amostra de baixo peso para cerca da metade do número inicialmente previsto. Foi selecionada uma em cada duas ocorrências de baixo peso ao nascer, perfazendo um total de 137 casos.

Tabela 2 - Distribuição estimada dos recém-nascidos segundo as maternidades. João Pessoa/PB, 1998.

\begin{tabular}{c|c|c|c|c|c}
\hline $\begin{array}{c}\text { Identificaçäo das } \\
\text { maternidades }\end{array}$ & $\begin{array}{c}\text { Média Mensal } \\
\text { de nascidos } \\
\text { vivos/96 }\end{array}$ & $\begin{array}{c}\text { Fator de } \\
\text { Multiplicacão }\end{array}$ & $\begin{array}{c}\text { Baixo peso } \\
\text { estimado/més }\end{array}$ & $\begin{array}{c}\text { Amostra de } \\
\text { baixo peso } \\
\text { estimada }\end{array}$ & $\begin{array}{c}\text { Amostra de } \\
\text { baixo peso } \\
\text { obtida }\end{array}$ \\
\hline 1. Cand. Vargas & 514 & $9 \%$ & 46 & 92 & 55 \\
\hline 2. H. Valentina & 43 & $9 \%$ & 4 & 8 & 6 \\
\hline 3. Ed. Ramalho & 220 & $5 \%$ & 11 & 22 & 14 \\
\hline 4. Frei Damião & 163 & $9 \%$ & 15 & 30 & 21 \\
\hline 5. H.Universitário & 155 & $9 \%$ & 14 & 28 & 19 \\
\hline 6. São Vicente & 104 & $5 \%$ & 6 & 12 & 18 \\
\hline 7. H.Guarnição & 70 & $5 \%$ & 4 & 8 & 5 \\
\hline 8. Sta. Isabel & 234 & $5 \%$ & 12 & 24 & - \\
\hline 9. Santa Maria & 33 & $9 \%$ & 3 & 6 & 5 \\
\hline 10. Lady Center & 31 & $5 \%$ & 2 & 4 & 4 \\
\hline T o t a I & 1567 & & 117 & 234 & 137 \\
\hline
\end{tabular}


Para a determinação do tamanho da amostra admitiu-se como pressuposto que as categorias de sociais das mães com maior ocorrência não ultrapassam a 50,0\% das mesmas, admitindo um erro amostral de 5,0\%. Isto por se tratar de uma das "variáveis" mais importantes do trabalho.

Quadro 1 - Demonstrativo do cálculo para definição do tamanho da amostra de não baixo peso.

$\begin{array}{lc}\text { Cálculo da variância: } & \text { Cálculo da amostra da população infinita: } \\ \mathrm{S}^{2}=\frac{\mathrm{d}^{2}}{\mathrm{Z}^{2}}=\frac{0,050^{2}}{1.96^{2}}=0,065 & n o=\frac{\mathrm{p} \mathrm{x} \mathrm{q}}{\mathrm{S}^{2}}=\frac{0,50 \times 0,50}{0,065}=384 \\ \text { sendo "d" o nivel de significância, } & \text { sendo " } \mathrm{p} \text { " } \mathrm{e} \text { " } \mathrm{q} \text { ", respectivamente o pressuposto } \\ \mathrm{e} \text { " } \mathrm{z} \text { " o erro amostral } & \text { máximo para os eventos favoráveis. }\end{array}$

Com isso teremos: Cálculo da amostra da população finita:

$n=\underline{n o}=\underline{384}=303+20,0 \%=363 \quad$ Obtêm-se, assim, a amostra da

$1+\frac{n o-1}{N} \quad 1+\frac{383}{1432} \quad$ investigação: $n=363$.

Onde " $N$ " = somatório da média

mensal aproximada de nascimentos de não baixo peso.

Quanto à amostra dos neonatos de não baixo peso ao nascer selecionou-se sistematicamente uma a cada quatro neonatos em cada hospital. A primeira a ser selecionada em cada hospital foi uma das oito primeiras sendo que a ordem desta foi determinada por:

Número de ordem do neonato $=$ maior inteiro (número aleatório multiplicado por quatro). As visitas aos serviços não se deram em dias consecutivos, preservando a proporcionalidade prevista para a cada serviço. No mesmo período de sessenta dias foi coletada a amostra de neonatos de não baixo peso ao nascer. 
A tabela 3, a seguir, apresenta o tamanho total previsto da amostra de não baixo peso distribuídos pelas maternidades investigadas.

Tabela 3 - Estimativas dos casos de neonatos de baixo peso e de não baixo peso e tamanho da amostra por serviços investigados. João Pessoa/PB.

\begin{tabular}{l|c|c|c}
\hline No/Maternidades & $\begin{array}{c}\text { Média mensal de } \\
\text { nascidos vivos/96 }\end{array}$ & $\begin{array}{c}\text { Não baixo peso } \\
\text { estimado }\end{array}$ & $\begin{array}{c}\text { Amostra de não } \\
\text { baixo peso }\end{array}$ \\
\hline 1. Cand. Vargas & 514 & 468 & 118 \\
\hline 2. H. Valentina & 43 & 41 & 10 \\
\hline 3. Ed. Ramalho & 220 & 200 & 51 \\
\hline 4. Frei Damião & 163 & 148 & 38 \\
\hline 5. H. Universitário & 155 & 141 & 36 \\
\hline 6. São Vicente & 104 & 94 & 24 \\
\hline 7. H. Guarnição & 70 & 66 & 16 \\
\hline 8. Sta. Isabel & 234 & 213 & 54 \\
\hline 9. Santa Maria & 33 & 31 & 8 \\
\hline 10. Lady Center & 31 & 30 & - \\
11. Santa Lúcia(*) & - & - & 363 \\
\hline T o t a I & $\mathbf{1 5 6 7}$ & $\mathbf{1 4 3 2}$ & \\
\hline
\end{tabular}

(*) Dados não fornecidos pela Direção da Maternidade.

Com base nessas amostras, foram investigadas, como eixo básico, as relações existentes entre o peso ao nascer, como condição de nascimento do neonato, e a categoria de classe social da mulher parturiente. 


\subsection{Coleta e processamento dos dados}

Conforme especificado, a estratégia da coleta dos dados seguiu um cronograma proposto, indo de abril a setembro de 2000 , incluindo as atividades de coleta dos casos e controles, entrevistas com as mulheres e consultas aos prontuários, com vistas a atingir a cobertura da amostra definida em função do número de serviços envolvidos. Para tanto, foi utilizado como instrumento de coleta de dados um formulário, previamente testado, contendo variáveis de diferentes naturezas, tais como: sócio-econômicas e demográficas, clínico-epidemiológicas e assistenciais, que foi aplicado junto às mulheres no momento imediato do pós-parto (Anexo 1).

Norteado pela hipótese básica e pelos objetivos propostos, foi elaborado um banco de dados através de software Epi-Info 6.4 (CDC,1997), Editor de texto Word e planilha eletrônica Excel, de modo a descrever as informações de interesses do estudo, representadas através de quadros, figuras e tabelas. Com vistas à análise estatística dos dados, o estudo foi constituído de 137 casos, definidos pela condição dos recém-nascidos de baixo peso (menos de $2500 \mathrm{~g}$ ao nascer) e de 372 controles, definidos pela condição dos recém-nascidos de não baixo peso (mais de $2499 \mathrm{~g}$ de peso ao nascer). 
De forma a orientar a leitura para o procedimento de aplicação de testes estatísticos, as tabelas apresentam faixa(s) sombreada(s) indicativa da categoria tomada como referência em relação às demais. Também para orientação do processo de descrição e análise dos dados.

O exame da existência de possivel associação entre as condições de peso ao nascer e possíveis fatores de risco foi feita empregando-se a odds ratio (OR) em função do delineamento da amostra. O nível máximo de significância para os testes de hipóteses foi fixado em $5 \%$ e para as estimativas da odds ratio por intervalos fixou-se um confiança de $95,5 \%$.

Para cada uma das variáveis tomadas isoladamente foi examinada estatisticamente, através do odds ratio, a existência de associação entre as mesmas e a condição de peso ao nascer. 


\subsection{Referencial teórico-metodológico}

\subsubsection{Aspectos conceituais e operacionais da perinatologia}

Em termos epidemiológicos, o período perinatal é representado pelo esquema classificatório do CLAP (1988, p. 17) que se constitui no esquema operacional básico para análise do problema da morbimortalidade infantil e das condições de nascimento, conforme indica a Figura 1.

Figura 1 - Classificação de mortalidades fetal, perinatal e infantil.

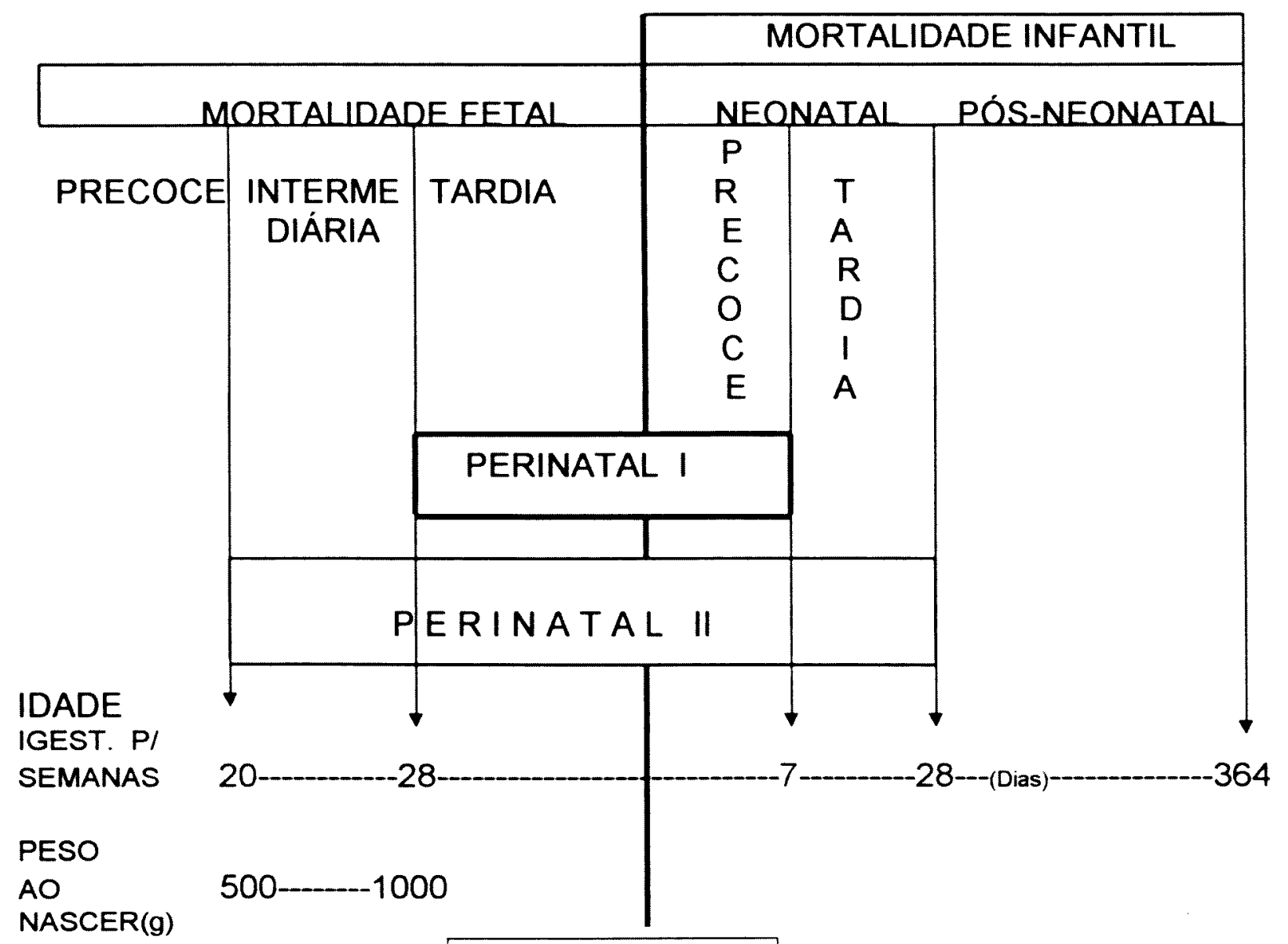

NAS CIMENTO

Fonte: CLAP (1988, p.17). 
Com base neste esquema o Ministério da Saúde, seguindo orientações da Organização Mundial de Saúde, define peso ao nascer como sendo a primeira mensuração do peso do recém-nascido, obtido preferencialmente à primeira hora do nascimento e expresso em gramas. Este é classificado em três categorias distintas: peso adequado, para as crianças que nascem com peso maior ou igual a 3.000g; peso insuficiente, para as crianças que nascem com peso na faixa de $2.500 \mathrm{~g}$ a $2.999 \mathrm{~g}$; e baixo peso ao nascer (BPN), para as crianças que nascem com peso menor que $2.500 \mathrm{~g}$.

A Academia Americana de Pediatria recomenda que a classificação do neonato obedeça a dois critérios: idade gestacional e peso ao nascer, fazendo interpretações de forma relacionada entre esses dois aspectos. Pela idade gestacional, os recém-nascidos são classificados em pré-termo e pós-termo; e segundo o peso ao nascer são classificados como recém-nascidos pequenos, apropriados e grandes para a idade gestacional representados, esquematicamente, na figura 2, pelas siglas PIG, AIG e GIG.

Figura 2 - Classificação de recém-nascidos segundo peso ao nascer e idade gestacional.

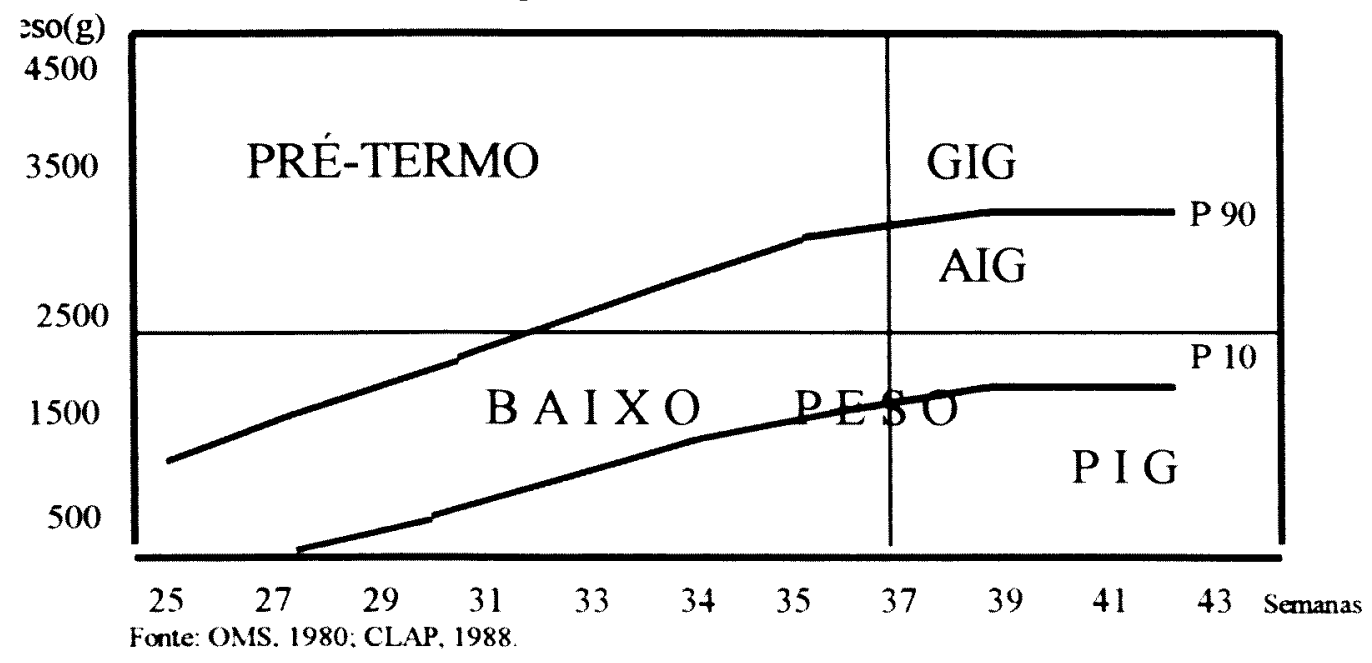


Esta diferenciação merece destaque visto que neonatos com pesos iguais ao nascer podem desenvolver riscos diferenciados de adoecer e morrer, na dependência da idade gestacional ou dos fatores que levaram a uma desnutrição intra-uterina, caracterizada pelo retardo de crescimento. Aspectos estes que trazem uma relação estreita com as condições sócio-econômicas das famílias dos recém-nascidos e diferenciam internamente o fenômeno do baixo peso. 


\subsubsection{Aspectos teórico-metodológicos sobre o conceito de classe social}

Não se pretende aqui retratar a ampla e complexa discussão existente, na literatura especializada, em torno da questão da conceituação do que seja classe social tendo em vista, sobretudo, que atualmente, com o processo de globalização, as relações de trabalho se redefinem em processos cada vez mais complexos. De uma maneira sucinta apresenta-se, aqui, alguns aspectos que merecem destaque tendo em vista questões relativas à sua aplicação em pesquisas empíricas no campo de saúde.

O conceito de classe social consiste em um dos grandes desafios aos pesquisadores das ciências humanas devido, em grande parte, à sua própria natureza e dificuldades de apreensão, na medida em que, em seu pressuposto ontológico, trata-se de uma totalidade social. Duas situações se apresentam como limitantes. A primeira é que cada classe social só pode ser apreendida nos diversos confrontos com as demais porque é desta forma dialética que elas se manifestam concretamente. A segunda é identificar como se estruturam as classes sociais na realidade notadamente hoje quando a globalização impõe mudanças profundas no processo de trabalho das sociedades capitalistas. Diante dessa dificuldade, estudiosos têm buscado indicadores simples, com menor grau de abstração, para 
definir operacionalmente o conceito de classe social. Neste processo há, segundo OLIVEIRA (1987), um reducionismo à dimensão econômica do conceito.

A despeito desta redução teórica que operam para a aplicação do conceito em pesquisas empíricas, o pressuposto básico do conceito não se perde como referência. Fundamentado pelo pensamento marxista, as propostas de apreender as classes sociais tem origem no texto "O manifesto do Partido Comunista" produzido por MARX e ENGELS. Esses autores analisaram os aspectos históricos das principais classes sociais das formações capitalistas com destaque para duas delas: a burguesia, como detentora dos meios de produção; e ao proletariado, como possuidora apenas da força de trabalho (CALDEIRA 1989).

Outro referencial é o último capítulo de "O Capital", escrito por MARX em 1860. Neste trabalho o autor faz uma análise da estrutura da sociedade capitalista. Em sua análise a sociedade está constituída em três classes fundamentais: dos trabalhadores assalariados, dos capitalistas e dos latifundiários. Segundo o autor, cada uma dessas classes caracteriza-se pela exploração de determinados fatores intrínsecos: força de trabalho, para os assalariados; meios de produção, para os capitalistas; e propriedades territoriais, para os latifundiários.

Contemplados esses dois marcos teóricos, os determinantes econômicos tem sido empregados como elementos-chave para a explicação empírica das classes sociais. Embora hajam fortes referenciais, não foi suficiente para a definição de uma concepção teórica de classe social inquestionável. Já no século passado, 
POULANTZAS, também citado por CALDEIRA (1989), apontou que as classes sociais constituem um resultado dos movimentos das estruturas sociais. Nesse contexto, as classes são derivações, produto do confronto das relações sociais gerais de produção; são destituídas de ações substantivas, ou seja, ao invés de determinarem a dinâmica social, as classes são por esta, determinadas. São, no entanto, as relações mais importantes no interior das relações de produção.

De um modo esquemático, as classes também podem ser apreendidas enquanto grupos caracterizáveis através da exploração dos tipos de capitais a eles relacionados. As classes podem ser apresentadas como condição específica através da apropriação e controle de fatores distintos delas, por estarem os mesmos inseridos no circuito da valorização econômica.

É certo que esta dinâmica social não se apresenta de uma forma homogênea, seja no meio rural e muito menos no meio urbano. Devido a seus diferentes graus de relações, estas aparecem expressas em diferentes frações, conforme o capital por elas explorado, ainda que estas frações não sejam encontradas em estado puro nas sociedades. Neste sentido, apresentam-se como aproximação da realidade social, tendo em vista sobretudo as mudanças atualmente operadas no processo de trabalho do mundo capitalista globalizado. 


\subsubsection{Aspectos operacionais do conceito de classe social}

Para efeito de operacionalização do conceito de classes sociais será adotada, no presente trabalho, a proposta de classificação de LOMBARDI e cols. (1988), visando a identificar as relações existentes entre as condições de nascimento dos neonatos e as condições de classe social das familias das parturientes na cidade de João Pessoa/PB.

A concepção teórica que norteia o modelo elaborado por LOMBARDI, baseado no trabalho mexicano de BRONFMAN e TUIRAN (1984), ao lado de outras propostas de operacionalização (FIGUEIREDO 1995, SOLLA 1996), é a de que a determinação básica da estrutura de classes sociais se dá em nivel das relações sociais de produção. Com base na proposta mexicana de BRONFMAN e TUIRÁN (1984), o modelo elaborado por LOMBARDI e cols. (1988) busca reter três elementos teóricos básicos do conceito de classes sociais, em sua dimensão econômica:

- A posição que o indivíduo ocupa no sistema de produção;

- Sua relação com os meios de produção;

- Seu papel na organização social do trabalho. 
Para reter tais elementos os autores privilegiam os seguintes indicadores:

- Empregador, conta própria e empregado;

- Setores econômicos;

- Renda;

- Propriedade dos meios de produção;

- Número de empregados;

- Conhecimento de ofício;

- Relação com a produção (direta/indireta); e

- Setores produtivos.

O modelo de operacionalização proposto por LOMBARDI e cols. (1988) define seis categorias de classes: burguesia, nova pequena burguesia, pequena burguesia tradicional, proletariado não típico, proletariado típico, e subproletariado. Os anexos 2, 3 e 4, relacionam os referidos critérios empregados por LOMBARDI e cols. (1988) para a classificação das seis referidas categorias de classe social, a serem empregadas no presente estudo.

De maneira mais específica, os autores LOMBARDI e cols.(1988) definiram a condição de inserção de classe de acordo com as "tipologias" descritas, a seguir:

Burguesia: classe ou fração de classe social que detém meios de produção e emprega cinco ou mais pessoas apresentando renda individual superior a quinze (15) salários mínimos;

Nova pequena burguesia: engloba assalariados com funções próprias do capital - cargos de chefia, direção e vigilância do processo de trabalho - e/ou com funções que - não sendo em direção - exigem formação superior; compreende, também, assalariados que exercem funções de direção dentro do setor público; por último, é composta também, por indivíduos que, portadores de práticas especializadas, não precisam vender sua "força de trabalho" (autônomos, como médicos, professores e demais que trabalham por conta própria);

Pequena burguesia tradicional: composta por indivíduos sem formação universitária mas que dispõem de meios de produção próprios, empregando até quatro pessoas e com renda individual inferior a quinze (15) salários mínimos; 
Proletariado: dividido em "típico" e "não típico", ambos com a característica de não possuírem meios de produção e de trabalho nem tampouco formação de nível superior ou outra qualificação, sendo obrigados a vender a força de trabalho cujo produto tem uma proporção apropriada pelo empregador; diferencia-se pelo fato de o primeiro exercer atividade diretamente vinculada à produção e transporte de mercadorias, enquanto que 0 segundo exerce atividades relacionadas indiretamente à produção (bancários, funcionários de escritório, funcionários públicos, etc.);

Subproletariado: formado pelos agentes sociais que desempenham atividade predominantemente não assalariada, geralmente instável, com remuneração normalmente inferior ao custo mínimo de reprodução da força de trabalho. 


\subsection{Definição de termos utilizados no estudo}

A definição de outras variáveis empregadas são abaixo descritas, tendo em vista a ambigüidade dos termos que nomeiam seus conceitos como a estrutura familiar, o estado civil, tempo e tipo de união conjugal, a renda familiar, a escolaridade.

A estrutura familiar, recebeu, quanto ao tipo a seguinte categorização:

Família nuclear típica: formada somente pelo núcleo familiar composto por pai, mãe e filhos, independentemente do número da prole;

Família nuclear atipica: semelhante a anterior mas apresentando ausência do pai e/ou mãe;

Família extensa típica: composta pela familia nuclear, mais parentes, não nucleares, de gerações diferentes;

Familia extensa atípica: composta por dois grupos nucleares aparentados, mas sem diferença de gerações;

Familia nuclear composta típica: formada pelo núcleo familiar e parentes do chefe;

Família nuclear composta atípica: semelhante à nuclear atípica mas incluindo pessoas não aparentadas ao chefe;

Família extensa composta típica: semelhante a familia extensa típica abrigando pessoas de outras gerações não aparentadas ao chefe;

Família extensa composta atípica: abrigando grupos familiares da mesma geração mas incluindo pessoas não aparentadas aos respectivos chefes. 
A renda, foi definida em termos de salários mínimos por pessoa da família a partir da distribuição empírica dos dados amostrais.

A variável escolaridade foi classificada em anos completos de escolaridade formal com base no sistema educacional vigente no país, tais como: ensino básico, fundamental, médio e superior.

Outras variáveis de natureza assistenciais que mereceram categorizações:

Pré-natal: considerou-se como pré-natal realizado, conforme o que preconiza a recomendação do Ministério da Saúde, a realização de pelo menos cinco consultas ao profissional médico durante o período gravídico.

Hábito de fumar. A condição de fumante foi definida para as situações: fumante ativa, ou seja, a parturiente que inala diretamente o cigarro, por iniciativa própria; fumante passiva, situam-se as parturientes que mantiveram contato direto e permanente com outras pessoas fumantes ativas durante $o$ período da gravidez.

Hábito de beber, considerado a situação referida pelas parturientes que confirmaram terem ingerido alguma bebida alcoólica durante o período da gravidez, independente do tipo e da quantidade.

Multípara, considerado as situações em que as parturientes apresentam mais de três partos em sua história obstétrica. Para os casos de número inferior a três, receberam a tipologia de primípara, secundípara e tercípara, respectivamente para um, dois e três partos.

Internação, considerado a situação em que o neonato permaneceu no hospital após as $\mathbf{2 4}$ horas de observação pós-parto de rotina, da mãe, independente do motivo de sua permanência.

Sobrevida, considerado a situação em que o neonato permaneceu vivo além das 24 horas pós-nascimento independente de ter sido internado ou não.

Óbito imediato, situação considerada para os óbitos que ocorreram no período inferior às seis primeiras horas pós-nascimento. 
4. APRESENTAÇÃO E DESCRIÇÃO DOS RESULTADOS 


\subsection{Caracterização sócio-demográfica familiar}

A tabela 4 apresenta a distribuição das amostras dos recém-nascidos de baixo peso e não baixo peso ao nascer em relação ao tipo de familia.

Tabela 4 - Distribuição dos recém-nascidos de baixo peso e não baixo peso segundo o tipo de família. João Pessoa/PB, 2000.

\begin{tabular}{|c|c|c|c|c|}
\hline Tipo de família & \multicolumn{2}{|c|}{$\begin{array}{lr}\text { Baixo } & \text { Peso } \\
\text { No } & \% \\
\end{array}$} & \multicolumn{2}{|c|}{$\begin{array}{c}\text { Não Baixo Peso } \\
\text { No }^{\circ} \quad \%\end{array}$} \\
\hline Vive só & 1 & 0,7 & 2 & 0,5 \\
\hline Nuclear típica & 91 & 66,4 & 260 & 69,9 \\
\hline Nuclear atípica & 12 & 8,8 & 24 & 6,5 \\
\hline Extensa típica & 22 & 16,1 & 55 & 14,8 \\
\hline Extensa atípica & 1 & 0,7 & 3 & 0,8 \\
\hline $\begin{array}{c}\text { Extensa atípica } \\
\text { composta }\end{array}$ & 1 & 0,7 & 1 & 0,3 \\
\hline $\begin{array}{l}\text { Nuclear típica } \\
\text { composta }\end{array}$ & 1 & 0,7 & 3 & 0,8 \\
\hline $\begin{array}{c}\text { Nuclear atípica } \\
\text { composta }\end{array}$ & 8 & 5,8 & 24 & 6,5 \\
\hline Total & 13 & & 37 & \\
\hline
\end{tabular}

Conforme pode-se observar pela tabela 4, a predominância da familia nuclear típica é semelhante para os dois grupos estudados, sendo $66,4 \%$ e $69,9 \%$, respectivamente. A segunda maior proporção cabe à familia "extensa típica", respectivamente, com $16,1 \%$ e $14,8 \%$. Vale destacar que $8,8 \%$ dos casos de 
"nuclear atípica" que, pela definição adotada refere-se a uma família onde um dos pais do neonato está ausente. Outra modalidade de família, denominada "nuclear atípica composta", também se fez presente na realidade da cidade de João Pessoa, com 5,8\% para o grupo de baixo peso e 6,5\% para os de não baixo peso. Como a anterior, é definida, também, pela ausência de um dos pais do recémnascido, mas envolve a convivência de outra família do mesmo tipo. A família do tipo "extensa atípica" apresentou pequena proporção nos dois grupos estudados.

Buscando aprofundar a descrição das condições familiares nos dois grupos estudados procurou-se caracterizar a situação conjugal das parturientes. Pela tabela 5 , verifica-se um predomínio de união legal $(43,8 \%)$, no grupo dos recémnascidos de baixo peso enquanto, em relação ao grupo de não baixo peso, a maior ocorrência ficou no tipo de "união livre" (38,2\%), esta definida pela situação de união conjugal não oficial.

Tabela 5 - Distribuição dos recém-nascidos de baixo peso e não baixo peso segundo o tipo de união conjugal das parturientes. João Pessoa/PB, 2000.

\begin{tabular}{|c|c|c|c|c|}
\hline \multirow[t]{2}{*}{ Situação conjugal } & \multicolumn{2}{|c|}{ Baixo peso } & \multicolumn{2}{|c|}{ Não baixo peso } \\
\hline & No & $\%$ & No & $\%$ \\
\hline $\begin{array}{l}\text { Solteira/separada/viúva/ } \\
\text { desquitada s/ união conjugal }\end{array}$ & 35 & 25,5 & 93 & 25,0 \\
\hline Uniăo Livre & 42 & 30,7 & 142 & 38,2 \\
\hline União legal & 60 & 43,8 & 136 & 36,8 \\
\hline Total & 13 & & 372 & \\
\hline
\end{tabular}


A seguir são apresentadas, na tabela 6 , as categorias de responsáveis pelas familias nas duas amostras estudadas.

Tabela 6 - Distribuição dos recém-nascidos de baixo peso e não baixo peso segundo os responsáveis pelas famílias. João Pessoa/PB, 2000.

\begin{tabular}{|c|c|c|}
\hline Responsável & Baixo peso & Não baixo peso \\
\hline pela familla & No $\quad \%$ & No $\%$ \\
\hline $\begin{array}{l}\text { Parturiente ou parentes } \\
\text { assemelhados do sexo } \\
\text { feminino }\end{array}$ & 8,7 & 8,6 \\
\hline $\begin{array}{l}\text { Pai da parturiente ou } \\
\text { parentes assemelhados do } \\
\text { sexo masculino }\end{array}$ & 14,5 & 14,8 \\
\hline $\begin{array}{c}\text { Marido ou companheiro da } \\
\text { parturiente }\end{array}$ & $102 \div 74,4$ & $\begin{array}{r}278-74,7 \\
\end{array}$ \\
\hline $\begin{array}{l}\text { Outros familiares } \\
\text { da parturiente }\end{array}$ & $3 \quad 2,2$ & $\begin{array}{ll}7 & 1,9\end{array}$ \\
\hline Total & 137 & 372 \\
\hline
\end{tabular}

A tabela 6 apresenta tanto para os casos de baixo peso, como para os de não baixo peso uma predominância de famílias "chefiadas" pelo marido/companheiro, $74,4 \%$ e $74,7 \%$, respectivamente. Em segundo lugar de ocorrência aparece, para ambos os grupos estudados, o pai da parturiente e assemelhados com 14,5\% e $14,8 \%$, respectivamente. Com proporção semelhante $(8,7 \%$ e $8,6 \%$, respectivamente) aparecem, em terceiro lugar, as familias "chefiadas" por mulheres. 
A tabela 7 apresenta, a seguir, a distribuiça da idade das mulheres no parto atual, nos dois grupos investigados.

Tabela 7 - Distribuiçăo dos recém-nascidos de baixo peso e não baixo peso segundo a idade das mulheres no momento do parto. Joso Pessoa/PB, 2000.

\begin{tabular}{|c|c|c|c|c|}
\hline \multirow{2}{*}{$\begin{array}{l}\text { Idade materna } \\
\text { (Em anos completos) }\end{array}$} & \multicolumn{2}{|c|}{ Baixo peso } & \multicolumn{2}{|c|}{ Não baixo peso } \\
\hline & & $\%$ & $\mathbf{N O}^{\circ}$ & $\%$ \\
\hline$<15$ & 1 & 0,7 & 2 & 0,5 \\
\hline 15 a 19 & 42 & 30,7 & 93 & 25,0 \\
\hline 20 a 24 & 45 & 32,8 & 125 & 33,6 \\
\hline 25 a 29 & 36 & 26,3 & 97 & 26,1 \\
\hline - & 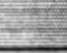 & +8 & +2 & $5=$ \\
\hline 30 a 34 & 8 & 5,8 & 38 & 10,2 \\
\hline 35 a 39 & 4 & 2,9 & 14 & 3,8 \\
\hline $40 \mathrm{e}+$ & 1 & 0,7 & 3 & 0,8 \\
\hline Total & 13 & & 37 & \\
\hline
\end{tabular}

Como se pode observar, é bastante elevada a proporção de gravidez na adolescência para os dois grupos analisados, mas com destaque para os recémnascidos de baixo peso, ou seja, $31,4 \%$ e $25,5 \%$, respectivamente.

Em relaçâo às mulheres com trinta anos e mais observa-se uma maior proporçăo no grupo de não baixo peso, com 14,8\% em comparaçäo com 9,4\% do grupo de balxo peso. 
A tabela 8 apresenta a distribuição da idade de início da atividade sexual das parturientes referentes aos dois grupos estudados, segundo informagōes das mesmas.

Tabela 8 - Distribuiç̃o dos recém-nascidos de baixo peso e não baixo peso segundo a idade das mulheres por ocasião da primeira relação sexual. João Pessoa/PB, 2000.

\begin{tabular}{|c|c|c|c|c|}
\hline \multirow{3}{*}{$\begin{array}{c}\text { Faixa Etária } \\
\text { (Em anos completos) } \\
<15\end{array}$} & \multicolumn{2}{|c|}{ Baixo peso } & \multicolumn{2}{|c|}{ Não baixo peso } \\
\hline & & $\%$ & No & $\%$ \\
\hline & 14 & 10,2 & 54 & 14,6 \\
\hline 15 a 19 & 95 & 69,3 & 235 & 63,2 \\
\hline 20 a 24 & & 13,9 & 61 & 6,4 \\
\hline $25 e+$ & & 6,5 & 22 & 5,9 \\
\hline Total & 13 & & 372 & \\
\hline
\end{tabular}

Conforme dados da tabela 8, 79,5\% das parturientes com neonatos de baixo peso e $77,8 \%$ das com neonatos de não babxo peso tiveram sua iniciação sexual antes dos vinte anos de idade. Estes dados não estão em desacordo com os dados da menarca considerando, por um lado, que pelos dados empiricos disponiveis a partir da informaço das parturientes pesquisadas, $88,2 \%$ e $92,2 \%$ para os grupos de recém-nascidos de baixo peso e não baixo peso, respectivamente, tiveram sua menarca na falxa de dez a quatorze anos de idade.

A tabela 9 apresenta, a seguir, a distribuiçäo da paridade das parturientes nos Jois grupos de peso dos recém-nascidos estudados. 
Tabela 9 - Distribuição dos recém-nascidos de baixo peso e não baixo peso, segundo a a paridade da mulher. João Pessoa/PB, 2000.

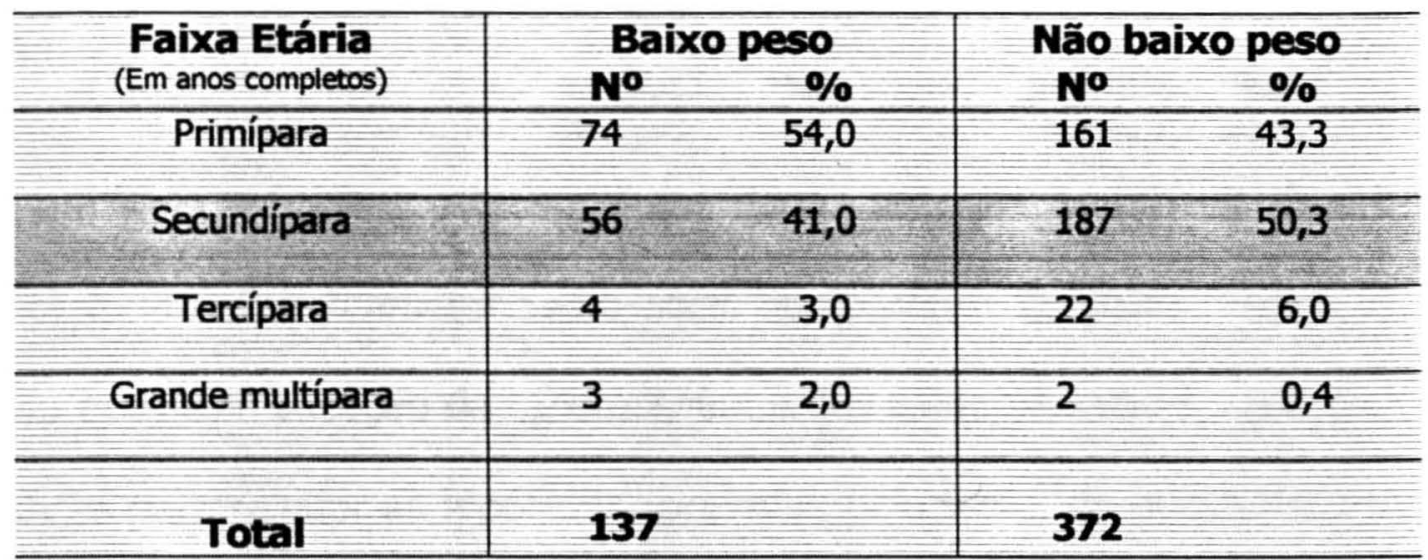

Como se pode observar, a grande proporgão dos neonatos referem-se ao primeiro e ao segundo filho(a), com 94,9\% para os recém-nascidos de baixo peso e 93,6\% para os de não baíxo peso.

Uma análise comparativa aponta, no entanto, para uma diferenciagåo entre os dois grupos estudados na medida em que, no caso da primeira gravidez, a maior proporção $(54,0 \%)$ refere-se às mulheres com recém-nascidos de baixo peso contra $43,3 \%$, para as de neonato de não baixo peso. Em contrapartida, tendência inversa observa-se no caso das secundíparas que apresentou menor proporção para os recém-nascidos de baixo peso $(\mathbf{4 0 , 9 \% )}$ contra $50,3 \%$ para os recémnascidos de não baixo peso. Destaque cabe à pequena proporção de grande multipara, com $2,2 \%$ e $0,5 \%$, respectivamente. Dentre as famílias estudadas, 0 predomínio do tipo nuclear, composto pelo casal e dois filhos, ao lado de uma tendência das mulheres com neonatos de baixo peso serem mais jovens do que as 
do grupo de não baixo peso, era de se esperar a proporção maior de gravidez na adolescência.

Tendo em vista a análise estatística dos dados relativos às tabelas descritas no presente item sobre "caracterização sócio-demográfica familiar" (anexo 5), vale observar que, com exceção da tabela 9, em todas as demais não houve evidências estatísticas para rejeitar as hipóteses, previstas pelo teste, de que o risco de uma criança de baixo peso em determinada categoria das diferentes variáveis estudadas é igual ao de uma criança de não baixo peso ao nascer, para cada uma das variáveis estudadas.

Em relação à tabela 9, que apresenta a distribuição da paridade das mulheres nos dois grupos de peso dos recém-nascidos estudados, observou-se, para o caso da primípara, uma odds ratio de 1,53 com intervalo de confiança de 1,00 a 2,35, o que poderia estar sugerindo a presença de um risco estatisticamente significante $(p<0,005)$ de baixo peso, quando tomada como categoria de referência a secundípara. 


\subsection{Caracterização da assistência pré-natal}

A tabela 10 apresenta a distribuição do número de consultas de pré-natal para os dois grupos investigados, tendo em vista a relevância deste tipo de assistência para as condições favoráveis de nascimento.

Tabela 10 - Distribuição dos recém-nascidos de baixo peso e não baixo peso segundo o número de consultas de pré-natal. João Pessoa/PB, 2000.

\begin{tabular}{|c|c|c|c|c|}
\hline \multirow{2}{*}{$\begin{array}{c}\text { Número de consultas } \\
\text { de pré-natal }\end{array}$} & \multicolumn{2}{|c|}{ Baixo peso } & \multicolumn{2}{|c|}{ Não baixo peso } \\
\hline & & $\%$ & No & $\%$ \\
\hline 124 & 21 & 15,3 & 51 & 13,7 \\
\hline $5 a 8$ & 76 & 55,5 & 198 & 53,2 \\
\hline $9 \mathrm{et}$ & 18 & 13,1 & 78 & 21,0 \\
\hline $\begin{array}{l}\text { Nãofez } \\
\text { Pré-natal }\end{array}$ & 22 & 16,1 & 45 & 12,1 \\
\hline Total & 13 & & 372 & \\
\hline
\end{tabular}

Pela tabela 10 , pode-se observar uma predominância de parturientes que não fizeram o pré-natal, no grupo dos recém-nascidos de baixo peso, com 16,1\%, em relação aos neonatos de não baixo peso, com $12,1 \%$. A mesma tendência se observa em relação ao número de consultas considerada insuficiente para a proteção à mãe e ao recém-nascido, que apresentou $15,3 \%$ e 13,7\%, respectivamente. Essa diferença aumenta quando se considera as duas categorias em conjunto, ou seja, $31,4 \%$ das parturientes que tiveram filhos com baixo peso 
não fizeram pré-natal ou somente de 1 a 4 consultas contra $25,8 \%$ das parturientes com neonatos de não baixo peso. 0 mesmo acontece com o número de consultas de 5 a 8, considerada padrão na assistência pré-natal oferecida no país. Tendência inversa acontece somente na categoria 9 e + consultas, quando se observa para o grupo de baixo peso um percentual de $13,1 \%$ e de $21,0 \%$ para o grupo de não baixo peso. Este fato poderia estar sugerindo a presença de uma gravidez de maior risco e/ou o acesso a uma maior proteção necessária para o recém-nascido.

Considerando a importância não só do número de consultas de pré-natal, mas também sua distribuição ao longo da gravidez, a tabela 11 apresenta, a seguir, a distribuição dos recém-nascidos de baixo peso e não baixo peso, segundo o número de consultas em relação à idade gestacional por trimestre da gestação.

Tabela 11 - Distribuição dos recém-nascidos de baixo peso e não baixo peso segundo o número de consultas em relação ao trimestre de início do pré-natal. João Pessoa/PB, 2000.

\begin{tabular}{|c|c|c|c|c|c|c|c|c|}
\hline \multirow{3}{*}{$\begin{array}{l}\text { Grupos } \\
\text { estudados }\end{array}$} & \multirow{3}{*}{$\begin{array}{l}\text { Número de } \\
\text { consultas }\end{array}$} & \multicolumn{6}{|c|}{ Trimestre da gravidez } & \multirow{3}{*}{ Total } \\
\hline & & \multicolumn{2}{|c|}{ Primeiro } & \multicolumn{2}{|c|}{ Segundo } & \multicolumn{2}{|c|}{ Terceiro } & \\
\hline & & No & $\%$ & No & $\%$ & No & $\%$ & \\
\hline \multirow{3}{*}{$\begin{array}{l}8 \\
8 \\
8 \\
\frac{8}{8}\end{array}$} & -4 & $\begin{array}{r}9 \\
13,0\end{array}$ & 42,5 & $\begin{array}{r}5 \\
25,0\end{array}$ & 23,8 & $\begin{array}{c}7 \\
27,0\end{array}$ & 33,4 & $18,3^{21}$ \\
\hline & $5 \cdot 8$ & $\begin{array}{r}46 \\
66,7\end{array}$ & 60,6 & $\begin{array}{r}13 \\
65,0 \\
\end{array}$ & 17,1 & $\begin{array}{r}17 \\
65,2\end{array}$ & 22,3 & $66,0^{76}$ \\
\hline & $9 e+$ & $\frac{14}{20,3}$ & 77,8 & $\begin{array}{r}2 \\
10,0\end{array}$ & 11,1 & $\begin{array}{r}2 \\
7,8\end{array}$ & 11,1 & $15,7^{18}$ \\
\hline \multicolumn{2}{|c|}{ Sub-Total } & 69 & 60,0 & 20 & 17,4 & 26 & 22,6 & 115* \\
\hline \multirow{3}{*}{ 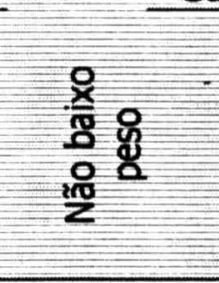 } & -4 & $\begin{array}{r}9 \\
4,3\end{array}$ & 17,6 & $\begin{array}{r}20 \\
36,4\end{array}$ & 39,2 & 22 & 43,2 & $15,6^{51}$ \\
\hline & $5-8$ & $\begin{array}{r}123 \\
59,1\end{array}$ & 62,1 & $\begin{array}{r}35 \\
63,6\end{array}$ & 17,7 & $\begin{array}{r}40 \\
62,6\end{array}$ & 20,2 & $60,5^{198}$ \\
\hline & $e+$ & $\begin{array}{r}76 \\
36,6\end{array}$ & 97,4 & $\div$ & - & $\begin{array}{r}2 \\
3,1\end{array}$ & 2,6 & $23,9^{78}$ \\
\hline \multicolumn{2}{|c|}{ Sub-total } & 208 & 63,6 & 55 & 16,8 & 64 & 19,6 & $327 *$ \\
\hline
\end{tabular}

(*) Foram excluídos 22 casos e 45 controles, respectivamente. 
Pela tabela 11, pode-se observar um padrão de comportamento semelhante para os dois grupos estudados em relação às mulheres que tiveram um número de consultas de pré-natal considerado adequado ( 5 a 8 consultas) para a proteção materno-infantil; ou seja, embora a maioria das mulheres tenham iniciado, nos dois grupos, o pré-natal no primeiro trimestre da gravidez $(60,6 \%$ e $62,1 \%$, respectivamente), $17,1 \%$ e $22,3 \%$ das mulheres, com recém-nascidos de baixo, peso iniciaram o pré-natal nos segundo e terceiro trimestres da gravidez, respectivamente, assim como as mulheres com neonatos de não baixo peso apresentam $17,7 \%$ para o segundo trimestre, e $20,2 \%$ para o terceiro trimestre.

Se considerarmos o total de mulheres que tiveram acesso ao pré-natal e fizeram pelo menos uma consulta relacionando, por outro, com o total de mulheres cujo início do pré-natal foi no primeiro e no segundo trimestre de gravidez e que tiveram mais de quatro consultas ter-se-á o cálculo da proporção do que aqui denominar-se-á de "cobertura distribuída".

Isso significa, para o grupo de recém-nascidos de baixo peso, uma "cobertura distribuida" do pré-natal, já no primeiro trimestre para o grupo de 5 a 8 consultas, na ordem de $40,0 \%$, isto considerando o total de parturientes estudadas que tiveram acesso ao serviço de pré-natal pelo menos a uma consulta. Se considerarmos, também, as mulheres que fizeram 9 e + consultas (60 mulheres), a referida "cobertura distribuída" sobe para 52,2\%, o que ainda pode ser considerada uma cobertura inadequada tendo em vista, sobretudo, que se tratam de mulheres que tiveram crianças de baixo peso ao nascer. No caso dos recém- 
nascidos de não baixo peso, a "cobertura distribuída" para a categoria de 5 a 8 consultas foi de $37,6 \%$, um pouco menor que a encontrada para os recémnascidos de baixo peso $(40,0 \%)$. Se a ela acrescentarmos as parturientes que fizeram 9 e mais consultas (199 mulheres) teremos uma "cobertura distribuída" de $60,8 \%$ contra $52,2 \%$ dos casos de baixo peso.

Mesmo supondo que as mulheres com neonatos de baixo peso que iniciaram, no segundo trimestre da gravidez, a exemplo das que iniciaram no primeiro, também recebem uma proteção adequada para o binômio mãe-filho, quando consideradas em relação às categorias de 5 a 8 e 9 e mais consultas, em quanto, a "cobertura distribuída" seria de $65,1 \%$, não alcançando, portanto, o parâmetro esperado de cobertura, que segundo o pacto de atenção básica foi estipulado, para o município de João Pessoa, em $85,0 \%$ (SMS/JP, 1997). O mesmo acontece para as parturientes com recém-nascidos de não baixo peso na medida em que, neste caso, a proporção de "cobertura distribuída" é de $71,5 \%$.

Em relação à análise estatística efetuada para os dados de cada uma das tabelas apresentadas neste item sobre a "caracterização da assistência pré-natal" (anexo 6), vale observar que em todos os testes efetuados não houve evidências estatísticas para rejeitar as hipóteses, pressupostas pelo teste, de que o risco de uma criança de baixo peso em determinada categoria, das diferentes variáveis estudadas, é igual ao de uma criança de não baixo peso ao nascer. 


\subsection{Caracterização da assistência ao parto e ao recém-nascido}

A tabela 12 apresenta a distribuição dos recém-nascidos de baixo peso e não baixo peso, segundo o sexo.

Tabela 12 - Distribuição dos recém-nascidos de baixo peso e não baixo peso segundo o sexo. João Pessoa/PB, 2000.

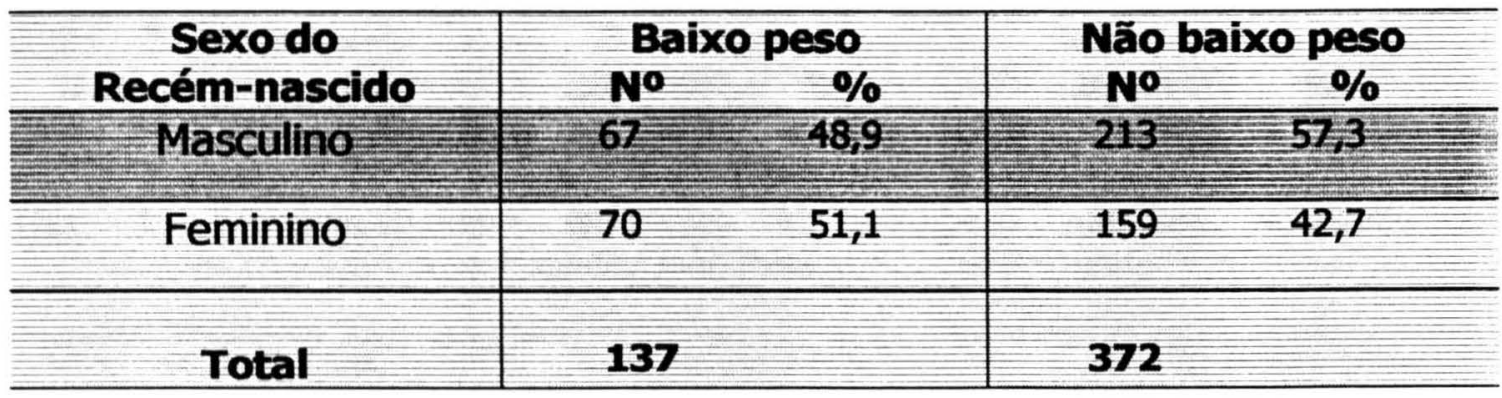

Conforme pode-se observar na tabela 12, a proporção de nascidos vivos de não baixo peso seguiu o comportamento esperado para este evento, ou seja, uma maior proporcão de neonatos do sexo masculino $(57,3 \%)$ comparados com $42,7 \%$ do sexo feminino. Tendência inversa observa-se, no entanto, no caso dos recémnascidos de baixo peso onde $48,9 \%$ foram do sexo masculino e $51,1 \%$ do sexo feminino. 
Vale observar que este resultado tem a ver com o fato de meninas nascerem menores que os meninos o que, para uma amostra de recém-nascidos de baixo peso, pode representar um predomínio de meninas, como o observado na tabela 12. Também, entre os neonatos de não baixo peso pode ter havido predomínio dos meninos, pela mesma razão. Além disso deve-se considerar que os grupos de baixo peso e não baixo peso representam proporções diferentes do conjunto de nascimentos.

A condição de nascimento para os dois grupos estudados pode ser observada na tabela 13, a seguir.

Tabela 13 - Distribuiç̃o dos recém-nascidos de baixo peso e não baixo peso, segundo a condiçăo de sobrevida. Jošo Pessoa/PB, 2000.

\begin{tabular}{|c|cc|cc}
\hline $\begin{array}{c}\text { Condicão de } \\
\text { sobrevida nas 1as } \\
\text { seis horas }\end{array}$ & \multicolumn{2}{|c|}{$\begin{array}{c}\text { Baixo peso } \\
\text { No }\end{array}$} & \multicolumn{2}{|c}{$\begin{array}{c}\text { Não baixo peso } \\
\text { No }\end{array}$} \\
\hline Óbito & 3 & 2,2 & 11 & 3,0 \\
\hline Sobrevida & 134 & 97,8 & 361 & 97,0 \\
\hline \hline Total & & & \\
\hline \hline
\end{tabular}

Os dados da tabela 13 apresentam proporções aproximadas quanto ao comportamento da mortalidade nas primeiras seis horas de nascimento. 
A tabela 14, a seguir, apresenta o tipo de parto para os dois grupos de recémnascidos estudados, em relação aos dois tipos de serviços utilizados, público e privado.

Tabela 14 - Distribuiç̄o dos reckm-nascidos de baiko peso e näo baixo peso segundo o tipo de servipo utilizado e o tipo de parto. J0\%5 Pessoa/PB, 2000.

\begin{tabular}{|c|c|c|c|c|c|c|c|}
\hline \multirow{3}{*}{$\begin{array}{c}\text { Grupos } \\
\text { do } \\
\text { estudo }\end{array}$} & \multirow{3}{*}{$\begin{array}{c}\text { Tipo de serviços } \\
\text { utilizados }\end{array}$} & \multicolumn{4}{|c|}{ Tipo de parto } & \multirow{2}{*}{\multicolumn{2}{|c|}{ Total }} \\
\hline & & & 1 & & & & \\
\hline & & No & $\%$ & No & $\%$ & $\mathbf{N}^{0}$ & $\%$ \\
\hline \multirow{2}{*}{$\begin{array}{l}\text { Baixo } \\
\text { peso }\end{array}$} & Público & $\begin{array}{r}70 \\
93,4 \\
\end{array}$ & 54,7 & $\begin{array}{r}58 \\
93,5 \\
\end{array}$ & 45,8 & 128 & 93,4 \\
\hline & Privado* & $\begin{array}{r}5 \\
6,6\end{array}$ & 55,6 & $\begin{array}{r}4 \\
6,5\end{array}$ & 44,4 & 9 & 6,6 \\
\hline \multicolumn{2}{|r|}{ Sub-total } & 75 & 54,7 & 62 & 45,3 & 137 & \\
\hline \multirow{2}{*}{$\begin{array}{l}\text { Não } \\
\text { baixo } \\
\text { peso }\end{array}$} & Pública & $\begin{array}{r}183 \\
96,8 \\
\end{array}$ & 54,4 & $\begin{array}{r}153 \\
83,6 \\
\end{array}$ & 45,6 & 336 & 90,3 \\
\hline & Privado* & $\begin{array}{r}6 \\
3,2\end{array}$ & 16,6 & $16,4^{30}$ & 83,4 & 36 & 9,7 \\
\hline & Sub-total & 189 & 50,8 & 183 & 49,2 & 372 & \\
\hline
\end{tabular}

(*) Nesta categoria "privado" encontram-se inscritos um hospital privado e, também, os casos de hospitais privados/conveniados.

Os dados da tabela 14 revelam a elevada taxa de cesarianas para os dois grupos investigados, inclusive com predominância para o grupo de recém-nascidos de não baixo peso, ou seja, $45,3 \%$ e $49,2 \%$, respectivamente.

Vale destacar que quando relacionado ao tipo de serviço ganha expressão a proporção de $\mathbf{8 3 , 4 \%}$ de cesarianas nos serviços privados, no grupo de recémnascidos de não baixo peso.

A tabela 15 a seguir, apresenta as indicações para cesáreas, segundo o registro no prontuário hospitalar. 
Tabela 15 - Distribuição dos recém-nascidos de baixo peso e não baixo peso segundo as indicações de parto cesáreo. João Pessoa/PB, 2000.

\begin{tabular}{|c|c|c|c|c|}
\hline \multirow{2}{*}{$\begin{array}{c}\text { Indicações de } \\
\text { cesáreas }\end{array}$} & \multicolumn{2}{|c|}{$\begin{array}{l}\text { Grupo de } \\
\text { baixo peso }\end{array}$} & \multicolumn{2}{|c|}{$\begin{array}{c}\text { Grupo de } \\
\text { não baixo peso }\end{array}$} \\
\hline & $\mathbf{N}^{0}$ & $\%$ & $\mathbf{N}^{0}$ & $\%$ \\
\hline Iteratividade & 7 & 11,3 & 38 & 20,8 \\
\hline $\begin{array}{l}\text { Desproporção } \\
\text { Feto-pélvica }\end{array}$ & 4 & 6,4 & 21 & 11,5 \\
\hline D.H.E.G & 4 & 6,4 & 3 & 1,6 \\
\hline Placenta Prévia & 1 & 1,6 & 4 & 2,2 \\
\hline Sofrimento fetal & 2 & 3,2 & 7 & 3,9 \\
\hline Distrofia de colo & 1 & 1,6 & 3 & 1,6 \\
\hline Outras indicações & 12 & 19,5 & 25 & 13,6 \\
\hline Sem registro & 31 & 50,0 & 82 & 44,8 \\
\hline Total & 62 & & 183 & \\
\hline
\end{tabular}

Das mulheres submetidas à cesárea, a grande maioria não teve a indicação registrada nos prontuários, nos dois grupos estudados, sendo 50,0\% para o grupo de baixo peso e 44,8\% para o de não baixo peso.

Dentre as indicações registradas a primeira foi a iteratividade, com $11,3 \%$ para 0 grupo de baixo peso e $20,8 \%$ para o de não baixo peso. Para o primeiro grupo, a desproporção feto-pélvica e o DHEG apresentaram-se em segundo lugar, com a proporção de $6,4 \%$. 0 mesmo não acontece para o segundo grupo, cuja predominância e o segundo lugar coube somente à desproporção feto-pélvica com 11,5\%. A maior proporção de indicação de cesárea por DHEG, no grupo de baixo peso, era de se esperar dada a relação existente entre ambos. 
Vale destacar que, na categoria "outras indicações", observou-se o registro de quatro casos onde a indicação para a cesárea seria a histerectomia, fato este estranho na medida em que este tipo de procedimento não se justifica como indicação para a cesárea.

Procurando reter a relação entre morbidade referida pela parturiente e morbidade registrada no prontuário hospitalar apresenta-se, a seguir, a tabela 16.

Tabela 16 - Distribuição dos recém-nascidos de baixo peso e não baixo peso segundo as morbidades referidas pelas parturientes e as registradas no prontuário hospitalar. João Pessoa/PB, 2000.

Tipos de
morbidades

Dentre as morbidades referidas pelas parturientes destacam-se, primeiramente, as infecções urinárias porque associadas diretamente à prematuridade. Se analisadas IS referidas nos dois grupos investigados, observa-se 7 (6,0\%) para o grupo de 
baixo peso e $11(4,5 \%)$ para o de não baixo peso. A presença desta patologia registrada no prontuário aponta para a possibilidade da mesma ter se apresentada já no período do pré-natal e não ter sido diagnosticada e tratada adequadamente.

A importância da existência de interação entre os serviços de pré-natal e de assistência ao parto apresenta-se, de maneira típica, no caso de patologias como a hipertensão arterial. Isto porque, identificadas em mais proporção nos registros dos prontuários, para os dois grupos de recém-nascidos, apresenta-se pouco referida pelas mulheres e mesmo ignorada pela maioria, o que poderia significar o não diagnóstico no pré-natal ou a ausência de informação à parturiente. O mesmo acontece com outras patologias como cardiopatia, diabetes, malária, sífilis, DHEG, pré-eclâmpsia e eclâmpsia, cujas ocorrências estão estreitamente relacionadas com as condições da qualidade da assistência pré-natal.

Chama a atenção a discrepância observada em relação às elevadas proporções de infecção respiratória referidas pelas parturientes dois grupos 69,0\% e 80,2\%, respectivamente, e a total ausência de registros nos prontuários hospitalares. Embora este tipo de morbidade referida possa representar uma informações acumulada, porque relativa a todo o processo da gravidez, pelos elevados percentuais apresentados era de se esperar algum tipo de registro.

A tabela 17, a seguir, permite observar a adequação do peso ao nascer para a idade gestacional dos neonatos, segundo CAPURRO (CLAP, 1988). 
Tabela 17 - Distribuição dos recém-nascidos de baixo peso e não baixo peso segundo a adequação peso/idade gestacional. Jošo Pessoa/PB, 2000.

\begin{tabular}{|c|c|c|}
\hline $\begin{array}{l}\text { Adequação } \\
\text { Peso/idade }\end{array}$ & $\begin{array}{c}\text { Grupo de baixo peso } \\
\text { No }\end{array}$ & $\begin{array}{c}\text { Grupo de não baixo peso } \\
\text { No } \quad \%\end{array}$ \\
\hline$P I G$ & $41 \quad 50,6$ & 3,9 \\
\hline AIG & 46,9 & $220 \quad 77,7$ \\
\hline GIG & 2 & 18,4 \\
\hline Total & $81 *$ & $283^{*}$ \\
\hline
\end{tabular}

(*) Foram excluídos 56 casos e 89 controles sem registros.

A distribuição apresentada na tabela 17 descreve a coerência dos dados relativos ao dois grupos estudados na medida em que os neonatos adequados para a idade gestacional (AIG) se encontram, em maior proporção, no grupo dos não baixo peso, com $77,7 \%$. Em relação ao grupo de baixo peso, as proporções para as condições de pequeno para a idade gestacional (PIG) e adequado para a idade gestacional (AIG) apresentam-se próximas, sendo 50,6\% para o PIG e 46,9\% para o AIG. No entanto, quando comparados os dois grupos estudados observase, como era de se esperar dados os critérios constitutivos da medida de avaliação, uma maior proporção $(50,6 \%)$ de pequenos para a idade gestacional no grupo de baixo peso em relação a de 3,9\% para o grupo de não baixo peso.

Chama a atenção a proporção de não registro deste tipo de dado, ou seja, 40,9\% para os 137 casos de baixo peso e $23,9 \%$ para os 372 controles de não baixo peso. 
A tabela 18 apresenta a distribuição da internação hospitalar para os recémnascidos de baixo peso e não baixo peso.

Tabela 18 - Distribuição dos recém-nascidos de baixo peso e não baixo peso segundo a internação hospitalar. João Pessoa/PB, 2000.

\begin{tabular}{|c|c|c|}
\hline & Grupo de baixo peso & Grupo de não baixo peso \\
\hline Internação & No $\quad \%$ & No $\%$ \\
\hline Sim & $18 \quad 13,1$ & 4,3 \\
\hline Não & $119 \quad 86,9$ & 95,7 \\
\hline Total & 137 & 372 \\
\hline
\end{tabular}

Como se pode observar, houve uma maior proporção, $13,1 \%$, de internação no grupo de baixo peso, quando comparado com 4,3\% no grupo de não baixo peso.

Do ponto de vista da análise estatística, com exceção das tabelas 14, 17 e 18, não houve evidências, em nenhuma das demais, para rejeitar as hipóteses de que o risco de uma criança de baixo peso, em determinada categoria das diferentes variáveis estudadas, é igual ao de uma criança de não baixo peso (anexo 7).

Em relação à tabela 14, que representa a distribuição dos recém-nascidos de baixo peso e não baixo peso segundo o tipo de serviço utilizado e o tipo de parto das mulheres, foi observada evidência estatística da diferença existente entre a proporção de cesáreas no setor privado quando relacionados os dois grupos estudados. A odds ratio foi de $8,75(1,27-68,93)$, estatisticamente significante $(p<0,005)$. 
Quanto à tabela 17, que apresenta a distribuição dos recém-nascidos de baixo peso e não baixo peso, segundo a adequação peso/idade gestacional, a odds ratio mostrou um risco maior da criança ser pequena para a idade gestacional (PIG), quando de baixo peso $(\mathrm{OR}=25,35(11,43$ - 57,35)); ou seja, a proporção de crianças de baixo peso - PIG $(50,6 \%)$ é estatisticamente diferente da proporção de não baixo peso - PIG $(3,9 \%) ;\left(x^{2}=108,0 ; g l=1 ; p<0,001\right)$.

Quanto à tabela 18, que apresenta a distribuição dos recém-nascidos de baixo peso e não baixo peso, segundo a internação hospitalar, a odds ratio revela um risco maior da criança ser internada, quando de baixo $(O R=3,37(1,57-7,25))$; ou seja, a proporção de crianças de baixo peso com necessidade de internação $(13,1 \%)$ é estatisticamente diferente desta proporção entre os de não baixo peso $(4,3 \%) ;\left(x^{2}=12,52 ; g l=1 ; p<0,001\right)$. 
4.4 Caracterização das relações existentes entre condições de nascimento e desigualdade social

A tabela 19 apresenta, a seguir, a distribuição dos recém-nascidos de baixo peso e não baixo peso segundo as categorias de classes sociais dos responsáveis pela familia.

Tabela 19 - Distribuição dos recém-nascidos de baixo peso e não baixo peso segundo as categorias de classes sociais dos responsáveis pelas famílias. João Pessoa/PB, 2000.

\begin{tabular}{|c|c|c|c|c|}
\hline \multirow[t]{2}{*}{$\begin{array}{l}\text { Categorias de } \\
\text { classes sociais }\end{array}$} & \multicolumn{2}{|c|}{$\begin{array}{c}\text { Grupo } \\
\text { de baixo peso }\end{array}$} & \multicolumn{2}{|c|}{$\begin{array}{c}\text { Grupo de } \\
\text { não baixo peso }\end{array}$} \\
\hline & $\mathbf{N}^{\circ}$ & $\%$ & $\mathbf{N}^{\circ}$ & $\%$ \\
\hline Subproletariado & 29 & 21,2 & 85 & 22,8 \\
\hline Proletariado típico & 14 & 10,2 & 23 & 6,2 \\
\hline Proletariado não típico & 74 & 54,0 & 198 & 53,2 \\
\hline Peq. Burg. Tradicional & 15 & 10,9 & 42 & 11,3 \\
\hline Nova peq. Burguesia & 5 & 3,7 & 21 & 5,7 \\
\hline Burguesia & ב. & & 3 & 0,8 \\
\hline Total & 137 & & 372 & \\
\hline
\end{tabular}

Conforme pode-se observar, tratam-se, no geral, de dois grupos relativamente homogêneos quanto à condição de classe, com predominância no "proletariado não típico". Consideradas como categorias polares, a maior proporção cabe, nos dois grupos estudados, para o proletariado, com $85,4 \%$ no grupo de baixo peso, e 82,2\% no grupo de não baixo peso, com pequena predominância do primeiro em relação ao segundo. 
As diferenças observadas encontram-se no interior da ampla categoria burguesia quando se constata, por um lado, as menores proporções de recém-nascidos de baixo peso nas classes "pequena burguesia tradicional" (10,9\%) e "nova pequena burguesia" (3,7\%) e, por outro, a ausência de neonatos de baixo peso na classe "burguesia", quando comparadas às distribuições presentes no grupo de não baixo peso.

A tabela 20, a seguir, apresenta as relações entre categorias de classes sociais e tipo de trabalho do responsável pela família, formal e não formal, para os dois grupos pesquisados.

Tabela 20 - Distribuição dos recém-nascidos de baixo peso e não baixo peso segundo as categorias de classes sociais e o tipo de trabalho do responsável pela família. João Pessoa/PB, 2000.

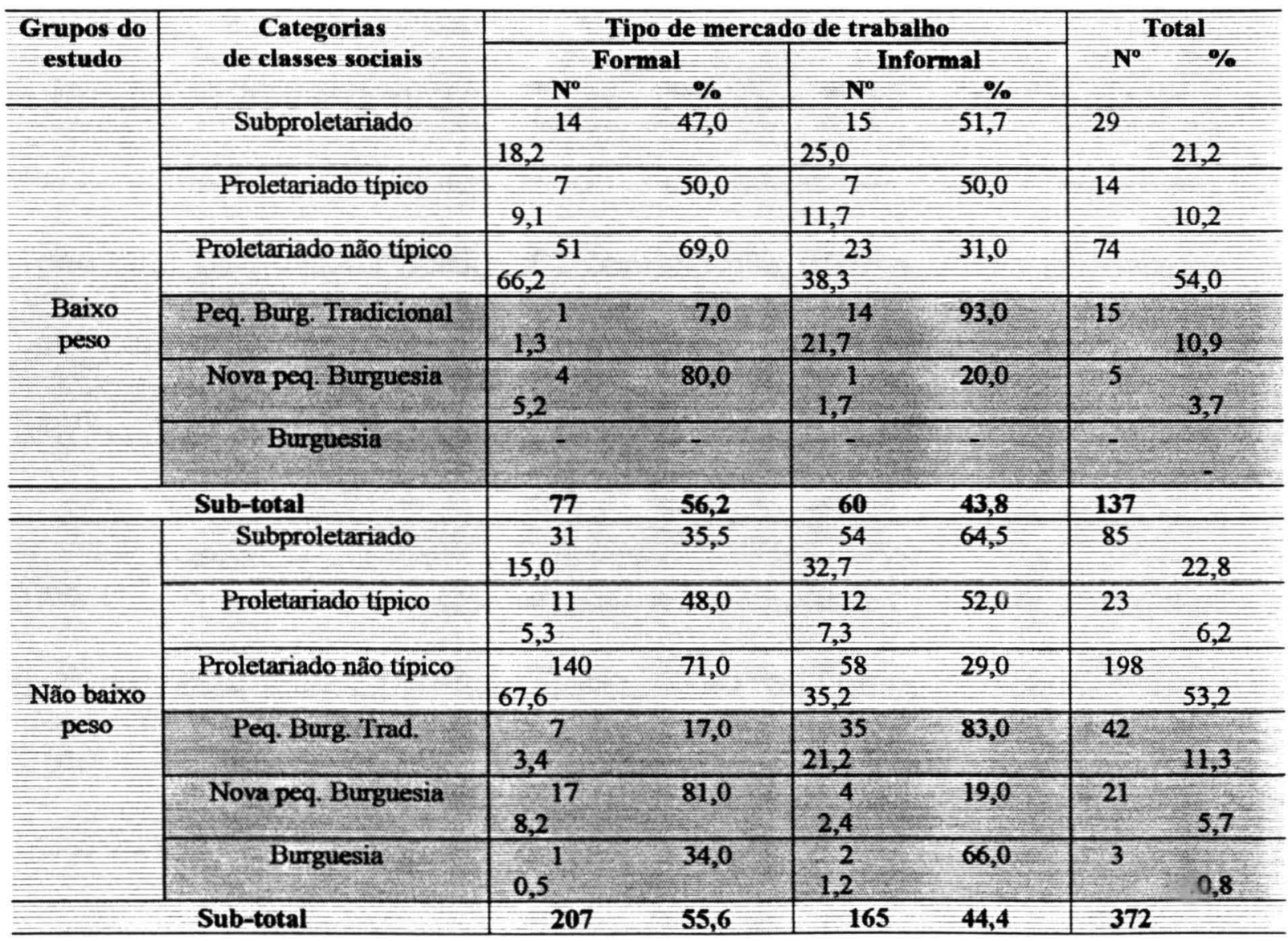


O comportamento dos dados, para os dois grupos observados, apresentou proporções semelhantes quando se constata que $56,2 \%$ e $55,6 \%$ dos responsáveis pelas familias de crianças dos grupos de baixo peso e não baixo peso inscrevem-se, respectivamente, no mercado de trabalho formal. Diante destes dados, cabe destaque a elevada proporção de responsáveis pelas famílias dos recém-nascidos exercendo atividades no setor informal, ou seja, $43,8 \%$ e $44,4 \%$, respectivamente.

A predominância, em relação ao trabalho formal, cabe, em primeiro lugar, à classe "nova pequena burguesia" para os dois grupos estudados, com $80,0 \%$ e $81,0 \%$, respectivamente. Em segundo lugar destaca-se, com 69,0\% e 71,0\%, respectivamente, o "proletariado não típico".

Em relação ao trabalho informal a predominância cabe, como era de se esperar pelas características definidoras das duas categorias de classes, em primeiro lugar, à "pequena burguesia tradicional", com $93,0 \%$ para o grupo de baixo peso e 83,0\% para o de não baixo peso; em segundo, ao "subproletariado", com 51,7\% e $64,7 \%$.

Tendo em vista observar a especificidade do emprego de indicadores simples em relação ao baixo peso e não baixo peso, como renda e escolaridade, em relação à estrutura de classes sociais, são apresentadas, a seguir, respectivamente, as tabelas 21 e 22. 
A tabela 21 refere-se à distribuição de recém-nascidos de baixo peso e não baixo peso em relação à renda per capita das famílias.

Tabela 21 - Distribuição dos recém-nascidos de baixo peso e não baixo peso segundo a per capita das famílias investigadas. João Pessoa/PB, 2000.

\begin{tabular}{|c|c|c|c|}
\hline \multirow{2}{*}{$\begin{array}{c}\text { Faixas de } \\
\text { renda per capita } \\
\text { (em salários mínimos) }\end{array}$} & \multirow[t]{2}{*}{$\begin{array}{l}\text { Grupo } \\
\text { de baixo peso } \\
\text { No }\end{array}$} & \multicolumn{2}{|c|}{$\begin{array}{c}\text { Grupo de } \\
\text { não baixo peso }\end{array}$} \\
\hline & & & \\
\hline$\leq 0,19$ & $1 \quad 1,0$ & 6 & 2,1 \\
\hline $0,20-0,49$ & 25,8 & 66 & 22,6 \\
\hline $0,50-0,73$ & 30,9 & 82 & 28,1 \\
\hline $0,74-0,99$ & 12,4 & 34 & 11,6 \\
\hline $1,00-1,49$ & 14,4 & 60 & 20,5 \\
\hline $1,50-1,99$ & 5,2 & 12 & 4,1 \\
\hline $2,00-2,99$ & 6,2 & 12 & 4,1 \\
\hline $3,00-6,60$ & 4 & 20 & 6,8 \\
\hline Total & $97 *$ & 292 & \\
\hline
\end{tabular}

(*) Foram excluídos 40 casos e 80 controles, sem informação.

Conforme se obsenva na tabela 21, os dados referentes aos dols grupos estudados possuem comportamento semelhante, ou seja, possuem uma tendêncta ascendente de rencla per caplta ate a faba de 0,50 a 0,73 saturio minimo vigente à época da investigacio, e depols decrescente. Apresenta como limite superior para cs dols gripos estudados a foba de 3,0 a 6,60 salíitos misimos.

Tomando como paraimetro, para a descrigöo dos dedos, as condigotes de pobren, (menor que 0,5 sabirio minimo), e de indigêncta (menor que 0,2 setêrio minimo), segundo cilletio de SINGER (2000) pode-se observar, na tabela 21, que 26,8\% 
das famílias dos neonatos de baixo peso estariam na condição de pobreza, proporção esta um pouco maior que a verificada para o grupo de não baixo peso, com $\mathbf{2 4 , 7 \%}$. Parcela mínima da famílias estão inscritas na situação de indigência, ou seja, $1,0 \%$ e $2,1 \%$, respectivamente, para os dois grupos estudados.

Se considerarmos a faixa de renda imediatamente superior, de 0,50 a 0,73 salário mínimo por pessoa da familia como ponte de corte para a condição de pobreza, podemos contatar que as proporções para os dois grupos estudados mais que duplicam, ou seja, apresentam $57,7 \%$ e $52,8 \%$, respectivamente. Isto dada a predominância da mesma em relação às primeiras, assim como às demais.

A tabela 22, a seguir, apresenta a distribuição dos recém-nascidos de baixo peso e de não baixo peso segundo os níveis de escolaridade das mulheres no momento do parto.

Tabela 22 - Distribuição dos recém-nascidos de baixo peso e não baixo peso segundo a escolaridade das mulheres no momento do parto. João Pessoa/PB, 2000.

\begin{tabular}{|c|c|c|}
\hline $\begin{array}{c}\text { Níveis de } \\
\text { escolaridade }\end{array}$ & $\begin{array}{c}\text { Grupo } \\
\text { de baixo peso }\end{array}$ & $\begin{array}{c}\text { Grupo de } \\
\text { não baixo peso }\end{array}$ \\
\hline (em anos completos) & No $\%$ & No $\%$ \\
\hline $\begin{array}{c}\text { Analfabeto }+ \text { básico } \\
\text { incompleto }\end{array}$ & 16,8 & 19,3 \\
\hline $\begin{array}{c}\text { Básico completo + fund. } \\
\text { incompleto }\end{array}$ & 46,7 & 44,0 \\
\hline $\begin{array}{l}\text { Fund. Completo + médio } \\
\text { incompleto }\end{array}$ & 25 & 20,3 \\
\hline $\begin{array}{l}\text { Médio completo }+ \\
\text { superior incompleto }\end{array}$ & $21 \quad 15,3$ & $49 \quad 13,2$ \\
\hline Superior completo & $\begin{array}{r}4 \\
4,0\end{array}$ & $12 \quad 3,2$ \\
\hline Total & 137 & 372 \\
\hline
\end{tabular}


À semelhança das categorias de classe e de renda per capita, anteriormente descritas, a escolaridade das parturientes apresenta o mesmo tipo de comportamento dos dados, com proporções próximas em todos os níveis de escolaridade para os dois grupos estudados. Cabe a predominância de proporção aos níveis "básico completo" somado ao "fundamental incompleto", com $46,7 \%$ para o grupo de baixo peso contra $44,0 \%$ para o de não baixo peso.

Somadas as duas primeiras categorias de escolaridade, que compreendem desde o "analfabeto" até o nivel "fundamental incompleto", constata-se que abarcam bem mais da metade das famílias dos recém-nascidos investigados, ou seja, 63,5\% para o grupo de baixo peso e 63,3\% para o de não baixo peso.

Para este primeiro conjunto de tabelas descritas no presente item, de números 19 , 21 e 22, as análises estatísticas (anexo 8) não apresentaram evidências para rejeitar as hipóteses propostas pelo tipo de teste de que o risco de uma criança de baixo peso em determinada categoria, de qualquer das "variáveis" descritas como classe social, tipo de mercado de trabalho, renda per capita e escolaridade da parturiente, é igual ao de uma criança de não baixo peso.

Um outro conjunto de tabelas busca relacionar, no presente item, as categorias de classe às variáveis idade e paridade da parturiente tendo em vista as naturezas 
sócio-demográficas e biológicas destas últimas e seu tradicional emprego na investigação dos problemas em foco.

A tabela 23, a seguir, apresenta a distribuição dos recém-nascidos de baixo peso e não baixo peso segundo as categorias de classes sociais e as de idade da mulher no momento do parto.

Tabela 23 - Distribuição dos recém-nascidos de baixo peso e não baixo peso segundo as categorias de classes sociais e a faixa etária da mulher no momento do parto. João Pessoa/PB, 2000.

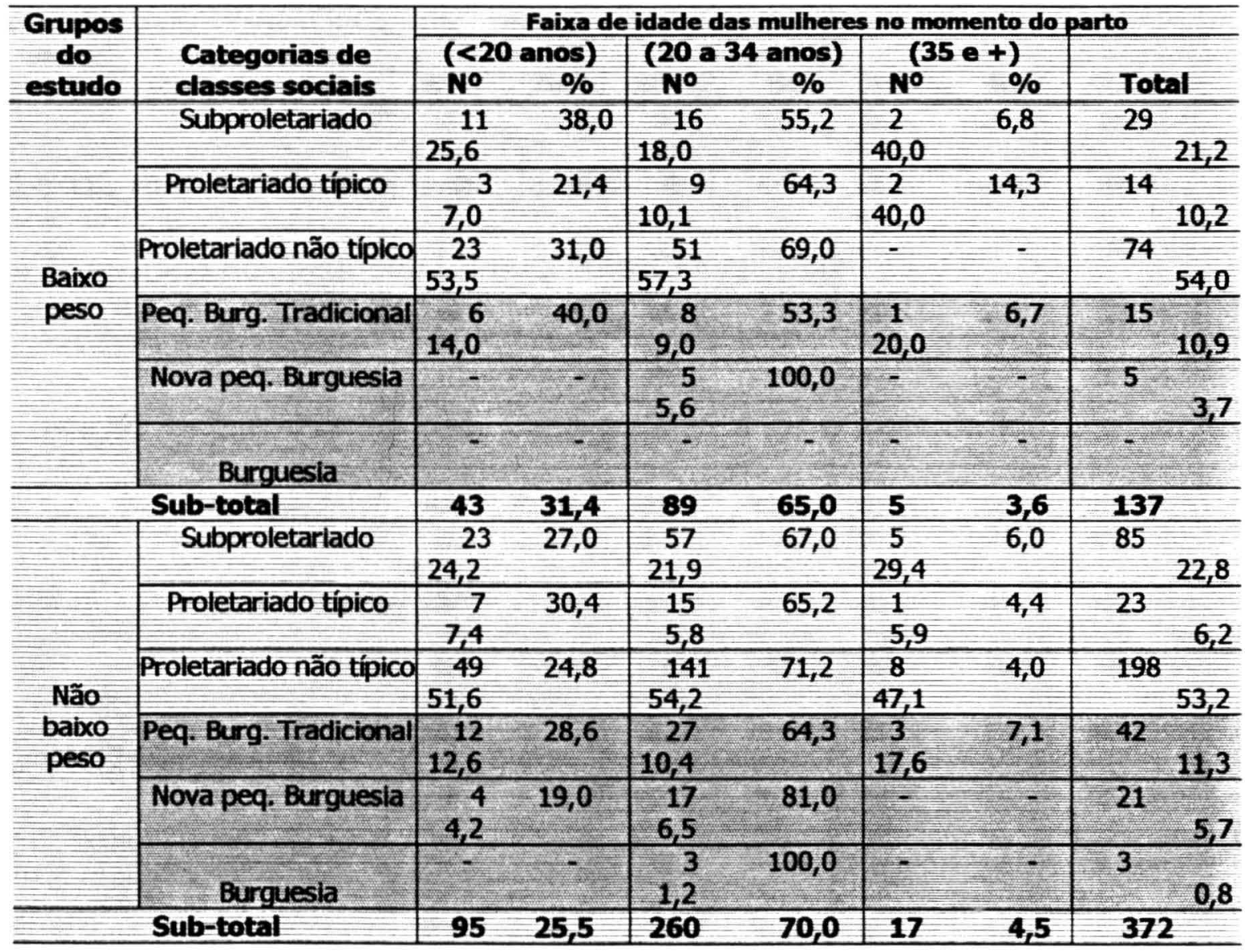

Conforme o observado na tabela 7, já descrita no item 4.1, "caracterização sóciodemográfica familiar", a proporção de mulheres com gravidez na adolescência é maior no grupo de baixo peso, com $31,4 \%$ em relação a $25,5 \%$ no grupo de não baixo peso. 
Na presente tabela, de número 23 , pode-se observar que as maiores proporções de gravidez ocorrem na faixa considerada ideal, do ponto de vista clínicoobstétrico, ou seja, de 20 a 34 anos de idade, porque considerada de baixo risco. São expressas, no total, nas seguintes proporções: $65,0 \%$ para os recém-nascidos de baixo peso e $70,0 \%$ para os de não baixo peso.

Considerando a diferença de 5,9\% existente na categoria das parturientes adolescentes entre os dois grupos estudados observa-se uma predominância, no caso dos recém-nascidos de baixo peso, primeiro na "pequena burguesia tradicional" com 40,0\%, seguido do "subproletariado", com 38,0\%. Em relação ao grupo de não baixo peso a predominância cabe ao "proletariado típico", com $30,4 \%$, seguida da "pequena burguesia tradicional", com $28,6 \%$.

Em relação às parturientes com trinta e cinco anos e mais de idade observa-se, com exceção do "proletariado típico", uma semelhança de comportamento dos dados nos dois grupos estudados.

A tabela 24 apresenta, a seguir, a distribuição dos recém-nascidos de baixo peso e não baixo peso segundo as categorias de classes sociais e a paridade das mulheres. 
Tabela 24 - Distribuição dos recém-nascidos de baixo peso e não baixo peso segundo as categorias de classes sociais e a paridade das mulheres. João Pessoa/PB, 2000.

\begin{tabular}{|c|c|c|c|c|c|c|c|c|c|}
\hline \multirow{3}{*}{$\begin{array}{l}\text { Grupos } \\
\text { do } \\
\text { estudo }\end{array}$} & \multirow{3}{*}{$\begin{array}{l}\text { Categorias } \\
\text { de classes sociais }\end{array}$} & \multicolumn{7}{|c|}{ Paridade das mulheres } & \multirow{3}{*}{ Total } \\
\hline & & Primípara & \multicolumn{2}{|c|}{ Secundipara } & \multicolumn{2}{|c|}{ cipara } & \multicolumn{2}{|c|}{$\begin{array}{l}\text { Grande } \\
\text { multipara }\end{array}$} & \\
\hline & & $N^{\circ} \%$ & $\mathrm{No}^{\circ}$ & $\%$ & No & $\%$ & & $\%$ & \\
\hline \multirow{6}{*}{$\begin{array}{l}\text { Baixo } \\
\text { peso }\end{array}$} & Subproletariado & $\begin{array}{rr}15 & 51,7 \\
21,6 & \end{array}$ & 11 & 38,0 & $\begin{array}{c}2 \\
50,0\end{array}$ & 6,9 & 1 & 3,4 & $\begin{array}{l}29 \\
21,2\end{array}$ \\
\hline & Proleta & $\begin{array}{rr}7 & 50,0 \\
9,5 & \\
\end{array}$ & $\begin{array}{c}7 \\
12,5 \\
\end{array}$ & 50,0 & - & $=$ & - & - & 14 \\
\hline & Proletariado não típico & $\begin{array}{rr}41 & 55,4 \\
55,4 & \end{array}$ & $\begin{array}{r}30 \\
53,6\end{array}$ & 40,5 & $\begin{array}{c}2 \\
50,0\end{array}$ & 2,7 & $\frac{1}{33,3}$ & 1,4 & $\begin{array}{l}74 \\
54,0\end{array}$ \\
\hline & Peq. Burg Tradicional & $\begin{array}{r}10 \quad 66,7 \\
13,5\end{array}$ & $\begin{array}{l}5 \\
8,9\end{array}$ & 34,3 & - & - & - & - & $\frac{15}{10,9}$ \\
\hline & Nova peq. Burguesia & $\begin{array}{cc}1 & 20,0 \\
1,4 & \end{array}$ & $\begin{array}{l}3 \\
5,4\end{array}$ & 60,0 & - & - & $\begin{array}{l}1 \\
33,4\end{array}$ & 20,0 & $5^{5}$ \\
\hline & Burguesia & $-\quad-$ & - & - & & & & & $-i$ \\
\hline \multicolumn{2}{|r|}{ Sub-total } & $74 \quad 54,0$ & 56 & 41,0 & 4 & 3,0 & 3 & 2,0 & 137 \\
\hline \multirow{6}{*}{$\begin{array}{c}\text { Não baixo } \\
\text { peso }\end{array}$} & Subproletariado & $\begin{array}{ll}43 & 50,5 \\
26,7 & \\
\end{array}$ & $\begin{array}{c}34 \\
18,2 \\
\end{array}$ & 40,0 & $\begin{array}{c}8 \\
36,4 \\
\end{array}$ & 9,5 & - & - & $\begin{array}{l}85 \\
22,8 \\
\end{array}$ \\
\hline & Proletariado típico & $\begin{array}{cc}8 & 35,0 \\
5,0 & \\
\end{array}$ & $\begin{array}{l}14 \\
7,5 \\
\end{array}$ & 61,0 & $\begin{array}{c}1 \\
4,5\end{array}$ & 4,0 & - & - & $\frac{23}{6,2}$ \\
\hline & Proletariado não típico & $\begin{array}{r}77 \\
47,8 \\
\end{array}$ & $\begin{array}{l}109 \\
58,3 \\
\end{array}$ & 55,0 & $\begin{array}{l}11 \\
50,0\end{array}$ & 5,6 & $\begin{array}{c}1 \\
50,0\end{array}$ & 0,4 & $\begin{array}{r}198 \\
53,2 \\
\end{array}$ \\
\hline & Peq. Burg. Trad & $\begin{array}{r}19 \\
11,8\end{array}$ & $\begin{array}{c}21 \\
11,2\end{array}$ & 50,0 & $\begin{array}{l}1 \\
4,5\end{array}$ & 2,4 & $\begin{array}{c}1 \\
50,0\end{array}$ & 2,4 & $\begin{array}{l}42 \\
11,3\end{array}$ \\
\hline & Nova peq. Burguesia & $\begin{array}{ll}11 & 52,4 \\
6,8 & \end{array}$ & $\begin{array}{l}9 \\
4,8\end{array}$ & 42,8 & 1 & & & - & $\begin{array}{l}21 \\
5,7\end{array}$ \\
\hline & Burguesia & $\begin{array}{l}3100,0 \\
1,9\end{array}$ & - & & - & & & & $\begin{array}{r}3 \\
0,8 \\
\end{array}$ \\
\hline & Sub-total & 16143,2 & 187 & 50,2 & 22 & 6,0 & & 0,6 & 372 \\
\hline
\end{tabular}

Conforme já observada na tabela 9, anteriormente descrita, a diferença de proporção de primíparas entre os dois grupos analisados é de $10,8 \%$. Quando se observa a diferenciação interna nos dois grupos polares de classe, proletariado e burguesia, fato a destacar é a predominância, no grupo de baixo peso, da inserção das mulheres no proletariado, ou seja, numa proporção de $86,5 \%$ contra $79,5 \%$ no grupo do não baixo peso. 
Tendo em vista o comportamento empírico dos dados, já descrito na tabela 5, que apresenta a maior proporção de recém-nascidos de baixo peso, $43,8 \%$, contra $36,8 \%$, entre as mulheres com união legal e uma tendência inversa, no caso da união livre, com 30,7\% e 38,2\%, respectivamente, buscou-se relacionar a situação de união, com a inserção de classe das mulheres, nos dois grupos investigados (tabela 25).

Tabela 25 - Distribuição dos recém-nascidos de baixo peso e não baixo peso segundo as categorias de classes sociais e 0 tipo de união conjugal das parturientes. João Pessoa/PB, 2000.

\begin{tabular}{|c|c|c|c|c|c|c|}
\hline \multirow{3}{*}{$\begin{array}{l}\text { Grupos } \\
\text { do } \\
\text { estudo }\end{array}$} & \multirow{3}{*}{$\begin{array}{l}\text { Categorias } \\
\text { de classes sociais }\end{array}$} & \multicolumn{4}{|c|}{ Tipo de união conjugal } & \multirow{3}{*}{ Total } \\
\hline & & $\begin{array}{l}\text { Solteira sem } \\
\text { uniâo conjugal }\end{array}$ & \begin{tabular}{c|} 
Casada/ \\
separada/ \\
viuva/desquit: \\
s/uniäo coni.
\end{tabular} & $\begin{array}{l}\text { Casada com } \\
\text { uniäo livre }\end{array}$ & $\begin{array}{c}\text { Casada } \\
\text { com unib̄o } \\
\text { legal }\end{array}$ & \\
\hline & & $\mathbf{N}^{\circ}$ & $\mathrm{N}^{\circ} \quad \%$ & $\mathrm{~N}^{\circ}$ & No & \\
\hline \multirow{6}{*}{$\begin{array}{l}\text { Baixo } \\
\text { peso }\end{array}$} & Subproletariado & $\begin{array}{c}8 \\
28,6\end{array}$ & $\begin{array}{c}2 \\
28,7\end{array}$ & $\begin{array}{c}9 \\
21,4\end{array}$ & $\begin{array}{cc}10 & 34,5 \\
16,6 & \end{array}$ & $\begin{array}{l}29 \\
21,2\end{array}$ \\
\hline & Proletariado típico & $\frac{1}{3,6}$ & $\frac{1}{14,2}$ & $\frac{7}{16,7}$ & $\begin{array}{cc}5 & 35,8 \\
8,4 & \\
\end{array}$ & 14 \\
\hline & Proletariado não típico & $\begin{array}{r}16 \\
57,1\end{array}$ & $\begin{array}{c}2 \\
28,7\end{array}$ & $\begin{array}{r}20 \\
47,6\end{array}$ & $\begin{array}{rr}36 & 48,6 \\
60,0 & \\
\end{array}$ & $\begin{array}{l}74 \\
54,0\end{array}$ \\
\hline & Peq. Burg. Tradicional & $\begin{array}{c}3 \\
10,7 \\
\end{array}$ & $\begin{array}{c}1 \\
14,2\end{array}$ & $\begin{array}{cc}6 & 40,0 \\
14,3 & \\
\end{array}$ & $\begin{array}{cc}5 & 33,4 \\
8,4 & \\
\end{array}$ & $\begin{array}{l}15 \\
10,9 \\
\end{array}$ \\
\hline & Nova peq. Burguesia & - & $\frac{1}{14,2}$ & $-\quad-$ & $\begin{array}{ll}4 & 80,0 \\
6,6 & \end{array}$ & $\begin{array}{r}5 \\
3,7\end{array}$ \\
\hline & Burguesia & - & - & - & & - \\
\hline \multicolumn{2}{|r|}{ Sub-total } & 20,4 & 5,1 & 30,7 & 43,8 & 137 \\
\hline \multirow{6}{*}{$\begin{array}{l}\text { Não } \\
\text { baixo } \\
\text { peso }\end{array}$} & Subproletariado & $\begin{array}{r}23 \\
38,3 \\
\end{array}$ & $\frac{12}{37,5}$ & $\begin{array}{r}29 \\
20,1\end{array}$ & $\begin{array}{c}21 \\
15,4 \\
\end{array}$ & $\begin{array}{l}85 \\
22,8 \\
\end{array}$ \\
\hline & Proletariado típico & 5,0 & - & 8,3 & $\begin{array}{l}8 \\
5,9 \\
\end{array}$ & $\begin{array}{l}23 \\
6,2 \\
\end{array}$ \\
\hline & Proletariado não típico & $\begin{array}{r}29 \\
48,3\end{array}$ & $\begin{array}{r}15 \\
46,8\end{array}$ & 79 & $\begin{array}{r}75 \\
55,1\end{array}$ & $\begin{array}{r}198 \\
53,2\end{array}$ \\
\hline & Peq. Burg. Trad. & $\begin{array}{l}3 \\
5,0 \\
\end{array}$ & $\begin{array}{cc}3 & 7,1 \\
9,3 & \\
\end{array}$ & $\begin{array}{r}21 \\
14,1 \\
\end{array}$ & $\begin{array}{rr}15 & 35,7 \\
11,0 & \\
\end{array}$ & $\begin{array}{l}42 \\
11,3\end{array}$ \\
\hline & Nova peq. Burguesia & $\begin{array}{l}2 \\
3,3\end{array}$ & $\begin{array}{cc}2 & 9,5 \\
6,2 & \end{array}$ & $\begin{array}{|ll|}3 & 14,2 \\
2,0 & \\
\end{array}$ & $\begin{array}{rr}14 & 66,7 \\
10,3 & \end{array}$ & $\begin{array}{l}21 \\
5,7\end{array}$ \\
\hline & Burguesia & & - & - & $\begin{array}{cc}3 & 100,0 \\
2,2 & \end{array}$ & $\begin{array}{l}3 \\
0,8\end{array}$ \\
\hline & Sub-total & 16,1 & 8,6 & 144 & $\begin{array}{ll}136 & 36,7 \\
\end{array}$ & 372 \\
\hline
\end{tabular}


O que se pode acrescentar, em relação aos resultados já descritos anteriormente (tabela 5), é o fato de que embora a condição de solteira com filho recém-nascido, assim como casadas separadas, viúvas e desquitadas, se constituam num padrão social de relações vigentes na cidade de João Pessoa, tal padrão não se aplica à classe "burguesia" na medida em que ausente desta categoria que apresenta, para o grupo de não baixo peso, somente o padrão de "mulheres com união legal".

Pelos dados da tabela 25 pode-se observar, ainda, que, no caso das mulheres estudadas, as mulheres solteiras sem união conjugal se constituem como padrão predominante, para a ampla categoria do "proletariado", nos dois grupos; ou seja, a proporção é de $89,3 \%$ para o grupo de recém-nascido de baixo peso e $91,6 \%$ para os de não baixo peso. Para os demais tipos de união observou-se, comparativamente, no caso dos recém-nascidos de baixo peso, $85,7 \%$ de mulheres com união livre no proletariado e $85,0 \%$ com união legal; vale destacar, pela semelhança de padrão com o das mulheres solteiras, e das "casadas separadas, viúvas e desquitadas" com recém-nascidos, que apresentam uma proporção de $71,6 \%$ para este grupo de baixo peso.

Para o grupo de mulheres com recém-nascidos de não baixo peso a proporção observada, para esta última situação, no proletariado como um todo, foi comparativamente maior, ou seja, de $84,3 \%$. Com proporções menores apresentam-se o padrão de mulheres com união livre, com $83,2 \%$, seguida do 
padrão de mulheres com união legal, o menor apresentado no grupo de neonatos de não baixo peso, com uma proporção para o proletariado de $76,4 \%$.

O hábito de fumar, assim como o consumo de álcool, constituem-se em duas práticas sociais generalizadas nos diversos grupos sociais da moderna sociedade brasileira e tradicionalmente consideradas como importantes indicadores, do ponto de vista clínico-obstétrico e da saúde pública, para a determinação dos condições do peso ao nascer. A tabela 26 , a seguir, apresenta as relações entre condições de classe e hábito de fumar das mulheres investigadas

Tabela 26 - Distribuição dos recém-nascidos de baixo peso e não baixo peso segundo as categorias de classes sociais e 0 hábito de fumar das parturientes.

João Pessoa/PB, 2000.

\begin{tabular}{|c|c|c|c|c|c|c|c|}
\hline \multirow{3}{*}{$\begin{array}{c}\text { Grupos } \\
\text { do } \\
\text { estudo }\end{array}$} & \multirow{3}{*}{$\begin{array}{c}\text { Categorias } \\
\text { de classes sociais }\end{array}$} & \multicolumn{5}{|c|}{ Hábito de fumar da parturiente } & \multirow[b]{3}{*}{ Total } \\
\hline & & \multicolumn{2}{|c|}{ N5̄o fuma } & \multicolumn{2}{|c|}{ Fumante passiva } & Fumante ativa & \\
\hline & & No & $\%$ & No & $\%$ & No $\quad \%$ & \\
\hline \multirow{4}{*}{$\begin{array}{l}\text { Baixo } \\
\text { peso }\end{array}$} & Subproletariado & $\begin{array}{c}16 \\
23,5\end{array}$ & 55,1 & $\begin{array}{c}7 \\
15,2\end{array}$ & 24,2 & $\begin{array}{c}6 \\
26,1\end{array}$ & 29 \\
\hline & Proletariado típioo & $\begin{array}{l}2 \\
2,9\end{array}$ & 14,3 & \multicolumn{2}{|l|}{23,9} & 4,3 & $\frac{14}{10,2}$ \\
\hline & Proletariadonãotípico & $\begin{array}{r}39 \\
57,4\end{array}$ & 52,7 & \multicolumn{2}{|l|}{$\begin{array}{r}22 \\
47,8 \\
\end{array}$} & $\begin{array}{rr}13 & 17,6\end{array}$ & 54,5 \\
\hline & Peq Burg, Tradicional & \multicolumn{2}{|c|}{$\begin{array}{cc}9 & 60,0 \\
13,2 & \end{array}$} & \multicolumn{2}{|c|}{$\begin{array}{cc}5 & 33,3 \\
10,9 & \end{array}$} & $\begin{array}{ll}1 & 6,7 \\
4,3 & \end{array}$ & $\begin{array}{l}15 \\
10,9 \\
\end{array}$ \\
\hline & Nova peq Burgiesia & \multicolumn{2}{|c|}{$\begin{array}{ll}2 & 40,0 \\
2,9 & \end{array}$} & & $2 \quad 40,0$ & $\frac{5}{3,7}$ \\
\hline & Burguesia & \multicolumn{2}{|c|}{-} & \multicolumn{2}{|l|}{$=$} & - & +3 \\
\hline \multicolumn{2}{|r|}{ Sub-total } & 68 & 49,6 & \multirow{2}{*}{\multicolumn{2}{|c|}{$\begin{array}{ll}46 & 33,6 \\
30 & 35,3\end{array}$}} & $23 \quad 16,8$ & 137 \\
\hline & Subproletariado & \multicolumn{2}{|c|}{$46 \quad 54,1$} & & & $\begin{array}{cc}9 & 10,6 \\
16,1\end{array}$ & $\begin{array}{l}85 \\
22,8\end{array}$ \\
\hline & Proletariado típico & $\begin{array}{l}17 \\
8,5\end{array}$ & 73,9 & \multicolumn{2}{|l|}{4} & 2 & 6,2 \\
\hline Não baixo & Proletariado não típico & $\begin{array}{r}99 \\
49,7\end{array}$ & 50,0 & $\begin{array}{c}64 \\
54,7\end{array}$ & 32,3 & $\begin{array}{rr}35 & 17,7 \\
62,5 & \end{array}$ & $\begin{array}{c}198 \\
53,2\end{array}$ \\
\hline peso & Peq. Burg Trad & $\begin{array}{r}22 \\
11,1\end{array}$ & 52,4 & $\begin{array}{c}13 \\
11,1\end{array}$ & 31,0 & $\begin{array}{cc}7 & 16,7 \\
12,5 & \\
\end{array}$ & $\begin{array}{r}42 \\
-11,3 \\
\end{array}$ \\
\hline & Nova peq Burguesia & $\begin{array}{r}12 \\
6,0\end{array}$ & 57,1 & $\begin{array}{l}6 \\
5,1\end{array}$ & 28,6 & $\begin{array}{cc}3 & 14,3 \\
5,4 & \end{array}$ & 21 \\
\hline & Burguesia & & 100,0 & 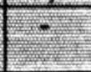 & - & $-\quad-\quad-$ & $\frac{3}{0,8}$ \\
\hline & Sub-total & 199 & 53,5 & 117 & 31,5 & 15,1 & 372 \\
\hline
\end{tabular}


Pelos dados da tabela 26 pode-se observar a predominância das mulheres que não fumam, ou são "fumantes passivas", tanto no grupo de recém-nascidos de baixo peso, quanto no de não baixo peso, com $53,5 \%$ e $31,5 \%$, respectivamente. No caso das fumantes, a proporção observada foi de $16,8 \%$ para os neonatos de baixo peso, valor este um pouco superior quando comparado ao de $15,1 \%$, do grupo de não baixo peso. Este fato aponta para um comportamento mais "tradicional" das mulheres investigadas.

Em termos da inserção de classe das mulheres fumantes pode se observar que embora em proporção diferentes elas se encontram distribuídas por todas as categorias de classe dos grupos estudados, com exceção da categoria "burguesia" no grupo de recém-nascidos de não baixo peso que apresenta somente três parturientes, que não fumam.

No entanto, quando comparadas as proporções para cada uma das classes, nos dois grupos estudados, o que se pode destacar é a maior proporção de fumantes na classe proletariado, com $20,7 \%$ para o grupo de baixo peso em relação às não fumantes do mesmo, contra $10,6 \%$ das fumantes para o grupo de não baixo peso. A mesma diferença de proporção se observa para a "nova pequena burguesia" que, no primeiro grupo, apresenta uma proporção de $40,0 \%$ e, no segundo, de $14,3 \%$.

A tabela 27, a seguir, apresenta as relações entre condições de classe e consumo de álcool, das mulheres investigadas. 
Tabela 27 - Distribuição dos recém-nascidos de baixo peso e não baixo peso segundo as categorias de classes sociais e o consumo de álcool durante a gravidez. João Pessoa/PB, 2000.

\begin{tabular}{|c|c|c|c|c|c|c|c|c|c|}
\hline \multirow{3}{*}{$\begin{array}{l}\text { Grupos } \\
\text { do } \\
\text { estudo }\end{array}$} & \multirow{3}{*}{$\begin{array}{c}\text { Categorias } \\
\text { de classes sociais }\end{array}$} & \multicolumn{7}{|c|}{ Consumo de álcool na gravidez } & \multirow{3}{*}{ Total } \\
\hline & & \multicolumn{2}{|c|}{ Năo bebeu } & \multicolumn{2}{|c|}{$\begin{array}{c}\text { Bebeu } \\
\text { diariamente }\end{array}$} & \multicolumn{2}{|c|}{$\begin{array}{c}\text { Bebeu } \\
\text { freqüentemente }\end{array}$} & \begin{tabular}{|c|} 
Bebeu \\
Ocasionalmente \\
\end{tabular} & \\
\hline & & No & $\%$ & $\mathbf{N}^{\circ}$ & $\%$ & No & $\%$ & $N^{\circ} \quad \%$ & \\
\hline \multirow{6}{*}{$\begin{array}{l}\text { Baixo } \\
\text { peso }\end{array}$} & Subproletariado & $\begin{array}{r}25 \\
21,3\end{array}$ & 86,2 & $\frac{1}{50,0}$ & 3,4 & $\frac{1}{25,0}$ & 3,4 & $\frac{2}{14,3}$ & $\begin{array}{l}29 \\
21,2 \\
\end{array}$ \\
\hline & Proletariado típico & $\begin{array}{l}11 \\
9,4\end{array}$ & 78,6 & - & - & $\frac{1}{25,0}$ & 7,1 & $\begin{array}{cc}2 & 14,3 \\
14,3 & \end{array}$ & 14 \\
\hline & Proletariado não típico & $\begin{array}{r}65 \\
55,6\end{array}$ & 87,8 & $\frac{1}{50,0}$ & 1,4 & $\frac{1}{25,0}$ & 1,4 & $\begin{array}{cc}7 & 9,5 \\
50,0 & \end{array}$ & $\begin{array}{l}74 \\
54,0\end{array}$ \\
\hline & Peq. Burg. Tradicional & $\begin{array}{r}13 \\
11,1 \\
\end{array}$ & 86,7 & $=$ & - & - & $=$ & $\begin{array}{cc}2 & 13,3 \\
14,3 & \\
\end{array}$ & $\begin{array}{l}15 \\
10,9 \\
\end{array}$ \\
\hline & Nova peq. Burguesia & $\begin{array}{c}3 \\
2,6\end{array}$ & 60,0 & - & - & - & & $\begin{array}{ll}1 & 20,0 \\
7,1 & \end{array}$ & $\begin{array}{l}5 \\
3,7 \\
\end{array}$ \\
\hline & Burguesia & - & & - & - & $\begin{array}{c}1 \\
25,0 \\
\end{array}$ & 20,0 & -5 & - \\
\hline \multirow{7}{*}{$\begin{array}{l}\text { Não } \\
\text { baixo } \\
\text { peso }\end{array}$} & Sub-total & 117 & 85,4 & 2 & 1,5 & 4 & 2,9 & 10,2 & 137 \\
\hline & Subproletariado & $\begin{array}{r}72 \\
21,9 \\
\end{array}$ & 84,7 & $\begin{array}{c}3 \\
50,0\end{array}$ & 3,5 & $\begin{array}{c}2 \\
22,2\end{array}$ & 2,4 & $\begin{array}{c}8 \\
28,6\end{array}$ & $\begin{array}{l}85 \\
22,8 \\
\end{array}$ \\
\hline & Proletariado típico & $\begin{array}{r}21 \\
6,4 \\
\end{array}$ & 91,3 & - & - & 11 & 4,3 & $\begin{array}{cc}1 & 4,3 \\
3,6 & \\
\end{array}$ & $\begin{array}{r}23 \\
6,2 \\
\end{array}$ \\
\hline & Proletariado não típico & $\begin{array}{r}177 \\
53,8\end{array}$ & 89,4 & $\frac{1}{16,7}$ & 0,5 & $\begin{array}{c}6 \\
66,7\end{array}$ & 3,0 & $\begin{array}{r}14 \\
50,0\end{array}$ & $\begin{array}{r}198 \\
53,2\end{array}$ \\
\hline & Peq. Burg. Trad. & $\begin{array}{r}39 \\
11,9\end{array}$ & 92,9 & - & $=$ & - & - & $\begin{array}{cc}3 & 7,1 \\
10,7 & \\
\end{array}$ & $\begin{array}{l}42 \\
11,3\end{array}$ \\
\hline & Nova peq. Burguesia & $\begin{array}{r}17 \\
5,2 \\
\end{array}$ & 81,0 & $\begin{array}{c}2 \\
33,3 \\
\end{array}$ & 9,5 & & & $\begin{array}{ll}2 & 9,5 \\
7,1 & \\
\end{array}$ & $\begin{array}{r}21 \\
5,7 \\
\end{array}$ \\
\hline & Burguesia & $\begin{array}{c}3 \\
0,9\end{array}$ & 100,0 & - & - & - & - & - & $\begin{array}{r}3 \\
\quad 0,8 \\
\end{array}$ \\
\hline & Sub-total & 329 & 88,4 & 6 & 1,6 & 9 & 2,4 & 28 & 372 \\
\hline
\end{tabular}

A exemplo do fumo, a bebida não se apresenta, nas amostras de mulheres com recém-nascidos de baixo peso e não baixo peso estudadas, como uma prática social vigente.

Conforme pode-se observar sua ingestão, quando mencionada, caracteriza-se predominantemente como prática social tradicional, ou seja, "bebe ocasionalmente", embora com proporção maior para o grupo de baixo.peso $(10,2 \%)$ em relação ao de não baixo peso $(7,5 \%)$. Beber diariamente ou 
freqüentemente são práticas com proporção próximas para os dois grupos investigados, ou seja, $4,4 \%$ e $4,0 \%$, respectivamente. Vale destacar que a despeito dos pequenos números a quase totalidade dos casos refere-se à ampla classe do proletariado.

A análise estatística dos dados das tabelas 26 e 27 foram realizados tomando somente as variáveis "hábito de fumar" e "consumo de álcool" em relação aos grupos de baixo peso e não baixo peso sem considerar, portanto, as categorias de classe. Encontram-se no anexo 8 e não apresentaram evidências estatísticas para rejeitar as hipóteses, previstas pelos testes, de que o risco de uma criança de baixo peso em determinada categoria das duas variáveis estudadas é igual ao de uma criança de não baixo peso.

Do ponto de vista da saúde materno-infantil, a questão da assistência ao parto tem assumido papel cada vez mais importante na atualidade, dado que o avanço tecnológico, aliado à qualidade dos serviços são considerados, do ponto de vista clínico-obstétrico e de saúde pública, como definidores das condições de nascimento e da sobrevida dos recém-nascidos, sobretudo nas primeiras horas de vida.
A tabela 28, a seguir, apresenta o local de ocorrência do parto segundo a natureza do tipo de hospital, público e privado. 
Tabela 28 - Distribuição dos recém-nascidos de baixo peso e não baixo peso segundo as categorias de classes sociais e o tipo de hospital utilizado pela parturientes. João Pessoa/PB, 2000.

\begin{tabular}{|c|c|c|c|c|}
\hline \multirow{3}{*}{$\begin{array}{c}\text { Grupos } \\
\text { do } \\
\text { estudo }\end{array}$} & \multirow{3}{*}{$\begin{array}{c}\text { Categorias } \\
\text { De classes sociais }\end{array}$} & \multicolumn{2}{|c|}{ Tipo de servico utilizado no parto } & \multirow[b]{2}{*}{ Total } \\
\hline & & Público & Privado/conv. & \\
\hline & & No & $\mathrm{N}^{\circ} \quad \%$ & No $\%$ \\
\hline \multirow{6}{*}{$\begin{array}{l}\text { Baixo } \\
\text { peso }\end{array}$} & Subproletariado & 29 & - & 21,2 \\
\hline & Proletariado típico & 11,1 & - & 10,2 \\
\hline & Proletariado não típico & $\begin{array}{r}68 \\
54,0\end{array}$ & $\begin{array}{r}6 \\
66,7\end{array}$ & 54,0 \\
\hline & Peq. Burg. Tradicional & $11,1^{14} \quad 93,4$ & $\begin{array}{rr}1 & 6,6 \\
11,1 & \\
\end{array}$ & $5 \quad 10,9$ \\
\hline & Nova peq. Burguesia & $2,4^{3} \quad 60,0$ & $\begin{array}{rr}\begin{array}{r}2 \\
22,2\end{array} & 40,0 \\
\end{array}$ & 3,7 \\
\hline & Burguesia & $-\quad-$ & - & - \\
\hline \multirow[b]{4}{*}{$\begin{array}{c}\text { Não baixo } \\
\text { peso }\end{array}$} & Sub-total & $128 \quad 93,4$ & 6,6 & 137 \\
\hline & Subproletariado & $\begin{array}{r}78 \\
23,2 \\
\end{array}$ & $\begin{array}{r}7 \\
19,3 \\
\end{array}$ & 22,8 \\
\hline & Proletariado típico & $\begin{array}{c}21 \\
6,2\end{array}$ & $\begin{array}{r}2 \\
5,6\end{array}$ & 6,2 \\
\hline & Proletariado não típico & $\begin{array}{r}183 \\
54,5\end{array}$ & $\begin{array}{r}15 \\
41,6\end{array}$ & $\begin{array}{l}198 \quad 53,2 \\
\quad 5\end{array}$ \\
\hline & Peq. Burg. Trad. & $\begin{array}{rr}38 & 90,4 \\
11,3 & \\
\end{array}$ & $\begin{array}{rr}4 & 9,6 \\
11,1 & \end{array}$ & $42 \quad 11,3$ \\
\hline & Nova peq. Burguesia & $4,5^{15} \quad 71,4$ & $\begin{array}{rr}6 & 28,6 \\
16,7 & \end{array}$ & 21 \\
\hline & Burguesia & $0,3^{1} \quad 33,4$ & $5,6^{2} \quad 66,6$ & $3 \quad 0,8$ \\
\hline & Sub-total & 90,3 & 9,7 & 372 \\
\hline
\end{tabular}

A presente tabela permite observar que a grande maioria dos partos para todas as classes, com exceção da categoria burguesia, foram realizados, em sua maioria, nos hospitais públicos tanto para o grupo de baixo peso, quando para o de não baixo peso. Vale destacar que o percentual do proletariado em hospitais privados, deve-se ao fato de estarem utilizando leitos do Sistema Único de Saúde (SUS).

Em termos de tendência pode-se observar que, em relação ao dos serviços públicos as menores proporções cabem às categorias da classe "nova pequena 
burguesia", com $60,0 \%$, para os neonatos de baixo peso e $71,4 \%$ para os de não baixo peso; a "nova pequena burguesia" apresentou uma proporção de 71,4\% e a "burguesia", com $33,4 \%$ foi a menor para os neonatos de não baixo peso.

Vale destacar como a "pequena burguesia tradicional" se aproxima, em relação ao uso que as mulheres fazem do serviço público no momento do parto, do padrão das demais categorias de classe pertencentes ao proletariado.

Dada a existência de convênios de muitos dos hospitais privados, inclusive com o sistema único de saúde (SUS), pode-se observar a presença de parturientes de todas as categorias de classe dando à luz neste tipo de hospital, principalmente quando se observa a distribuição dos dados do grupo de neonatos de não baixo peso.

A tabela 29 apresenta, a seguir, a distribuição das parturientes segundo o tipo de parto, vaginal ou cesáreo, e categorias de classe social. 
Tabela 29 - Distribuição dos recém-nascidos de baixo peso e não baixo peso, segundo as categorias de classes sociais e tipo de parto das mulheres. João Pessoa/PB, 2000.

\begin{tabular}{|c|c|c|c|c|c|c|c|}
\hline \multirow{3}{*}{$\begin{array}{c}\text { Grupos } \\
\text { do } \\
\text { estudo }\end{array}$} & \multirow{3}{*}{$\begin{array}{l}\text { Categorias } \\
\text { de classes sociais }\end{array}$} & \multicolumn{4}{|c|}{ Tipo de parto } & \multirow{2}{*}{\multicolumn{2}{|c|}{ Total }} \\
\hline & & \multicolumn{2}{|c|}{ Vaginal } & \multicolumn{2}{|c|}{ Cesariana } & & \\
\hline & & $\mathrm{N}^{0}$ & $\%$ & $\mathrm{~N}^{0}$ & $\%$ & $\mathbf{N}^{\circ}$ & $\%$ \\
\hline \multirow{6}{*}{$\begin{array}{l}\text { Baixo } \\
\text { peso }\end{array}$} & Subproletariado & $\begin{aligned} 19 \\
25,3\end{aligned}$ & 65,5 & 10 & 34,5 & \multicolumn{2}{|c|}{21,2} \\
\hline & Proletariado típico & $\begin{array}{r}8 \\
10,7\end{array}$ & 57,1 & $\begin{array}{r}6 \\
9,7 \\
\end{array}$ & 42,9 & 14 & 10,2 \\
\hline & Proletariado não típico & $\begin{array}{r}36 \\
48,0 \\
\end{array}$ & 48,6 & $\begin{array}{r}38 \\
61,3 \\
\end{array}$ & 51,4 & 74 & 54,0 \\
\hline & Peq. Burg Tradicional & $\begin{array}{r}11 \\
14,7 \\
\end{array}$ & 73,3 & $\begin{array}{r}4 \\
4,8\end{array}$ & 26,7 & \multicolumn{2}{|c|}{$15 \quad 10,9$} \\
\hline & Nova peq. Burguesia & 1,3 & 20,0 & $\begin{array}{r}4 \\
6,5 \\
\end{array}$ & 80,0 & \multicolumn{2}{|c|}{5} \\
\hline & Burguesia & \multicolumn{2}{|c|}{$-\frac{1}{4}-$} & \multicolumn{2}{|c|}{$-\frac{1}{4}-$} & & 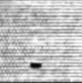 \\
\hline \multicolumn{2}{|r|}{ Sub-total } & 75 & 54,7 & 62 & 45,3 & \multicolumn{2}{|l|}{137} \\
\hline \multirow{6}{*}{$\begin{array}{c}\text { Não baixo } \\
\text { peso }\end{array}$} & Subproletariado & $\begin{array}{r}39 \\
20,6 \\
\end{array}$ & 45,8 & $\begin{array}{r}46 \\
25,1 \\
\end{array}$ & 54,2 & \multicolumn{2}{|r|}{22,8} \\
\hline & Proletariado típico & $\begin{array}{l}14 \\
7,4 \\
\end{array}$ & 60,8 & $\begin{array}{r}9 \\
4,9\end{array}$ & 39,2 & \multicolumn{2}{|r|}{6,2} \\
\hline & Proletariado não típico & $\begin{array}{r}105 \\
55,6 \\
\end{array}$ & 53,0 & $\begin{array}{r}93 \\
50,8 \\
\end{array}$ & 47,0 & \multicolumn{2}{|r|}{53,2} \\
\hline & Peq. Burg. Trad. & $11,1^{21}$ & 50,0 & $\begin{array}{r}21 \\
11,5 \\
\end{array}$ & 50,0 & \multicolumn{2}{|c|}{13,3} \\
\hline & Nova peq. Burguesia & $4,8^{9}$ & 42,8 & $\begin{array}{r}12 \\
6,6\end{array}$ & 57,2 & \multicolumn{2}{|c|}{$\begin{array}{ll}21 & 5,7 \\
\end{array}$} \\
\hline & Burguesia & $0,5^{1}$ & 33,4 & $\begin{array}{r}2 \\
1,1 \\
\end{array}$ & 66,6 & \multicolumn{2}{|r|}{0,8} \\
\hline & Sub-total & 189 & 50,8 & 183 & 49,2 & \multicolumn{2}{|c|}{372} \\
\hline
\end{tabular}

Conforme o descrito na tabela 14, anteriormente apresentada, para os dois grupos de neonatos estudados observou-se uma elevada proporção de cesarianas, com $45,3 \%$ para o grupo de baixo peso e $49,2 \%$ para o de não baixo peso. Na referida tabela, que associa tipo de parto ao tipo de hospital, público ou privado, é possível observar que a maior proporção de cesáreas coube ao serviços privados e referese ao grupo das parturientes com recém-nascidos de não baixo peso. A proporção apresentada é de $83,4 \%$ em relação a $44,4 \%$, para o grupo de baixo peso. 
Tendo em vista as novas relações presentes na tabela 30, é possível observar que a predominância de proporção de cesáreas encontra-se, nos dois grupos estudados, nas classes pertencentes à burguesia. No caso do grupo de baixo peso, a proporção é maior, $80,0 \%$, e refere-se à parturiente inscritas na "nova pequena burguesia". No caso do grupo de não baixo peso, a proporção é de $66,7 \%$ e refere-se a mulheres pertencentes à classe "burguesia", propriamente dita.

Em termos polares, vale observar que a menor proporção de cesarianas observada para os neonatos de baixo peso refere-se às parturientes da "pequena burguesia tradicional", com $26,7 \%$, seguida do "subproletariado", com $34,5 \%$. No caso dos recém-nascidos de não baixo peso a menor proporção coube às parturientes pertencentes ao "proletariado típico", com 39,2\%, seguida do "proletariado não típico", com 47,0\%.

A tabela 30 apresenta a distribuição dos neonatos segundo a adequação peso/idade e inserção de classe. 
Tabela 30 - Distribuição dos recém-nascidos de baixo peso e não baixo peso segundo as categorias de classes sociais e a adequação peso/idade dos neonatos.

João Pessoa/PB, 2000.

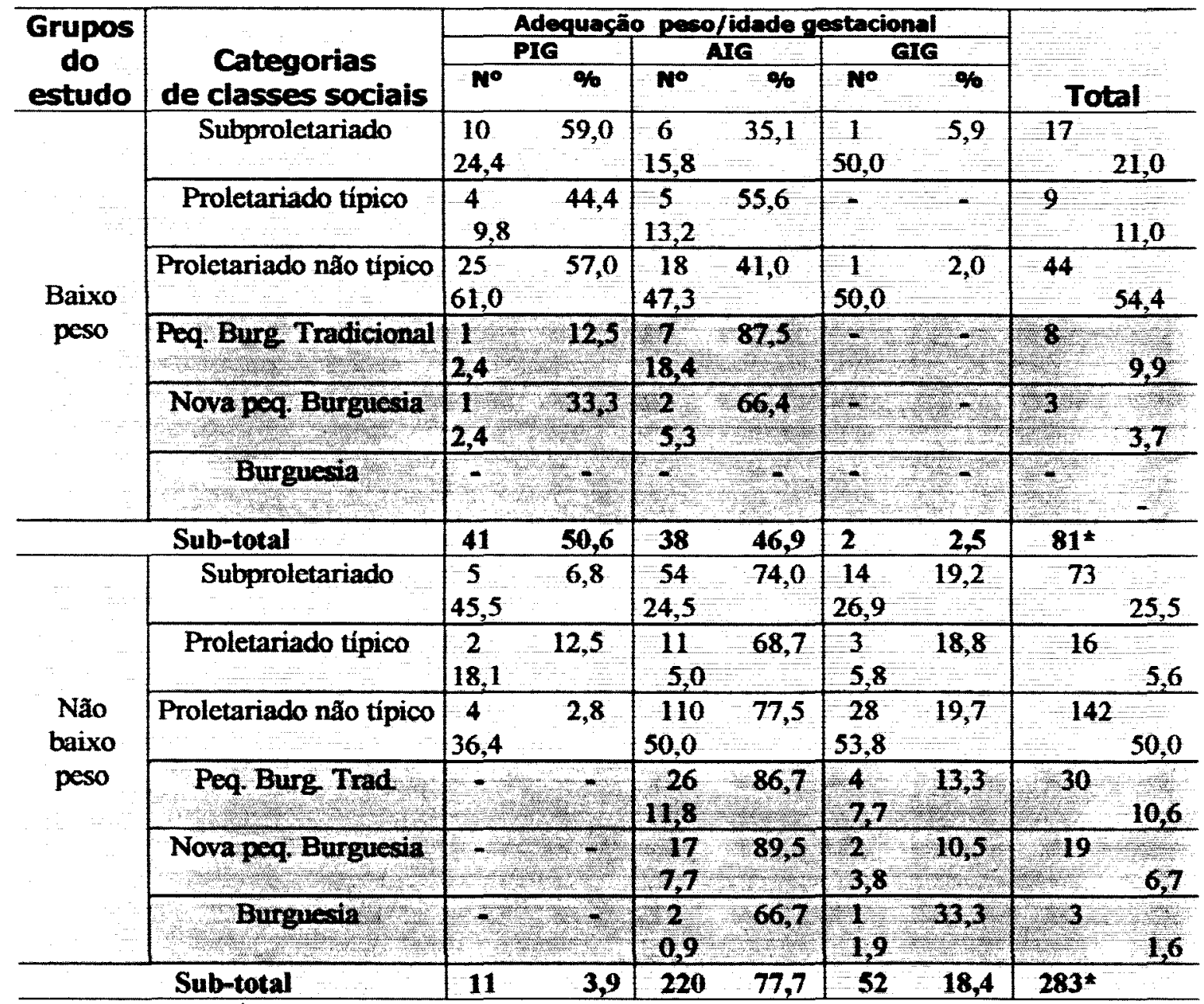

$\left(^{*}\right)$ Foram excluídos 56 casos e 89 controles, sem registros nos prontuários hospitalares.

Pelos dados de tabela 30 pode-se observar, no grupo de neonatos de baixo peso, que as maiores proporções de pequenos para a idade gestacional (PIG) referemse às classes do proletariado como um todo, com predominância no "subproletariado", com 59,0\%. Em contrapartida, as maiores proporções observadas para os adequados para a idade gestacional (AIG) encontram-se em duas categorias da burguesia, com $87,5 \%$ para a "pequena burguesia tradicional" e $66,4 \%$ para a "nova pequena burguesia". 
No caso dos recém-nascidos de não baixo peso, a totalidade dos casos de pequenos para a idade gestacional observados (PIG) inscrevem-se nas três categorias de classe do proletariado. Em relação aos adequados para a idade gestacional (AIG) as maiores proporções observadas referem-se a duas categorias de classes da burguesia, com $86,7 \%$ para a "pequena burguesia tradicional" e $89,5 \%$ na "nova pequena burguesia".

A tabela 31, a seguir, apresenta as relações observadas entre condições de classe e sobrevida dos neonatos, nas primeiras horas de vida, nos dois grupos estudados.

Tabela 31 - Distribuição dos recém-nascidos de baixo peso e não baixo peso, segundo as categorias de classes sociais e condição de sobrevida dos neonatos. João Pessoa/PB, 2000.

\begin{tabular}{|c|c|c|c|c|c|c|c|}
\hline \multirow{3}{*}{$\begin{array}{l}\text { Grupos } \\
\text { do estudo }\end{array}$} & \multirow{3}{*}{$\begin{array}{c}\text { Categorias } \\
\text { de classes sociais }\end{array}$} & \multicolumn{4}{|c|}{ Sobrevida dos neonatos nas 1's seis horas } & \multirow{2}{*}{\multicolumn{2}{|c|}{ Total }} \\
\hline & & \multicolumn{2}{|c|}{ Obito } & \multicolumn{2}{|c|}{ Sobrevida } & & \\
\hline & & $\mathrm{N}^{0}$ & $\%$ & $\mathrm{~N}^{\circ}$ & $\%$ & $\mathbf{N}^{\circ}$ & $\%$ \\
\hline \multirow{6}{*}{$\begin{array}{l}\text { Baixo } \\
\text { peso }\end{array}$} & Subproletariado & 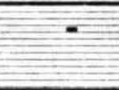 & . & $\begin{array}{r}29 \\
21,6\end{array}$ & 100,0 & 29 & 21,2 \\
\hline & Proletariado típico & - & - & $\begin{array}{r}14 \\
10,4\end{array}$ & 100,0 & 14 & 10,2 \\
\hline & Proletariado não típico & $\begin{array}{r}2 \\
66,7\end{array}$ & 2,7 & $\begin{array}{r}72 \\
53,7\end{array}$ & 97,3 & \multicolumn{2}{|l|}{74} \\
\hline & Peq. Burg. Tradicional & 13 & 6,7 & 10,4 & 85,9 & \multicolumn{2}{|c|}{$\begin{array}{ll}15 \quad 10,9 \\
\end{array}$} \\
\hline & Nova peq. Burguesia & $-\frac{1}{2}$ & $=$ & $\begin{array}{r}5 \\
3,7\end{array}$ & 93,3 & 5 & 3,7 \\
\hline & Burguesia & \multicolumn{2}{|c|}{-5} & \multicolumn{2}{|c|}{-} & - & $=$ \\
\hline \multicolumn{2}{|r|}{ Sub-total } & 3 & 2,2 & 134 & 97,8 & 137 & \\
\hline \multirow{7}{*}{$\begin{array}{c}\text { Nâo baixo } \\
\text { peso }\end{array}$} & Subproletariado & $\begin{array}{r}4 \\
36,4 \\
\end{array}$ & 4,7 & $\begin{array}{r}81 \\
22,4 \\
\end{array}$ & 95,3 & \multicolumn{2}{|l|}{85} \\
\hline & Proletariado típico & 9.1 & 4,3 & 6,22 & 95,7 & \multicolumn{2}{|l|}{23} \\
\hline & Prolet. não típico & $\begin{array}{r}2 \\
18,2\end{array}$ & 1,0 & 54,196 & 99,0 & \multicolumn{2}{|c|}{$\begin{array}{ll} & 198 \quad \\
& 53,2 \\
\end{array}$} \\
\hline & Peq. Burg. Trad. & $\begin{array}{r}1 \\
9,1\end{array}$ & 2,4 & $\begin{array}{r}41 \\
11,4\end{array}$ & 97,6 & 42 & 11,3 \\
\hline & Nova peq. Burguesia & 3 & 14,3 & 18 & 85,7 & 21 & $=$ \\
\hline & Puronecia & 27,3 & & $\frac{5,0}{3}$ & 1000 & 3 & 3,1 \\
\hline & & +5 & & 0,8 & & & \\
\hline & Sub-total & 11 & 3,0 & 361 & 97,0 & 37. & \\
\hline
\end{tabular}


Pelo comportamento dos dados, a tabela 31 apresenta uma proporção aproximada de óbitos nos dois grupos estudados, 2,2\% para o grupo de baixo peso e 3,0\%, para o de não baixo peso, conforme já observado na descrição da tabela 14. Vale destacar, a despeito da pequena diferença, a predominância da referida mortalidade no grupo de não baixo peso. Quando relacionada às condições de classe, as maiores proporções, $66,7 \%$ e $63,7 \%$, respectivamente, se localizam na ampla categoria de classe do proletariado, com predominância, embora pequena, para o grupo de baixo peso.

Tendo em vista a pequena casuística dos óbitos nas primeiras horas de vida (tabela 31) e o pressuposto básico da importância da questão da assistência prénatal, ao lado da assistência ao parto, neste tipo de evento pretende-se, a partir da busca de relações mais estreitas entre condições de nascimento e desigualdade social, realizar uma descrição mais detalhada, de natureza qualitativa, portanto, da distribuição dos óbitos nos dois grupos estudados.

Diante disto, a tabela 32, a seguir, apresenta tanto as diferenças empíricas observadas na cobertura do pré-natal, quanto as relacionadas às condições de classe da parturiente, além da distribuição dos óbitos dos recém-nascidos de baixo peso e não baixo peso ocorridos nas primeiras seis horas pós-nascimento. 
Tabela 32 - Distribuição dos recém-nascidos de baixo peso e não baixo peso segundo as categorias de classes sociais, assistência de pré-natal e número de óbitos perinatais imediatos . João Pessoa/PB, 2000.

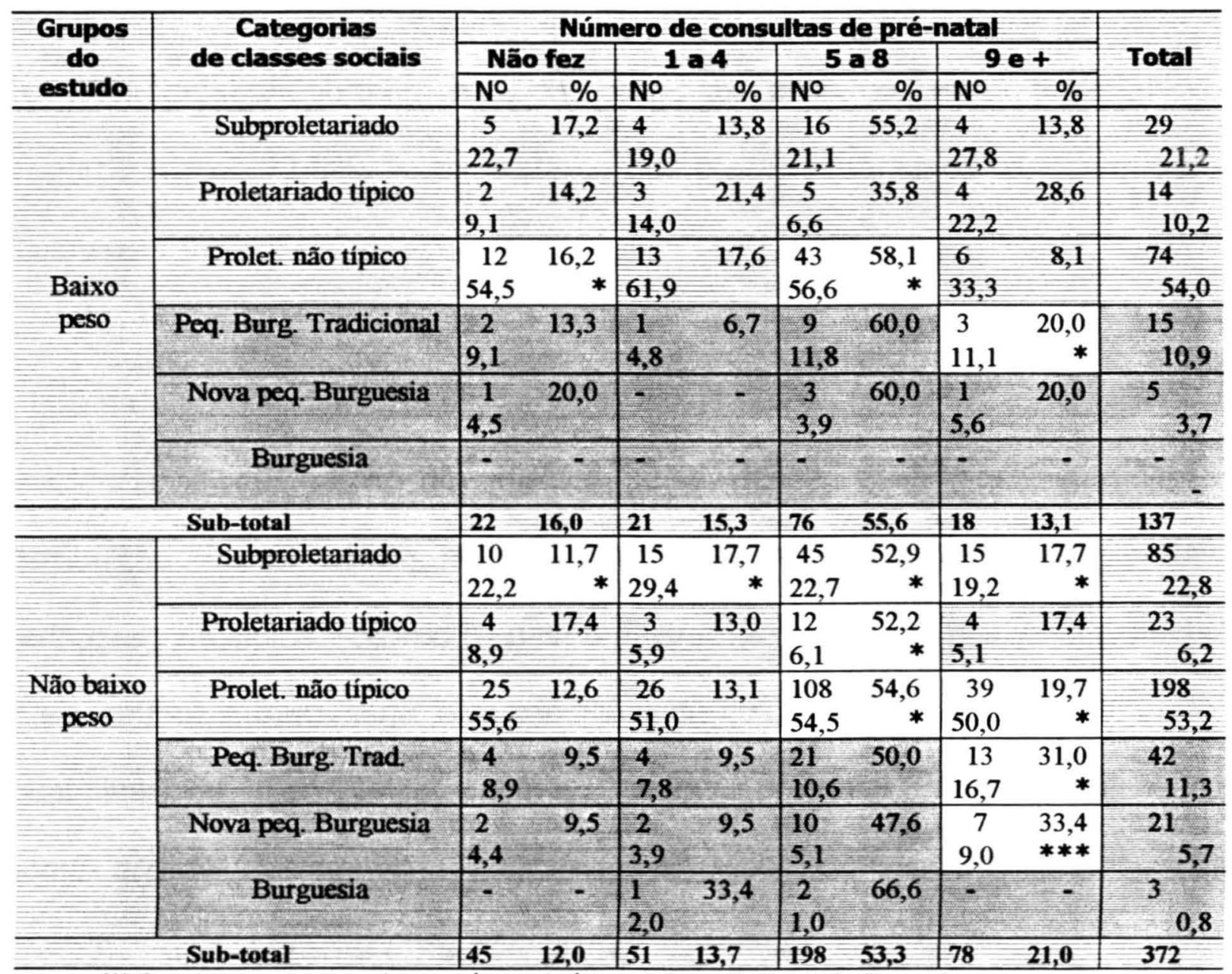

(*) Os asteriscos correspondem ao número de óbitos de "casos" e "controles" ocorridos nas primeiras horas pós-nascimento.

Pela tabela 32, pode-se observar que dentre os 20 casos de recém-nascidos de baixo peso pertencentes à ampla classe da burguesia, em 16 deles, ou seja, $80,0 \%$, as parturientes fizeram pré-natal (mais de 4 consultas). Quanto à ampla categoria de classe do proletariado (117 casos) observa-se uma proporção menor de pré-natal, ou seja, na ordem de $66,7 \%$, com uma diferença de $13,3 \%$. 
Em relação ao grupo de não baixo peso a mesma diferença de proporção inter classes se observa, embora em menor grau, ou seja, da ordem de 7,5\%. Isto porque, enquanto para a ampla classe da burguesia, a realização do pré-natal foi de $80,3 \%$, próxima, portanto, à do grupo de baixo peso, no caso do proletariado a proporção foi de $72,8 \%$, acima portanto dos $66,7 \%$ observados para o grupo de baixo peso.

A busca de aprofundamento das relações existentes entre condições de classe, de assistência e de nascimento melhor se evidencia quando se considera a distribuição dos óbitos na referida tabela 32. Na medida em que os óbitos perinatais imediatos, ocorridos nas primeiras seis horas após o nascimento, relacionam-se estreitamente com condições de qualidade de assistência ao parto e igualmente, ou, especialmente, com a assistência pré-natal procurou-se identificar, numa análise de natureza qualitativa, situações específicas relacionadas às condições de nascimento, nos dois grupos estudados, capazes de apontar para o lugar ocupado pelo conceito de classe social em estudos deste tipo de evento, em relação ao da qualidade da assistência.

Para tanto, a partir da identificação de cada óbito, assim como da inscrição de classe da parturiente e da realização ou não de pré-natal, tabela 32, outros dados empíricos observados no processo de investigação foram articulados a estes três primeiros. Isto tendo em vista melhor contextualizar e caracterizar as condições de nascimento e de morte de cada recém-nascido, em cada um dos grupos estudados. Destacou-se, portanto, como outras variáveis importantes para este 
processo de descrição dos óbitos, o tipo da assistência ao parto, ao pré-natal, a adequação peso/idade gestacional, o Apgar no primeiro e no quinto minutos, além da idade e da paridade da mulher, quando considerados de risco clínico-obstétrico e perinatal.

Em relação aos neonatos de baixo peso, a tabela 32 permite observar que, dos três óbitos ocorridos, dois pertenciam à ampla categoria do proletariado, correspondendo a uma proporção de $66,7 \%$, e um pertencia à ampla categoria da burguesia, com $33,3 \%$.

Dos dois óbitos ocorridos no proletariado, embora ambos pertencessem à classe do "proletariado não típico", diferiam em relação à assistência pré-natal; isto na medida em que em um deles a parturiente não fez pré-natal e foi, de acordo com os demais dados empíricos disponíveis, submetida a uma intervenção cesariana, possivel indicadora do risco materno-fetal. Não foram registrados, no prontuário hospitalar, nem a adequação peso/idade, nem o Apgar do mesmo, o que pode ser indicativo da gravidade das condições do neonato que não permitiu a realização de tais procedimentos.

Com relação ao segundo caso, observou-se uma assistência pré-natal de cinco a oito consultas acompanhada, no parto, de uma indicação de cesárea, embora se tratasse de um neonato adequado para a idade gestacional com um Apgar de 7 no primeiro minuto e de 8 no quinto minuto. Neste caso há uma evidente 
incongruência entre as condições favoráveis de nascimento da criança e a mortalidade nas primeiras seis horas de vida.

Em relação ao terceiro óbito ocorrido neste grupo de baixo peso pode-se observar que o mesmo se referia a um recém-nascido pertencente à "pequena burguesia tradicional" que, do ponto de vista da assistência pré-natal, poderia ser considerado uma gravidez de maior risco tendo em vista que a parturiente realizou mais de nove consultas. Quanto à assistência ao parto pode-se observar, quando da articulação de outros dados empíricos disponíveis, que a indicação de cesárea permite corroborar o pressuposto da existência de uma gravidez de risco, na medida em que o recém-nascido foi de baixo peso. No entanto, destaque cabe ao fato de se tratar de um neonato adequado para a idade gestacional (AIG) e com Apgar de 8 no primeiro minuto e 9 no quinto minuto. Tais características apontam para uma dupla condição desfavorável, ou seja, tanto das condições clínicoobstétricas quanto também, ao que parece, da assistencial, na medida em que o recém-nascido apresentou boas condições de nascimento o que, em tese, contradiz a existência de um risco maior de mortalidade nas primeiras seis horas de vida. Sobretudo quando se considera que a parturiente pertencia à "pequena burguesia tradicional".

O que se pode constatar desta descrição qualitativa dos casos de óbitos perinatais nas primeiras seis horas de nascimento é que tanto as condições da qualidade da assistência, quanto as condições sociais apresentam-se como relevantes para definirem as condições de nascimento e sobrevida do neonato, na medida em que 
se observa que a maioria dos casos de óbitos, neste grupo de baixo peso, pertenciam à ampla categoria do proletariado. Vale considerar que somente uma das parturientes, a pertencente à "pequena burguesia tradicional", era uma adolescente, primigesta, de 18 anos.

A relevância dessas mesmas condições sociais e de assistência aparece de maneira explícita quando da observação empírica das relações existentes entre ambas e as condições de sobrevida no grupo de recém-nascidos de não baixo peso. Conforme tabela 32 , dos onze óbitos ocorridos nas primeiras seis horas após o nascimento sete deles, ou seja, $63,6 \%$ pertenciam à ampla categoria do proletariado, em relação a $36,4 \%$ pertencentes à ampla categoria da burguesia, que no presente caso incluíam somente as classes da "pequena burguesia tradicional", com um óbito, e da "nova pequena burguesia", com três óbitos.

Dentre os sete óbitos referidos, quatro deles $(57,1 \%)$ pertenciam ao "subproletariado" e dentre estes, duas das parturientes não fizeram o pré-natal; em relação aos outros dois, em um deles a parturiente realizou de cinco a oito consultas e em outro a mulher teve, além das suas precárias condições de vida, dada a sua inserção de classe no "subproletariado", uma suposta gravidez de risco na medida em que fez mais de nove consultas de pré-natal, fez cesariana dando à luz a um recém-nascido pequeno para a idade gestacional (PIG), embora com um Apgar de 9 no primeiro e no quinto minutos. Todos os demais partos das mulheres pertencentes a esta classe do "subproletariado" foram vaginais e destaque cabe ao fato de que, em relação a uma das parturientes que não fez o 
pré-natal seu neonato se apresentou pequeno para a idade gestacional (PIG), com um Apgar de 7 no primeiro minuto e 9 no quinto minuto, enquanto o outro recémnascido não teve registro em relação a este evento. Vale também registrar que, este último caso, tratava-se de um recém-nascido com "peso insuficiente" (de 2500 a 2999g), cuja parturiente era uma adolescente secundípara, de 17 anos, que embora não tenha feito o pré-natal teve acesso ao serviço de saúde realizando o mínimo de consultas, ou seja, de "uma a quatro consultas".

Em relação aos outros três neonatos que foram a óbito e também pertencentes à ampla categoria do proletariado, um deles pertencia ao "proletariado típico" e os outros dois ao "proletariado não típico". Todas as parturientes que deram à luz a estes três neonatos fizeram pré-natal, mas, uma delas, pertencente ao "proletariado não típico", teve seu neonato supostamente com risco perinatal, dada a ocorrência de nove consultas e mais e a indicação de cesárea, muito embora o Apgar de 9 no primeiro e no quinto minutos assinale boas condições de nascimento. Com exceção deste, cuja adequação peso/idade gestacional não foi registrada, todos os dois outros trataram-se de recém-nascidos adequados para a idade gestacional (AIG) sendo que um deles, pertencente ao "proletariado não típico", nasceu de cesárea, com Apgar de 8 no primeiro minuto e 10 no quinto minuto; o outro, pertencente ao "proletariado típico", nasceu de parto vaginal, com Apgar de 8 no primeiro minuto e 9 no quinto minuto.

Desta descrição, o que podemos inferir é a relevância que a consideração da condição de inserção de classe adquire quando se pretende avançar na 
interpretação deste tipo de evento. Isto na medida em que pode-se constatar que ao pertencerem, estas sete parturientes, à ampla categoria de classe do proletariado e receberem, em sua maioria, $71,4 \%$, assistência pré-natal e, na totalidade, assistência ao parto $(100,0 \%)$ seus neonatos tiveram, a despeito das condições favoráveis de nascimento em relação ao peso, assim como em relação ao Apgar, morte nas primeiras seis horas de vida. Vale lembrar que dentre estes óbitos de recém-nascidos descritos, somente um deles, pertencente ao "subproletariado" e cuja mãe apresentava apenas de "uma a quatro consultas" de pré-natal, teve peso insuficiente ao nascer, ou seja, de 2500 a $2999 \mathrm{~g}$.

Em relação aos outros quatro óbitos, pertencentes à ampla categoria da burguesia, a suposição básica presente é a de que as causas de morte do recémnascido nas seis primeiras horas estejam mais relacionadas às condições de risco gravídico e perinatal tendo em vista que todas as parturientes receberam mais de nove consultas de pré-natal e acesso a um mesmo hospital particular, considerado, em tese, prestador de bom nivel de assistência. Todas as crianças nasceram de cesárea.

Dentre estes quatro neonatos, somente dois, um deles pertencente à "pequena burguesia tradicional" e outro pertencente à "nova pequena burguesia", tiveram os registros da adequação peso/idade gestacional; o primeiro referido foi pequeno para a idade gestacional (PIG), embora com um Apgar de 10 tanto no primeiro, quanto no quinto minuto; o segundo recém-nascido foi adequado para a idade gestacional (AIG), com Apgar de 9 no primeiro minuto e 10 no quinto minuto. 
Em relação aos outros dois recém-nascidos que não tiveram os registros da adequação peso/idade gestacional, ambos pertenciam à "nova pequena burguesia". O primeiro deles nasceu com "peso insuficiente", ou seja, inscreveu-se na faixa de 2500 a 2999 g gramas, sua mãe era uma adolescente primigesta, de 18 anos. Apresentou um Apgar de 9 tanto no primeiro, quanto no quinto minutos. Em relação ao segundo deles, vale mencionar que a parturiente, de 30 anos, era uma grande multípara, inscrita na categoria de "mais de quatro filhos", portanto. Quanto ao neonato, o Apgar foi de 8 no primeiro minuto e 10 no quinto minuto.

Desta descrição qualitativa dos óbitos dos recém-nascidos de baixo peso e não baixo peso, nas primeiras seis horas de vida, pode-se depreender a complexidade presente quando da busca de aprofundamento para a interpretação do processo saúde-doença-morte, dentro de uma visão interdisciplinar, no campo da perinatologia. 
5. DISCUSSÃO E ANÁLISE DOS RESULTADOS 
A análise das condições de vida e de sobrevivência familiar tem sido tradicionalmente realizada utilizando indicadores sociais como a renda e a escolaridade porque estreitamente relacionados às possibilidades de aquisição de bens e serviços.

No presente estudo, que compara dois grupos de recém-nascidos de baixo peso e não baixo peso tendo em vista relacionar condições de nascimento e desigualdade social, estes indicadores permitem uma primeira caracterização social das duas amostras.

Segundo a investigação sobre as condições de vida do IPEA (1996), o Brasil tem apresentado ao longo dos anos uma forte concentração de renda. Em 1996 os vinte por cento mais ricos da população detinham sessenta e cinco por cento da renda total e os cinqüenta por cento mais pobres ficavam com doze por cento. Esta situação econômica, segundo o PNUD, a década de noventa coloca o Brasil com a pior distribuição de renda entre todos os países. A renda per capita dos vinte por cento mais ricos é vinte e seis vezes maior do que os vinte por cento mais pobres. O Nordeste brasileiro concentra o maior contigente de pobres e, ao mesmo tempo, a maior concentração de renda do país (YANAKIEW, 2000). 
Esta situação crônica de concentração de renda, ou mesmo de baixo poder aquisitivo fica ainda mais agravante, ao se comparar a renda com a composição familiar, quando o poder per capita fica bem abaixo do recomendado para uma família padrão brasileira. No Brasil, segundo MENDONÇA (1991) e o IPEA (1996), existem $45,5 \%$ de pobres, sendo que mais de $1 / 3$ destes estão situados na Região Nordeste. Os achados do presente estudo refletem esta realidade quando evidencia que $70,1 \%$ das famílias dos recém-nascidos de baixo peso e $64,3 \%$ dos recém-nascidos de não baixo peso possuem uma renda per capita equivalente a menos de um salário mínimo revelando, assim, segundo este critério, uma situação de pobreza existente na região.

É certo que quando se fala de pobreza deve-se ter em mente o contexto social determinante desta condição. A condição de pobreza recebe diferentes parâmetros a depender de sua historicidade. Por exemplo, falar de pobreza nos Estados Unidos é falar de uma família padrão de quatro membros (pai, mãe e dois filhos) com renda mensal mínima equivalente a $R \$ 2.658,00$ reais. No geral esse padrão de pobreza atinge doze por cento da população; muito embora este índice venha caindo ultimamente a participação das crianças tem se mantido estável. As características das famílias dessas crianças são negras, hispânicas e são chefiadas por mulheres, dependentes quase que exclusivamente da assistência governamental. Isto aponta para a questão de que as desigualdades se apresentam em regiões ditas desenvolvidas com suas próprias peculiaridades. 
Devido a este aspecto peculiar de cada região, a Organização das Nações Unidas produziu dois índices distintos para os chamados paises industrializados e outro para os subdesenvolvidos. Neste sentido é que atualmente os Estados Unidos, juntamente como Reino Unido, é o país que tem a maior desigualdade social entre os países industrializados. É evidente que ser pobre no Brasil não é o mesmo que ser pobre nos Estados Unidos e, por conseqüência, os níveis de desigualdades sociais também são bem distintos.

A condição de pobreza para os estudiosos contemporâneos é definida segundo duas modalidades: situação de pobreza e situação de indigência. A primeira baseia-se numa renda mensal suficiente para suprir as necessidades individuais. A segunda toma por base a renda mínima mensal insuficiente para satisfazer as necessidades alimentares. Considerando os resultados do estudo desenvolvido por SINGER(2000) em sua análise da globalização e desemprego, conforme demonstra o quadro a seguir, cada região do país apresenta um parâmetro específico para mensurar estas duas situações.

Quadro 01 - Parâmetros para as linhas de pobreza e de indigência, segundo as regiöes brasileiras. (valores per capita em U\$\$)

\begin{tabular}{|c|c|c|c|}
\hline Regiões & Áreas Metropolitanas & $\begin{array}{c}\text { Linha de } \\
\text { Indigência }\end{array}$ & $\begin{array}{c}\text { Linha de } \\
\text { Pobreza }\end{array}$ \\
\hline Norte e & Belém & 22,94 & 54,37 \\
& Brasilia & & 60,69 \\
& Fortaleza & 16,36 & 65,11 \\
\hline Nordeste & Recife & & 35,41 \\
& Salvador & & 36,38 \\
& Belo Horizonte & 20,41 & 44,26 \\
& Rio de Janeiro & & 52,70 \\
\hline Sudeste & São Paulo & & 48,37 \\
& Curitiba & 19,32 & 46,16 \\
& Porto Alegre & & 53,31 \\
& Sul & & 38,64 \\
\hline & & & 40,15 \\
& & & 52,01 \\
\hline
\end{tabular}

Fonte: Lopes(1993) Apud SINGER (2000). 
Fazendo uma aproximação da renda mensal das famílias investigadas e o valor estimado para a linha de pobreza, segundo critério de SINGER (2000), considerase a composição média das famílias e chega-se a uma renda mínima familiar de $\mathrm{R} \$ 252,28$ [valor definido para a linha de pobreza da cidade de João Pessoa com base no valor estimado para Recife, dada a proximidade sócio-econômica entre ambas cidades $(44,26) \times$ valor médio da composição das familias $(3,0) \times$ cotação do dólar vigente $(R \$ 1,9)$ ] como sendo a necessária para garantir a subsistência individual de seus membros. Portanto, seguindo este raciocínio verifica-se que, aproximadamente, $46,7 \%$ das famílias com recém-nascidos de baixo peso e $37,7 \%$ das com neonatos de não baixo peso estão abaixo ou no limite da linha de pobreza, o que indica uma situação altamente desfavorável do ponto de vista sócio-econômico. É interessante confrontar estes dados com a situação que vem se conformando para o pais como um todo. Nas regiões metropolitanas, segundo IPEA (1996), a situação de pobreza está presente em $29,0 \%$ da população, determinada em grande parte pelo fluxo acentuado das pessoas para os grandes centros. Na Região Nordeste, o Piaui e o Ceará comportam a maior proporção de pobres, respectivamente $59,0 \%$ e $52,0 \%$.

Cabe aqui levantar algumas questões sobre renda e condições de vida. A identificação da pobreza baseada pela renda, tem suas facilidades e dificuldades. É facilitada pelos dados serem obtidos por intervalos de valores em relação a um parâmetro usualmente utilizado - salário mínimo. As dificuldades referem-se à obtenção confiável dessa informação, visto que as rendas mais baixas são normalmente superestimadas e as mais elevadas são também subestimadas. 
Apesar das dificuldades na sua manipulação, a renda ainda é o instrumento bastante útil e prático para uma ampla e rápida identificação das condições de vida. Se garantida certa fidedignidade, constitui em um dos indicadores relevantes para uma aproximação às condições materiais de vida.

Se por um lado, o nível de renda é indicador das possibilidades de aquisição de bens de mercado, a exemplo de alimentação, moradia, transporte, assim como acesso a diferentes modalidades de serviços, inclusive saúde, é revelador, por outro, da inserção diferencial das pessoas no mercado de trabalho, formal ou informal.

A condição de trabalho do tipo formal (com carteira assinada) e informal (sem carteira assinada), retrata o contexto sócio-econômico em que vive a população brasileira e que se agudiza em todos os centros urbanos. Segundo DUPAS (1999), trabalhando os dados do IBGE, enquanto em 1989 a proporção do trabalho formal era de mais de $57,5 \%$ contra menos de $42,5 \%$ no informal, em 1998 a situação se inverte apresentando $54,2 \%$ de trabalho informal em relação a $45,8 \%$ de trabalho formal. No presente estudo observou uma tendência inversa, à apontada por DUPAS, nos dois grupos de recém-nascidos estudados. Em relação aos neonatos de baixo peso os responsáveis pela familia estavam ocupados no setor formal na ordem de $56,2 \%$ contra $43,8 \%$ no informal, valores bem próximos aos verificado para o grupo de recém-nascidos de não baixo peso, cujos responsáveis trabalhando no setor formal era da ordem de $55,6 \%$ em relação a $44,4 \%$ no setor 
informal. A despeito desta tendência inversa a situação das familias pesquisadas reflete esta precariedade do mercado de trabalho vigente no país.

Esta situação levanta uma questão bastante atual que é a das condições de trabalho como condicionante das condições de vida. A população brasileira, na década de 90, enfrentou uma recessão econômica que se prolonga até nossos dias, desencadeando uma redução da taxa de atividade do conjunto da população metropolitana, na ordem de $16,4 \%$ no período de noventa a noventa e cinco. Outro indicador que revela esta situação é, conforme já mencionado por DUPAS (1999), a proporção de empregados com carteira assinada, que na região metropolitana neste periodo, caiu de $58,0 \%$ para $48,0 \%$, aumentando os empregados sem carteira assinada e aqueles que trabalham por conta própria.

Este quadro aponta para uma questão muito discutida nesta última década que amplia a discussão sobre a desigualdade: a da exclusão social. Como declara SINGER (2000), as principais causas de exclusão social no país, são de natureza institucional. Segundo este autor, as pessoas que se encontram nesta situação são desprovidas do usufruto dos direitos garantidos pelas instituições. Empregados informais não tem acesso aos direitos trabalhistas assegurados pela Previdência Social, entre outros. Isto se dá pelo contigente crescente da população atingida. Portanto, a exclusão do trabalho formal está em função de grandes alterações estruturais das relações de trabalho não só no Brasil, mas em escala mundial, delineada, em última instância, pela terceira revolução industrial. Ainda segundo SINGER (2000, p. 100), "na medida em que o Brasil vem abrindo sua economia ao 
comércio e investimento exteriores, tais tendências provavelmente estão se reforçando".

É interessante observar que a população que está no trabalho informal, em sua grande maioria, está aí situada não por opção, visto que busca alternativas para mudar de situação; e mesmo considerando a população do Nordeste, área deste estudo, essa intenção está presente em 39,71\% deles. Por outro lado, estudos já realizados no país (SINGER 1996, PINTO 1994), demonstram que a exclusão social se dá também pelo déficit de oferta de trabalho na medida em que as empresas, subretudo as de médio pequeno portes, não estão preparadas para assumirem obrigações definidas pela legislação trabalhista. No Nordeste brasileiro, estar empregado formalmente é considerado um privilégio, visto que são poucos os que alcançam esta condição tão desejada. Apesar de, historicamente, a demanda do mercado formal de trabalho apresentar um crescimento, nesta última década essa tendência se modificou diante de diversas crises econômicas e adoção de medidas fiscais, caracterizando uma época de recessão econômica. Situação exemplar são os casos de diversas empresas, de porte micro e médio, que tornaram-se informais para escapar dos tributos, considerados onerosos para a manutenção da produção.

Um outro aspecto importante é o surgimento de uma modalidade em expansão que é a terceirização, caracterizada pela substituição de trabalhadores formais especializados por fornecedores de serviços. Este processo de abertura do mercado de trabalho e de produção tanto no meio interno, como internacional 
resultam em um nível de competição mundial e de revolução das formas e modalidades do trabalho. Esta é uma conseqüência evidenciada pelo processo denominado de globalização da economia (SINGER 2000, UNICEF 1998).

Fazendo uma síntese sobre pontos de vistas convergentes quanto à análise desta questão, BUSS (1990) resume bem quando afirma que a situação socio-econômica característica da dinâmica social no Brasil, e particularmente na Região Nordeste, está fundamentada em diversos aspectos, tais como: acelerada urbanização nas últimas três décadas, configurando uma concentração da população rural para os centros urbanos industrializados na perspectiva de oferta de emprego, salários mais atrativos; mobilidade espacial com a expansão do capitalismo no meio rural; emergência de megalópolis em regiões de grande atividade econômica; queda acentuada do crescimento populacional, conseqüência de alterações dos padrões de natalidade e fecundidade; e elevada concentração de renda. Dada a situação histórica da população Nordestina, a realidade observada nesta investigação, descrita por dados como situação de trabalho atual e renda, reforçam estes aspectos.

Neste sentido, cumpre informar que no tratamento dos dados empíricos, não apresentados na descrição do conjunto das tabelas, a participação da mulher no mercado foi de $21,1 \%$ para o grupo de parturientes com neonatos de baixo peso e $26,3 \%$ para os de não baixo peso. Isto vai de encontro ao fato observado de sua pequena participação como provedora da familia nos dois grupos estudados, 
ou seja, somente $8,7 \%$ e $8,6 \%$ das mulheres com neonatos de baixo peso e não baixo peso eram, respectivamente, responsáveis pela família.

Vale observar que esta percentagem de familias chefiadas por mulheres encontrase bem abaixo do valor observado para o Brasil, referido no livro 'Mulheres latinoamericanas em dados", onde consta que a mesma assume a condição de chefe de $30,0 \%$ das cerca de 38 milhões de familias brasileiras (VALDEZ e GOMARIS, 1993); isto, mesmo considerado que a categoria "outros familiares", presente na tabela 6, possa conter uma percentagem de mulheres que se acrescente ao referido valor. Esta situação pode ser explicada pelas características de valores mais tradicionais que norteiam a composição familiar dos grupos investigados em função do contexto sociocultural onde se inserem.

A propósito do assunto, um dos aspectos que retrata a tradição da família brasileira, presente nos grupos estudados, refere-se à situação do estado civil dos cônjuges. Na maioria dos casos investigados, as parturientes são casadas oficialmente ou possuem "união livre", na ordem de $74,5 \%$ para o grupo de baixo peso e $75,0 \%$ para o grupo de não baixo peso. Isto pode significar que, em grande parte, no interior dessas famílias, as relações de gênero se caracterizem pela predominância do domínio do homem (marido/companheiro) em relação à mulher, no provimento das necessidades da família. Situação que corresponde aos dados do IBGE(1997), com 73,2\% dos homens como chefes das famílias. 
Esta predominância do papel masculino nas famílias dos dois grupos estudados manifesta-se, também, quando da análise da estrutura familiar dos mesmos. Nos dados descritos pode-se observar que as famílias, em sua maioria, são do tipo nuclear, com 66,4\% para o grupo de baixo peso e $69,9 \%$ para o de não baixo peso. Este aspecto reflete a dinâmica sócio-demográfica das famílias brasileiras. Na população geral, a média de pessoas na família é de 3,8, taxa semelhante a do estudo do IBGE (1997), o que aponta para uma acentuada redução da natalidade e da fecundidade, particularmente nas famílias do Nordeste, que tradicionalmente eram compostas por famílias extensas e atualmente apresentam um declínio em sua composição. Este fato é explicado por BUSS (1990) como resultado da intensa migração da população para os grandes centros urbanos, pela necessidade de inserção no mercado de trabalho e pelas sucessivas crises econômicas presentes no cenário brasileiro, fato que possibilita incorporar um novo padrão de família denominada "moderna".

Diante disto vale considerar, a exemplo do que ocorre na sociedade brasileira, que em sua maioria, as mulheres ocupam uma posição considerada secundária, porque caracterizada como "do lar", nos dois grupos estudados, ou seja, 78,9\% para o grupo de baixo peso e $73,7 \%$ para o de não baixo peso. Esta não inserção de mulheres no mercado de trabalho não apresenta, no entanto, que ela não exerça um papel fundamental no processo produtivo, uma vez que seu trabalho "no lar" oferece as condições básicas necessárias para que os demais membros da familia, que trabalham nos setores formal ou informal, tenham garantida a manutenção de seus potenciais de produção. Dizer que a mulher "do lar" não 
trabalha é negligenciar a sua rotina de no mínimo oito horas de "trabalho doméstico".

Nesse contexto, o modo como a sociedade está organizada é o que determina o ritmo, orientação e os limites das dinâmicas sociais que possam ocorrer. Particularmente no Nordeste brasileiro esse ritmo de mudanças sempre obedeceu às normas impostas pelo mercado externo, seja de dentro como de fora do país. Essa subordinação nordestina favoreceu a absorção passiva da tecnologia gerada no centro-sul e no exterior, resultando em menor rendimento do investimento em empregos, heterogeneidade do processo produtivo, fortalecendo a precarização do trabalho, ocasionando desocupação tecnológica o que pode explicar também a pequena inserção da mulher no mercado de trabalho dada a pequena oferta e nível de desemprego.

Vale considerar que as migrações para as grandes cidades contribuíram para o aumento significativo da participação relativa da população ocupada em atividades predominantemente urbanas, de baixa renda, de caráter instável e sem acesso a benefícios sociais e trabalhistas, caracterizando uma urbanização e proliferação da estrutura produtiva das chamadas atividades informais, conforme bem aponta DUPAS (1999). Consequentemente esta situação determina as condições de vida desfavoráveis, sob o ponto de vista da problemática da pobreza absoluta, a qual se apresenta como um outro tipo de fragmentação social, caracterizada por uma desigualdade exacerbada no próprio interior da sociedade. 
Dentro desta mesma linha de interpretação, uma outra modalidade de análise, particularmente importante de verificar as condições de desigualdades sociais é a caracterizada pelo índice de desenvolvimento humano (IDH). Este indice é operacionalizado através de indicadores de desenvolvimento econômico como a renda, juntamente com outros indicadores de desenvolvimento social como escolaridade, assim como a esperança de vida ao nascer. Através dessa análise o país está classificado num índice de nível médio de desenvolvimento $(0,797)$, quando os países de alto desenvolvimento alcançam uma média de 0,800. É interessante notar que a Região Nordeste é a que apresenta o menor índice $(0,548)$, sendo que a Paraíba apresenta um índice de 0,466 (IPEA, 1996). Nesse contexto, o Estado da Paraiba apresenta uma das piores condições de vida, caracterizada por baixo nível de desenvolvimento humano, baixo PIB per capita, baixa esperança de vida ao nascer e baixos níveis de escolaridade. Esta situação define uma característica de desigualdade sócio-econômica evidente, ao que o IPEA classifica como três sub-países definidos pelo sul e sudeste, centro-oeste, e norte-nordeste.

Conforme já observado, a escolaridade assume atualmente, ao lado da renda, papel expressivo na caracterização das condições de vida sobretudo porque aponta, mais do que nunca, para as possibilidades de inserção das pessoas no mercado de trabalho, dado que as exigências que o novo capitalismo globalizado e informatizado impõe é a mão de obra super especializada. 
Diante disto educar sua população para a promoção do desenvolvimento econômico e social é o grande desafio que se coloca para o Brasil onde somente $13,0 \%$, da população metropolitana, alcançavam, na década de 90 , o ensino médio (IPEA, 1996). Ao considerar-se os dados da PNADS de 1996 pode-se observar que somente $4,0 \%$ da população brasileira freqüentavam ou finalizaram o curso universitário, no momento da pesquisa, e cerca de $12,0 \%$ da população de 6 anos e mais eram analfabetos.

Comparando com os dados do IPEA (1996), a constatação de subdesenvolvimento da Paraíba pelo IDH (Índice de Desenvolvimento Humano) se confirma na medida em que o Estado conta, no período, com $16,4 \%$ de analfabetos jovens e $18,4 \%$ de analfabetos adultos, acima, portanto, da média nacional.

Na presente pesquisa, a proporção de analfabetos, incluindo aqueles que referiram ter o nível básico incompleto, foi, segundo dados disponíveis mas não descritos em tabelas, de 10,4\% para os responsáveis pelas famílias dos recém-nascidos de baixo peso e 6,3\% para os responsáveis pelas famílias dos recém-nascidos de não baixo peso.

Em relação ao ensino médio, acrescidos os responsáveis pela família que informaram terem o superior incompleto, a proporção foi de $24,6 \%$ para o grupo de recém-nascido de baixo peso e 23,6\% para o grupo de recém-nascido de não baixo peso, enquanto que para o curso superior completo os valores apresentados foram de $5,2 \%$ e $6,8 \%$ respectivamente. 
Se considerarmos as parturientes, as proporções de analfabetismo mais o básico incompleto foram de $16,8 \%$ e $19,3 \%$ para os grupos de neonatos de baixo peso e não baixo peso, respectivamente. Em relação ao ensino médio, incluindo o superior incompleto, as proporções foram de $15,3 \%$ e 13,0\% enquanto que, para o superior completo, foram de $3,0 \%$ e $3,2 \%$, respectivamente.

Relacionando os dados dos dois grupos pesquisados observa-se, com relação à parturiente, pequenas diferenças de proporções para ambos, em todos os níveis, com exceção do superior completo onde os valores são praticamente idênticos.

Em relação aos responsáveis pelas famílias os valores seguem a mesma tendência de proximidade de proporções, com exceção do analfabetismo que se apresenta maior no grupo de neonato de baixo peso, em relação ao de não baixo peso, com uma diferença de $4,1 \%$.

Comparando os níveis de escolaridade dos responsáveis pela família e das parturientes, e tendo em vista que cerca de $8,0 \%$ destas são responsáveis pelas familias, o que constata é que os mais baixos níveis de escolaridade são os das mulheres parturientes, o que as aproxima, em relação ao analfabetismo, da média do Estado. Em contrapartida, os responsáveis pelas famílias, nos dois grupos de recém-nascidos, superam a média nacional.

Estes dados permitem inferir que a relevância do emprego dos níveis de escolaridade e de renda aumenta quando combinados, a exemplo, do IDH, por 
permitir melhor identificar situações de desigualdade por apontarem para aspectos diferenciais da realidade em termos de configuração de contextos.

Nesta perspectiva de analisar a desigualdade social de forma mais abrangente é que se apresentam as tentativas de operacionalização do conceito de classe social, notadamente para investigações empíricas no campo da saúde (BRONFMAN e TUIRÁN 1984, BARBIERI 1985, BARROS 1986, LOMBARDI e cols. 1988, SOLA 1996).

Apesar dos riscos de simplificação do conceito teórico de classe social, que qualquer proposta de operacionalização encerra, a principal vantagem que se coloca no seu emprego encontra-se no pressuposto básico presente de que, em vez de identificar individuos específicos, como no caso do emprego de indicadores simples como renda e escolaridade, a busca de análise das desigualdades a partir do conceito de classes permite aproximar-se da identificação de grupos sociais visando às variações inter grupais (LAURELL, 1993; SEN, 2001:185).

No presente trabalho, o emprego do sistema de classificação proposto por LOMBARDI e cols. (1988) permitiu observar que os dois grupos de recém-nascidos pesquisados são relativamente homogêneos quanto à distribuição inter-classes. Analisadas como duas grandes classes polares, a maior proporção coube para a ampla categoria nomeada proletariado (com $85,5 \%$ e $82,2 \%$, respectivamente) e, dentro desta, a predominância foi a da classe "proletariado não típico", com $54,0 \%$ e $53,2 \%$. Na ampla categoria nomeada como burguesia, houve diferença 
de proporção entre os dois grupos estudados, com 14,6\% para o grupo de neonatos de baixo peso, em relação a $17,8 \%$ para o grupo de neonatos de não baixo peso. Nesta, a predominância coube à "pequena burguesia tradicional", com $10,9 \%$ e $11,3 \%$, respectivamente. Vale destacar que na classe "burguesia", propriamente dita, somente se observa a presença de recém-nascidos para o grupo de não baixo peso, com a pequena percentagem de $0,8 \%$.

Em relação à distribuição observada vale algumas considerações de ordem teóricometodológica tendo em vista que não se assume, no presente trabalho, que a mesma corresponda à realidade local e mesmo regional, uma vez que a identificação do pertencimento de pessoas à categorias de classe é complexa, sobretudo nos tempos atuais quando o capitalismo se redefine no contexto da globalização e da informatização e a questão da definição da nova estrutura de classes existente e da diferenciação inter-classes ganham novas nuances e novas desafios teóricos. Neste sentido, a busca de emprego deste conceito no presente trabalho parte, portanto, do reconhecimento, a priori, da sua redução teóricometodológica a um conjunto de indicadores "simples", conforme explicitado em nivel da metodologia. A vantagem presente é a de que os mesmos se apresentam de maneira articulada, como num "índice". Esta articulação, diferentemente dos estudos de estratificação social, não se dá de maneira estatística, mas de maneira teórica, ou seja, levando em conta alguns dos pressupostos básicos que fundamentam o conceito. 
Esta articulação teórica permite ampliar a busca de interpretação dos dados na medida em que possibilita, com base na proposta de Boltanski, citado por ALVARENGA (1978) analisar as relações encontradas entre condições e nascimento e condições de classe num duplo aspecto: por um lado, em termos das condições objetivas de existência, que diferenciam grupos de mulheres pelas possibilidades diferenciais de compra de bens e serviços disponíveis no mercado e, por outro, pela cultura ou hábitos de classe, que tais condições objetivas propiciam construir.

Esta mesma possibilidade de análise não se observa quando da utilização de indicadores simples, como é o caso da renda ou escolaridade. Isto na medida em que os mesmos, dada a sua condição de indicadores, carecem da dimensão teórica que o processo de interpretação exige.

Esta questão pode ser exemplificada, no caso da renda, a partir da discussão que SEM (2001) apresenta quando de seu emprego para a caracterização do conceito de "pobreza" amplamente utilizado nos estudos de desigualdade social. Para este autor, analisar o pobreza baseada somente na renda é deixar a história pela metade; isto na medida em que o fenômeno da pobreza é complexo e não se reduz, portanto, à privação da renda, sendo a mesma somente um dos parâmetros ligados à pobreza, mas não o único. 
Tendo em vista tais considerações vale destacar que o reconhecimento de que o emprego do conceito de classe social apresenta melhores possibilidades de interpretação dos dados não implica deixar de reconhecer igualmente seus limites.

Exemplo típico de que ao se falar de "classe", se está colocando-a entre aspas, dado o pequeno alcance teórico que adquire neste contexto de operacionalização, trata-se da própria diferenciação que LOMBARDI e colaboradores (1988) apresentam quando buscam comparar seu esquema de operacionalização de classe social com o de BARROS (1986).

Assim, longe de se poder avaliar a proximidade maior ou menor à realidade social investigada, na medida em que não se dispõe desses dados em nível nacional, de ambos os esquemas propostos, o problema do "modelo" de BARROS "superestimar", na linguagem de LOMBARDI e cols. (1988), o subproletariado, tendência semelhante de "superestimação" poderia estar ocorrendo, igualmente, com seu esquema, na medida em que o mesmo poderia, por exemplo, estar superestimando a categoria "proletariado não típico" no presente estudo. Isto porque, além do presente trabalho, na aplicação desta proposta de operacionalização em outros estudos, esta categoria de classe sempre apresentou valor marcante (SILVA 1991, SIQUEIRA 1993, ALVARENGA 1994).

Esta problemática teórico-metodológica poderá ser observada, em muitos momentos, quando da análise das condições de classe dos neonatos de baixo peso e não baixo peso em relação às diferentes variáveis empregadas, muitas 
delas igualmente complexas, para o estudo do problema sob investigação. No entanto, a despeito desses limites, permite enriquecer a interpretação dos dados, em muitas das relações analisadas.

A busca das relações existentes entre condições de nascimento e condições de classe das parturientes pertencentes às duas amostras de neonatos implica numa articulação entre diferentes ordens de eventos complexos como a assistência ao parto e ao recém-nascido, a assistência pré-natal, a ocorrência de óbito neonatal precoce, além da consideração implícita de indicadores "simples" de risco materno e perinatal, tradicionalmente empregados pela saúde da mulher e perinatal, tais como, a idade e a paridade da mulher, o hábito de fumar e o consumo de álcool, dentre outros.

Ao se analisar as diferenças existentes entre parto vaginal e cesariana nos dois grupos estudados o que se pode constatar é a elevada taxa de cesáreas para os dois grupos de recém-nascidos, $45,3 \%$ e $49,2 \%$, respectivamente, portanto bem acima do valor estimado para a média nacional que é de 36,0\% (FIOCRUZ, 1999) e, ainda mais grave, bem superior ao parâmetro internacional proposto pela Organização Mundial da Saúde (OMS), que é de 10,0\% a 13,0\% (NOTZON, 1990). 
Um estudo recente sobre a análise da assistência perinatal e obstétrica realizado por GUERREIRO e cols. (2000), no Estado da Paraíba, apresenta esta mesma tendência onde se verificou que a maioria das maternidades apresentaram uma taxa de cesariana em torno de $55,0 \%$.

Ao se relacionar tipo de parto ao tipo de serviço, o que se pode observar é que a grande predominância de cesáreas cabe ao setor privado que, estranhamente, apresenta $83,4 \%$ para o grupo de recém-nascidos de não baixo peso, contra 44,4\% para o de baixo peso. Esta considerável diferença de 39,0\% não encontra, ao que parece, justificativa do ponto de vista clínico-obstétrico na medida em que, por hipótese, a cesárea deveria ser mais indicada para o grupo de baixo peso que por si só já apresenta, pelos dados observados, uma proporção elevada.

Dada a elevada ocorrência de cesáreas, cabe um destaque para o registro de sua indicação. Apesar das indicações mais freqüentes serem em função da "iteratividade" e "desproporção feto-pélvica" é de chamar a atenção encontrar "distrofia de colo", como indicação de parto cesáreo. Neste aspecto cabe uma confirmação se o que se registrou como "distrofia de colo" não seria, na verdade, uma distorcia causada por uma lesão no colo, de origem hormonal, representada por um tumor disfuncional do colo, o que poderia justificar uma indicação para a cesárea. Muito mais estranho foi encontrar o registro de quatro "histerectomias" como indicação de cesárea, o que parece ser mais um registro de interesse particular do que uma indicação clínica na medida em que isto não se jıstifica. Outro aspecto não justificável é a falta de registro da indicação para o 
procedimento cirúrgico. Neste aspecto parece não haver uma relação direta entre o ato cirúrgico e a necessidade clínico-obstétrica de fazê-lo, fazendo supor que boa parte destas cesáreas foram feitas desnecessariamente.

Corroborando esta análise, estudo sobre as condições de assistência obstétrica e perinatal no Estado (GUERREIRO e cols. 2000) apontou que a maioria das maternidades, inclusive as da capital que foram envolvidas nesta investigação, não fazem uso do partograma - um instrumento útil para avaliações das condições das parturientes nos momentos que antecedem ao parto. Esta observação, somada a outras, como ausência de monitor fetal, estetoscópio de pinard, indica o grau de ausência de critérios de avaliação prévia das parturientes, de modo a fazer uma escolha acertada entre o procedimento de cesariana ou do parto normal, levando em consideração as condições biológicas e sociais das parturientes. Esta questão relaciona-se, sobretudo, com a da qualidade da assistência ao parto e pré-parto. Como observa TANAKA em estudos sobre saúde materna e perinatal "... além dos riscos orgânicos e sócio-econômicos a que a população está exposta, acrescentase o risco institucional, agravando as condições de sobrevida do recém-nascido, principalmente no período mais crítico de sua vida que é o parto e a primeira semana de vida pós-natal" (TANAKA 1995, p.135). É neste sentido também que BERQUÓ afirma que a postura dos profissionais obstétras é a de que "continuam a preferir partos operatórios ou por comodismo ou por despreparo para realizá-los via vaginal" (BERQUÓ 1993, p. 28). 
Para evidenciar ainda mais esta questão foram investigadas as intercorrências na gravidez seja do ponto de vista das parturientes, como também do profissional que a atendeu no momento do parto. A maioria das mulheres dos dois grupos estudados referiu ter tido infecção respiratória, enquanto no registro hospitalar ficou mais evidenciado, para o grupo de baixo peso, a hemorragia, a hipertensão arterial, e a rotura de membrana. Para o grupo de não baixo peso foi a hipertensão arterial, o DHEG e a pré-eclâmpsia, respetivamente. Pelo descrito pode-se observar que as morbidades referidas pelas mulheres não correspondem às registradas pelo profissional, no momento do parto. É certo que se tratam de informações referentes ao pré-natal e que no momento do parto não foram valorizados ou não consistiam mais em problemas de saúde para a parturiente; ou que foram valorizados, apenas, os eventos que tinham implicação direta para este momento; no entanto, chama a atenção o número de casos sem registros de intercorrências no prontuário hospitalar dos dois grupos, ou seja, 83,2\% e 85,0\%, respectivamente.

Ao que parece, esta discrepância parte de pontos de vista distintos, uma vez que as parturientes referem intercorrências privilegiadas durante a gravidez, enquanto que o prontuário reflete a importância clínica-obstétrica, do ponto de vista do profissional. Uma possivel explicação, por um lado, é que realmente as informações das parturientes não são valorizadas no momento da atenção ao parto, isto quando se toma como exemplo o fato de que não há nenhum registro de infecção respiratória referida, em grande proporção, pelas mulheres; e por 
sutro, que elas chegam à maternidade já no período expulsivo da gestação juando não é mais possivel fazer uma anamnese adequada.

Jm outro aspecto bastante importante e que tem a ver diretamente com os Jados empregados na presente pesquisa refere-se, por um lado, ao sub-registro to peso dos recém-nascidos e, por outro, do registro inadequado dos mesmos que rodem subestimar ou superestimar as condições de nascimento em relação a esta rariável.

Jiante disto, investigações levadas a cabo tanto em João Pessoa, quanto na Zegião Nordeste como um todo, puderam estimar a ocorrência destes fenômenos. Em relação à Região Nordeste estudo da BENFAM (1996) apresenta uma sub1otificação para o registro de peso ao nascer da ordem de $21,2 \%$.

Zuanto ao município de João Pessoa, trabalho de TEIXEIRA-LIMA (1995) pôde zonstatar um erro de registro em relação ao peso ao nascer na proporção de $57,0 \%$ tanto nos serviços públicos, quanto nos privados. Desse modo observou que a taxa média de baixo peso ao nascer era, no período, de $12,0 \%$ ao invés de 8,6\% conforme os dados "oficiais" revelados através de pesquisa anterior desenvolvida por SANTANA (1990).

Diante disto vale observar que no ano de 2000, correspondente à presente pesquisa, levantamento complementar permitiu informar que a taxa média de baixo peso ao nascer registrada, nos hospitais, para o município foi de $8,7 \%$, com 
uma variação de $3,0 \%$ a $11,6 \%$. Em relação ao "peso insuficiente" e "peso adequado" as taxas médias foram de $22,3 \%$ e $69,0 \%$, respectivamente. Estas taxas são correspondentes a um total de 17.990 nascidos vivos no período.

Vale assinalar que o fato do sistema de vigilância epidemiológica local apresentar este valor relativamente próximo à média nacional $(10,0 \%)$ pode apontar, por um lado, para uma possivel melhoria das condições de nascimento após 1995 e, por outro, para a persistência ainda hoje de subestimação no registro deste evento, visto que a qualidade da assistência materno-infantil ainda não demonstra tal tendência de melhoria.

A despeito dos problemas existentes em termos dos registros de dados hospitalares, utilizados neste trabalho, pode se observar que a análise da ocorrência de cesariana em relação às categorias de classes sociais permite aprofundar a interpretação deste fenômeno quando comparadas as duas amostras de recém-nascidos, de baixo peso e não baixo peso.

Pelos dados apresentados, as maiores proporções referem-se tanto no grupo de neonato de baixo peso, quanto no de neonatos de não baixo peso, à ampla categoria denominada burguesia, chegando a $80,0 \%$ no grupo de baixo peso.

No entanto, ao se calcular as taxas de cesariana para as duas classes tomadas como polares, proletariado e burguesia, os resultados obtidos revelam que é no grupo de não baixo peso que se encontram os maiores índices de cesariana. E o 
que é mais contraditório, do ponto de vista clínico-obstétrico, com predominância para a classe da burguesia, ou seja, 53,0\% em relação a $48,3 \%$ para a classe do proletariado. Com taxas menores e predominância na classe do proletariado coloca-se o grupo de neonatos de baixo peso, com $46,2 \%$ em relação à $40,0 \%$ na classe da burguesia.

Estes dados evidenciam que a cesariana, longe de se constituir como indicação de um risco clínico-obstétrico e perinatal apresenta-se muito mais como resultado de uma prática profissional e institucional, sobretudo no setor privado, que apresenta, no Brasil, taxas de $80,0 \%$ a $90,0 \%$ (HOPKINS, 2000). Neste sentido é que o estudo de Hopkins permite observar que, longe da cesárea se constituir numa adesão "consciente" por parte da mulher, ela é resultado do exercício do poder médico que induz, com base na construção social de uma "cultura de cesárea" no Brasil, a própria legitimação deste ato. O mesmo fato ocorre em relação à construção de uma "cultura da esterilização", bem caracterizada por BERQUÓ (1993).

Mesmo considerando que as parturientes estudadas são na maioria primíparas no grupo de baixo peso $(54,0 \%)$, inclusive com evidência estatística para o risco de ter recém-nascidos de baixo peso, ainda assim tal proporção de cesárea, no pressuposto de uma gravidez de maior risco para esta categoria de mulheres não se justificaria dado, por um lado, a sua magnitude e, por outro, o fato de a maioria das primíparas pertencerem à ampla classe do proletariado. 
A caracterização do nascimento como um evento complexo apresenta-se de maneira mais evidente quando se procura relacionar mais estreitamente às condições de nascimento, as condições de assistência, pré-natal e ao parto, e as condições sociais de classe.

Este fato pode ser evidenciado quando se analisa o comportamento dos dados da tabela 31, de diferentes ângulos. Pela distribuição dos óbitos segundo as categorias de classe, já descritos, pode-se observar que a maioria deles, ou seja, $66,7 \%$ e $63,7 \%$, respectivamente, se localizam na ampla categoria de classe do proletariado com predominância, embora pequena, para o grupo de baixo peso.

Pela distribuição dos dados da mesma tabela pode-se estimar os coeficientes de mortalidade neonatal precoce para os dois grupos, de baixo peso e não baixo peso, segundo as duas categorias de classe tomadas como polares, o proletariado e a burguesia, o que permite ampliar a análise.

O que se constata nesta interpretação, contrariamente ao esperado, é que o menor coeficiente de morte neonatal precoce estimado é o do proletariado, no grupo de baixo peso, com 17/1000, em contraposição o maior, de 60/1000, que se refere à burguesia pertencente ao grupo de recém-nascidos de não baixo peso. Como coeficientes intermediários estimados obteve-se 50/1000 para a classe burguesia do grupo de neonatos de baixo peso e 22/1000 para o proletariado do grupo de não baixo peso. 
A busca de explicação para a ocorrência desta maior mortalidade neonatal precoce em recém-nascidos pertencentes à burguesia redimensiona a discussão da questão da baixa qualidade de assistência à gravidez e ao parto, tradicionalmente atribuída aos serviços públicos. No presente estudo, o que se evidencia é que, talvez em função da elevada taxa de cesariana nos serviços privados, os recémnascidos pertencentes à burguesia tenham morrido mais e, sobretudo, no grupo de não baixo peso.

No entanto, este fato não se circunscreve, ao que parece, somente à questão da qualidade de assistência à mulher, mas, igualmente, à assistência ao recémnascido. Isto tendo em vista que na descrição qualitativa dos óbitos, constante do item 4.4, pode-se observar que no grupo de baixo peso todos, com exceção de um, tiveram Apgar elevado tanto para primeiro, quanto para o quinto minutos e eram adequados para a idade gestacional (AIG). E dentre eles somente uma das parturientes não tinha realizado o pré-natal.

Em relação ao grupo de recém-nascidos de não baixo peso, embora não se dispusesse do registro da avaliação de CAPURRO para alguns dos onze casos de óbitos, dentre os registrados três deles eram pequeno para a idade gestacional (PIG) e quatro adequados para a idade gestacional (AIG). Segundo o Apgar de primeiro e quinto minutos todos, com exceção de um dos recém-nascidos que não possuia registro, nasceram em boas condições clínicas. Vale ressaltar que somente dois destes neonatos eram de "peso insuficiente". Também, que somente duas parturientes não fizeram o pré-natal. 
Em relação à avaliação das condições de nascimento dos neonatos cabe observar que as medidas disponíveis, como o Apgar e CAPURRO, caracterizam-se, a exemplo da classe social, como complexas tendo em vista que procuram diferenciar o normal, do patológico.

Neste sentido, KRAMER (1989) traz à tona uma discussão importante sobre a problemática de mensurar o crescimento e desenvolvimento intra-uterino, bem como sua relevância prognóstica trazendo, em suas conclusões, a recomendação de que são necessários mais estudos para se poder melhor identificar os determinantes desses processos. Ainda nesta ótica, NAUFEL (1998) faz uma análise crítica dos vários métodos empregados para a mensuração do crescimento e do desenvolvimento da criança constatando que os neonatos avaliados como com retardo de crescimento uterino podem apresentar os mesmos valores que os com não retardo de crescimento quando utilizadas, por exemplo, medidas como a estatura, o perímetro cefálico e o índice ponderal.

Muito embora a questão da complexidade da avaliação das condições de nascimento se coloque com questão relevante, não se pode deixar de considerar os dados de avaliação, do Apgar e CAPURRO, registrados nos prontuários hospitalares, o que levanta as possibilidades de uma baixa qualidade de assistência também ao recém-nascido que, no caso, não se circunscreve aos serviços privados, mas também se estende aos serviços públicos. 
Ao lado dos aspectos apresentados para a interpretação da maior mortalidade neonatal precoce, observada na ampla classe burguesia, com predominância para o grupo de não baixo peso, uma outra questão que se coloca, igualmente importante, é a da assistência pré-natal. Isto porque, no Brasil, ao lado da questão do acesso aos serviços de pré-natal disponíveis, coloca-se igualmente o fenômeno da fragmentação da assistência à mulher o que, muitas vezes, pela não garantia institucional para realizar o parto a mulher é levada a "peregrinar" na busca pessoal de assistência (TANAKA, 1995), o que a coloca em risco, assim como ao seu concepto, a despeito de ter realizado um pré-natal de boa qualidade.

Se partirmos do pressuposto de que as mulheres que fizeram mais de nove consultas de pré-natal apresentavam um maior risco materno-fetal, pela tabela 32 pode-se inferir que o grupo de não baixo peso apresentou a maior proporção de mulheres nesta condição, ou seja, $7,7 \%$ em relação a $0,05 \%$ no grupo de baixo peso. Avançando na busca de interpretação, ao considerar-se a proporção de $7,7 \%$ observada no grupo de não baixo peso constata-se que $5,1 \%$ destas mulheres de maior risco pertenciam à burguesia; diante disto, poder-se-ia supor, então, que tal condição de risco clínico-obstétrico teria igualmente contribuído para a maior mortalidade neonatal precoce neste grupo.

A importância da articulação institucional entre as assistências ao pré-natal e ao parto oferecidas à mulher remete para a necessidade de interpretação de como as parturientes, pertencentes às duas amostras estudadas, receberam este tipo de assistência durante a gravidez. 
Buscando contextualizar os resultados da pesquisa vale destacar, primeiramente, que estudos da PNDS (BENFAM 1996) estimaram uma taxa de 25,0\% de ausência de mães ao pré-natal para a Região Nordeste e, ao que parece, a tendência vem se mantendo apesar de alguns esforços que atualmente vem se observando nos serviços de assistência materno-infantil. Isto na medida em que, na presente pesquisa, somando-se as mulheres que não fizeram pré-natal com as que fizeram só de uma a quatro consultas, a proporção é de $31,3 \%$ para o grupo de baixo peso, acima, portanto, da taxa estimada pela PNDS, em relação a de $25,7 \%$ para o grupo de não baixo peso, que acompanha o valor da taxa de $25,0 \%$ estimada para a Região Nordeste. Uma outra questão que se coloca é a de que o pré-natal realizado talvez não esteja adequado do ponto de vista do número de consultas considerando igualmente o trimestre de início do mesmo. Isto fica evidenciado quando se observa que $13,0 \%$ das parturientes com neonatos de baixo peso e $4,3 \%$ dos com neonatos de não baixo peso tem acesso ao pré-natal mas não dão continuidade e $27,0 \%$ e $34,3 \%$, respectivamente, o iniciam tardiamente.

Estudo da BENFAM (1996) constata que a média nacional de mulheres que iniciam o pré-natal no primeiro trimestre foi de $66,0 \%$ e de $51,9 \%$ para a Região Nordeste. Na presente pesquisa observou-se uma proporção bem acima do observado para a Região; ou seja, quando se considera as mulheres que iniciaram o pré-natal no primeiro trimestre e fizeram mais de quatro consultas, a proporção é de $87,0 \%$ para o grupo de neonatos de baixo peso e $95,7 \%$ para o de não baixo peso. Por estes cálculos poder-se inferir que nos dois grupos de recém-nascidos 
estudados houve uma proteção materno-infantil acima da média nacional, com predominância para o grupo de recém-nascido de não baixo peso, isto tendo em vista o trabalho de NEUMANN (2000) que em estudos no município de Criciúma/SC, observou uma taxa média de $83,1 \%$ das mulheres, com um número médio de 7 consultas, valor atribuído pelos autores como igual à média nacional. Se considerarmos, no entanto, a denominada "cobertura distribuída", descrita no item 4.2 deste trabalho, constata-se que a mesma encontra-se abaixo do previsto pelo "pacto de atenção básica do município" que é da ordem de $85,0 \%$ (SMS/JP, 1997), para os dois grupos estudados; isto na medida em que as proporções desta modalidade de cobertura foi de $60,6 \%$ para o grupo de baixo peso e $62,1 \%$ para o de não baixo peso. Vale destacar que ao se considerar, além das mulheres que tiveram pelo menos de uma a quatro consultas tomadas, no item 4.2 para o cálculo da "cobertura distribuída", também as que não fizeram pré-natal mas estavam grávidas no período da pesquisa, a questão da cobertura de pré-natal, para as parturientes das amostras estudadas, mostra-se bastante precária.

Esta questão da assistência pré-natal ganha relevância quando se observa que vários estudos ressaltam a importância do pré-natal como fator preditivo para uma condição de nascimento favorável (BOLZAN 2000, TANAKA 1999, RAMIREZZEDINA 2000, SCHIRME 2000, NEUMANN 2000, FIOCRUZ 1999). Como exemplo, estudo de RAMIREZ-ZEDINA, analisando a atenção pré-natal no México, observou uma associação significativa da ausência do controle do pré-natal com o baixo peso ao nascer. 
Considerando a ausência de pré-natal como indicador de risco materno-fetal para cada uma das amplas classes sociais pode-se dizer que o risco maior caberia, no caso das duas amostras estudadas, aos recém-nascidos de baixo peso pertencentes ao proletariado, cuja taxa estimada de ausência de pré-natal foi de $33,4 \%$, seguida da dos neonatos de não baixo peso pertencentes também do proletariado, com uma taxa de $27,1 \%$. Para os recém-nascidos pertencentes à burguesia as taxas foram bem próximas, ou seja, $20,0 \%$ e $19,7 \%$, respectivamente, valores bem abaixo dos observados para o proletariado, portanto.

Este fato aponta para as características que assume a assistência pré-natal, uma vez que os motivos da ausência da mesma refletem, conforme observação empírica dos dados, não só as condições objetivas de existência que definem as possibilidades de acesso diferencial das mulheres aos referidos serviços mesmo quando disponíveis, mas também o "hábito de classe" (BOLTANSKI, citado por ALVARENGA, 1978) através do qual as mulheres simplesmente alegam que não fazem o pré-natal por que "não querem". Em relação às dificuldades de acesso, os motivos alegados foram porque "moram longe" ou "não tinham dinheiro para a condução".

Destas análises pode-se inferir que a interpretação dos eventos perinatais, como a condição de peso ao nascer e a mortalidade nas primeiras seis horas de vida do recém-nascido, tratam-se de fenômenos complexos, de natureza tanto biológica quanto social, o que exige para sua melhor compreensão o concurso não só do 
conhecimento gerado pela Epidemiologia, mas igualmente do conhecimento gerado pelas ciências sociais.

Neste particular, diante do reconhecimento da crescente desigualdade social e da emergência de formas crescentes de exclusão social, na realidade brasileira, pode se observar como alguns pesquisadores do campo da Epidemiologia tem buscado ampliar, com o concurso das ciências sociais, a reflexão sobre os diferenciais de saúde-doença observados nos vários grupos sociais, tomados como objeto de investigação e de prática profissional (BARATA e cols.,1997).

Neste cenário, a despeito dos problemas teórico-metodológicos que o conceito de classes sociais encerra devido, sobretudo, às mudanças históricas sofridas pelo capitalismo no mundo globalizado o mesmo consiste, ainda, num dos conceitos mais férteis para a caracterização de situações de desigualdade e de exclusão social.

Isto a despeito da tentativa dos pensadores pós-estruturalistas e pós-modernistas buscarem decretar, a todo custo, a morte do pensamento marxista por considerarem que a classe perdeu importância, como instrumento de transformação social e das possibilidades humanas de ação política, diante da materialidade totalizante do capitalismo moderno.

Refutando este tipo de argumento PALMER (1999) afirma que a classe não deixou de existir, com as quedas do socialismo na antiga União Soviética e do Muro de 
Berlim. Ao contrário, a "classe não caiu" afirma contra-argumentando a declaração enfática de Patrick Joyce; ela naturalmente nunca foi a parte alguma. "Identificada como sendo simplesmente uma de muitas subjetividades pluralistas, a classe foi, na verdade, obscurecida e reduzida à visão analítica e política pelo edifício analítico do pós-estruturalismo, erigido no exato momento em que a esquerda precisa urgentemente da clareza e direção que a classe, como categoria e instrumento, estrutura e política, pode oferecer" (PALMER 1999: 81).

Diante disto, o que se coloca para o emprego do conceito de classes sociais em pesquisas empíricas no campo das ciências sociais em geral e, no da Saúde Pública e Coletiva, em particular, é a necessidade de reconhecer, diante das mudanças que a globalização e a informatização tem operado no capitalismo atual, gerando mudanças profundas nos processos de trabalho, como se estruturam as classes, que novas características assumem neste novo cenário onde o capital é global e o trabalho é local.

Neste sentido, a despeito do reconhecimento das limitações que o esquema para a operacionalização do conceito de classes, proposto por LOMBARDI e cols. (1988), encerra, dada a redução teórico-metodológica que apresenta seu emprego, no presente trabalho mostrou-se frutifero por permitir aprofundar algumas das questões básicas presentes quando se toma as condições de nascimento, o baixo peso e a morte neonatal precoce como objeto de investigação. 
6. CONSIDERAÇÕES FINAIS 
Tomar como objeto de estudo as relações existentes entre condições de nascimento de crianças de baixo peso e não baixo peso ao nascer, condições de assistência e condições de classe, mostrou-se como estratégia teóricometodológica frutífera, na medida em que questões relevantes de natureza interdisciplinar se apresentaram enriquecendo o entendimento sobre o problema em foco.

Das análises realizadas pode-se inferir que a interpretação dos eventos perinatais, como a condição de peso ao nascer e a mortalidade neonatal precoce apresentam-se, ao investigador, a exemplo das classes sociais, como fenômenos complexos. Isto decorre, sobretudo, da sua natureza tanto biológica, quanto social o que requer instrumental teórico-metodológico específico para dar conta da apreensão dos mesmos.

Neste sentido, cabe lembrar como a questão dos fenômenos perinatais, como outros assemelhados, requerem, para sua investigação, a concepção básica de 
que são históricos e, portanto, apresentam configurações diferenciadas na dependência, sobretudo, da crescente tecnologia que redefine, por exemplo, no caso do baixo peso, novas pontos de corte em relação às possibilidades de sobrevida neonatal.

No entanto, sua historicidade se amplia porque à este complexo chamado "nascimento" articulam-se outros, como as condições de classe e a qualidade de assistência, a ponto de TANAKA (1995) colocar a maternidade como um dilema para as mulheres. Isto porque a mesma pode representar, no contexto da realidade brasileira, tanto a oportunidade do nascimento, como o risco social da morte.

É neste cenário social, de reconhecimento das desigualdades e crescente formas de exclusão social, que a importância do emprego de um conceito como o de classes sociais mostrou adquirir sentido, a despeito das limitações que sua operacionalização encerra, considerando especialmente 0 contexto de transformações sociais que o processo de globalização tem imprimido à nova configuração do capitalismo.

Neste sentido, a busca do emprego deste conceito no presente trabalho partiu do reconhecimento, a priori, da sua redução teórico-metodológica a um conjunto de indicadores "simples", mas considerando a vantagem dos mesmos não operarem isoladamente mas poderem ser articulados teoricamente, e não estatisticamente, como num "índice". Segundo SEN (2001:185), na busca de análise das 
desigualdades o conceito de classe permite, diferentemente de indicadores simples como a renda e escolaridade, melhor aproximação da identificação não de pessoas, mas de grupos sociais com vistas às variações inter-grupais.

Esta observação refere-se ao fato de que ao se tomar como referência o conceito de classe social, o processo de interpretação dos dados pode ancorar-se num quadro de referência teórico que permite, a exemplo da proposta de Boltanski, citado por ALVARENGA (1978), analisar a questão da desigualdade social não somente em termos das condições objetivas de existência, que falam a respeito das possibilidades diferenciais de se adquirir "bens no mercado", como é o caso da assistência à saúde, mas também da existência de uma cultura ou hábitos de classe igualmente diferenciada.

Buscando destacar algumas das contribuições que a aplicação deste conceito ofereceu para a interpretação dos dados vale mencionar, primeiramente, o fato de que, em termos da distribuição de classe, os grupos de recém-nascidos de baixo peso e não baixo peso apresentaram comportamento homogêneo, com proporções aproximadas, portanto, em todas as categorias. O predomínio foi no "proletariado não típico".

No entanto, quando relacionados a eventos como assistência ao pré-natal, assistência ao parto e óbito neonatal precoce estas categorias de classe permitiram ampliar o processo de análise do problema tomado como objeto de estudo, sobretudo porque comparados os grupos de recém-nascidos de baixo peso e os de não baixo peso. 
Em relação à assistência ao parto identificou-se uma elevada ocorrência de cesarianas cuja predominância coube ao setor privado que apresentou, estranhamente, $83,4 \%$ para o grupo de neonatos de baixo peso e $44,4 \%$ para o de não baixo peso, com uma elevada ausência de registros para justificar sua indicação. Quando relacionada sua ocorrência às categorias de classe observa-se que as maiores proporções referiam-se, nos dois grupos de recém-nascidos estudados, à ampla categoria chamada burguesia, chegando a $80,0 \%$ no grupo de baixo peso.

Quando calculadas as taxas de cesarianas para as duas classes, tomadas como grupos sociais polares, ou seja, proletariado e burguesia, os resultados obtidos puderam revelar que foi no grupo de neonatos de não baixo peso que se encontrou os maiores índices. E o que é mais contraditório, do ponto de vista clínico-obstétrico, com predominância para a classe da burguesia, ou seja, 53,0\% em relação a $48,3 \%$ para a classe do proletariado. Com taxas menores e predominância no proletariado coloca-se o grupo de neonatos de baixo peso, com $46,2 \%$ em relação à $40,0 \%$ na classe da burguesia.

Diante disto evidencia-se o fato de que longe de se constituir como indicação de um risco clínico-obstétrico e perinatal a cesariana apresenta-se muito mais como resultado de uma prática profissional e institucional socialmente sancionada, cuja construção responde tanto aos interesses da burguesia empresarial, no caso os proprietários de hospitais particulares, quanto aos dos profissionais médicos, cuja 
hora de trabalho é mercantilizada a preço elevados a quem dispõe do poder de compra, como é o caso da burguesia. Daí poder-se caracterizar a predominância das cesáreas observadas nesta categoria de classe também como uma cultura ou hábitus de classe da burguesia que ocorre, dada a sua internalização como prática social, de maneira indiferente aos riscos que pode acarretar, quando desnecessária, quer a saúde da mulher, quer à do recém-nascido.

A caracterização do nascimento como um evento complexo apresentou-se de maneira mais evidente quando se procurou relacionar mais estreitamente as condições de nascimento e condições de assistência às condições de classe. Neste particular, a busca de interpretação do como e o por quê da ocorrência de óbitos nas primeiras seis horas de vida foi enriquecedor, dadas as possibilidades de abordagem do problema de diferentes ângulos.

Ao observar-se o comportamento dos dados sobre mortalidade neonatal precoce em relação à sobrevida do recém-nascido pode-se verificar, por exemplo, que a maioria deles, ou seja, $66,7 \%$ e $63,7 \%$ se localizavam, respectivamente, na ampla categoria de classe do proletariado com predominância, embora pequena, para o grupo de baixo peso.

Quando analisados a partir dos coeficientes de mortalidade neonatal precoce estimados para os dois grupos de recém-nascidos, segundo as duas categorias de classe tomadas como polares, pode-se ampliar a interpretação. Isto porque, contraditoriamente, o menor coeficiente de morte neonatal precoce estimado, de 
17/1000, referiu-se aos recém-nascidos de baixo peso pertencentes ao proletariado e, em contraposição, o maior, de 60/1000, coube aos neonatos de não baixo peso pertencentes à burguesia. Como coeficientes intermediários obteve-se 50/1000 para a classe burguesia do grupo de neonatos de baixo peso e 22/1000 para o proletariado do grupo de não baixo peso. Em suma, os neonatos que, por hipótese corrente, não são de risco por não serem de baixo peso e por pertencerem à burguesia foram os que morreram mais, quando comparados os dois grupos de recém-nascidos estudados.

Diante destes dados uma das hipóteses explicativas foi a de que, em função da elevada taxa de cesariana nos serviços privados, os recém-nascidos de não baixo peso, pertencentes à burguesia, tenham morrido mais o que, em tese, permitiu redimensionar a clássica discussão da baixa qualidade de assistência à gravidez e ao parto tradicionalmente atribuída aos serviços públicos.

No entanto, quando da descrição de natureza qualitativa de cada um dos óbitos novas evidências se apresentaram articulando ainda mais as relações existentes entre condições de nascimento, qualidade de assistência e condições de classe. Isto na medida em que a totalidade das mulheres com recém-nascidos de baixo peso pertencentes a burguesia fizeram mais de oito consultas de pré-natal, o que poderia estar representando a presença de gravidez de maior risco. No entanto, vale finalizar dizendo que embora um dos quatro recém-nascidos fosse pequeno para a idade gestacional (PIG) e que um outro não tivesse registro da adequação peso/idade gestacional e fosse de "peso insuficiente" ambos nasceram em boas 
condições de vida, segundo o Apgar. Isto sem considerar que os dois outros nasceram adequados para idade gestacional (AIG) e em boas condições de vida, segundo o Apgar.

Diante disto, a questão básica que se apresenta como desafio tanto aos investigadores, como aos profissionais deste campo de conhecimento e de prática é a de como contribuir para que o nascimento de uma criança seja para a vida e não para a morte. 
7. REFERÊNCIAS 
1. AERTS D, et al. A determinação do baixo peso ao nascer: um estudo a partir do SINASC. In: III Congresso Brasileiro/II Congresso Ibero-Americano/ I Congresso Latino-Americano de Epidemiologia. Anais. Salvador, Bahia, Brasil; abril 1995, p. 230.

2. ALMEIDA LEA et al. Peso ao Nascer, classe social e mortalidade infantil em Ribeirão Preto, São Paulo. Cadernos de Saúde Pública, Rio de Janeiro, v.8, n.2, p.190-198, Abr-Jun, 1992.

3. ALMEIDA MF. Mortalidade neonatal em Santo André. São Paulo, 1994. 140 p. Tese de Doutoramento - Faculdade de Saúde Pública da USP.

4. ALMEIDA MF \& NOVAES MHD. Mortalidade neonatal: estudo das associaçães entre fatores de risco materno-infantil e assistência ao parto e recém-nascido. In: V Congresso Brasileiro de Saúde Coletiva/ V Congresso Paulista de Saúde Pública. ABRASCO/APSP/FSP/USP. Anais. Sistemas de informações em saúde. 1997. P. 107.

5. ALVARENGA AT. Investigação interdisciplinar em mortalidade materna: contribuição da abordagem sociológica. Série Investigacão em Saúde da Mulher. Crianca e Adolescente. São Paulo, n.2, p. 189-95, 1992.

6. ALVARENGA AT. Caracterizacão das relacóes existentes entre condicöes de classe, assistência à saúde e perfil de mortalidade materna. São Paulo, 1994. (Relatório final - CNPq -FSP/USP).

7. ALVARENGA AT. 0 conceito de risco na área materno-infantil: consideracöes téricas, metodológicas e de aplicacão. São Paulo, 1984. Tese de Doutoramento - Faculdade de Saúde Pública da USP.

8. ALVARENGA AT. Contribuicão ao estudo das relacões entre status socio-econômico-familiar e saúde materna. São Paulo, 1978. Dissertação de Mestrado. Faculdade de Saúde Pública da USP .

9. ARNTZEN A, et al. Is the higher postneonatal mortality in lower social status groups due to SIDA? Acta Paedriatr. 1995. v. 84, n.2. p. 188-92.

10. BARBIERI MA, et al. Saúde perinatal em Ribeirão Preto, São Paulo, Brasil. A questão do método. Cadernos de Saúde Pública. Rio de Janeiro, v. 5, n.4, p. 376-387. Out/Dez., 1989.

11. BARBIERI MA. Saúde materno infantil e classe social. Alguns aspectos do período neonatal da mãe e do recém-nascido. Tese de Livre Docência. Faculdade de Medicina da Universidade de São Paulo. Ribeirão Preto, São Paulo, 1985.

12. BARVAZIAN AP, BEHAR M. Bajo peso de nacimiento, un gran problema mundial. Revista Sueca AMBIO. v. VII. n. 4. Ginebra. 1978. p. 31-37.

13. BARROS FC, VICTORA CG. Saúde materno-infantil em Pelotas, Rio Grande do Sul. Brasil, 19821993: uma década de transição. Cadernos de Saúde Pública. V. 12. Supl. 1. 1996. Rio de janeiro. 1996. p. 93.

14. BARROS MBA. A utilização do conceito de classe social nos estudos dos perfiz epidemiológicos: uma proposta. Revista de Saúde Pública, v.20, n.4. São Paulo, 1986; p. 269-273. 
15. BARATA RB, et al. Equidade e saúde: contribuições da epidemiologia. Série Epidemiológica I. ABRASCO/FIOCRUZ. Rio de Janeiro, 1997. p. 256.

16. BARTLEY $M$, et al. Birth weight and later socioeconomic disadvantage: evidence from the 1958: british cohort study. B.M.J. 1994, Dec. V.3, n. 309 (6967), p. 1475-8.

17. BERTAGNON JRD. Recém-nascido pequeno para idade gestacional: algumas caracteristicas Epidemiológicas. São Paulo, 1991, p.157. Dissertação de Mestrado. Faculdade de Saúde Pública da USP

18. BELLIZZI ALM. Características da Mortalidade infantil na coorte de nascimento de 1992 do Município de Niterói/RJ. In: V Congresso Brasileiro de Saúde Coletiva. Anais. Epidemiologia. 1997. p. 287

19. BESSA AM et al. Mortalidade neonatal e baixo peso ao nascer no município de Belo Horizonte, 1995. In: III Congresso Brasileiro/II Congresso Ibero-Americano/I Congresso Latino-Americano. Anais. Estudos de Mortalidade. (1190). Salvador, Bahia, Brasil, 24 a 28 de Abril, 1995. p. 309.

20. BERQUÒ E. Brasil: um caso exemplar: anticoncepcão e parto cirúrgico, à espera de uma ação exemplar. NEPO/UNICAMP. p. 1993. (Mimeo)

21. BOLTANSKI L. Prime education et morale de classe. Paris, Mouton, 1969. (Cahiers du Centre de Sociologie Europeenne, 5). Apud: ALVARENGA AT. Contribuição ao estudo das relacões entre status socio-econômico-familiar e saúde materna. São Paulo, 1978. Dissertação de Mestrado. Faculdade de Saúde Pública da USP. p. 163.

22. BOLZÁN A, et al. Factores d riesgo de retardo de crescimiento intrauterino ey prematurez en los municipios de la Provincia de Buenos Aires, Argentina. Revista Chilena de Pediatria. V.71, n. 3 ; mayo-jun. 2000 , p. 255-62

23. BREILH J. Reprodução social e investigação em saúde coletiva. In: CZERESNIA, C. D. Epidemiologia: teoria e objeto. HUCITEC-ABRASCO. São Paulo, 1989.

24. BRONFMAN M, TUIRÁN R. La desigualdad ante la muerte: classes sociales y mortalidad en la niñez. Cadernos Médicos Sociales, v.29, n.30, p. 53-57, 1984. Apud: SOLLA JJPS. Problemas e limites da utilização do conceito de classe social em investigação epidemiológica: uma revisão crítica da literatura. Cadernos de Saúde Pública, Rio de Janeiro, v.12, n.2, p. 207-216, Abr-Jun, 1996.

25. BRUGHA R, KEVANY J. Determinants of nutrition status children in the eastern region of Ghana. J. Trop. Pediatr. 1994, Oct. V.40, n.5, p. 307-11.

26. BUSS P, LABRA ME. Saúde e Desigualdade: o caso do Brasil. In: Sistema de Saúde: continuidade e mudanças. Editora HUCITEC. São Paulo, 1990, p. 62-101.

27. CAETANO R et al. Os nascidos vivos no HUPE/UERJ: dois anos após a implantação do SINASC. In: V Congresso Brasileiro de Saúde Coletiva/V Congresso Paulista de Saúde Pública. ABRASCO/APSP/FSP/USP. Anais. Comunicação coordenada. 1997, p. 130-131.

28. CALDEIRA JRC. Classes Sociais e Estrutura Social. Revista FIPES. São Luís/MA. v. 4 n.1 p. 91-101; jan./jun., 1989.

29. CENTER FOR DISEASE CONTROL AND PREVENTION. Epi Info. Versão 6.04. A Word Processing. Database and Statistic Program for Public Health. Atlanta, 1997.

30. CEESAY SM et al. Effects on birth weight and perinatal mortality of maternal dietary supplements in rural Gambia: 5 year randomised controlled trial. B. M. J. v. 315 , Sept. 1997. P. 786-790 
31. CENTRO LATINO AMERICANO DE PERINATOLOGIA E DESENVOLVIMENTO

HUMANO - CLAP. Edicão Salud Perinatal. Boletin do CLAP. Montevidéo, p. 179, 1988.

32. CONTER $V$ et al. Weigth growth in infants born to mothers who smoked during pregnancy. Boletin Medicina Perinatal, v. 310, n. 6982, p. 768-771, Mar., 1995.

33. COHEN SE. Biosocial factors in erly infancy as predictors of competence who were born prematurely. J. Dev. Behav. Pedratr. 1995, Feb. V. 16, n. 1, p. 36-41

34. DELGADO M. Recall bias in a case-control study of low birth weight. J. Clin. Epidemiol. 1995, Sep., v.48, n.9, p. 1133-40.

35. DUPAS G. Economia global e exclusão social. Editora Paz e Terra. São Paulo, 1999, p. 219.

36. EVER-HADANI $P$, et al. Breast feeding in Israel: maternal factors associated with choice and duration. J. Epidemiol. Comunity Health. 1994, Jun., v.48, n.3, p. 281-5.

37. FAWER CL, et al. Influence of perinatal, development factors on cognitive abilites of preterm children without major impairments ar 5 years. Development Unit.; Departament of Paediatrics, Lausanne. Early Hum Dev. 2 Ouct. V. 2, n.43, 1995. P 151-64.

38. FIGUEIREDO GM, et al. Classificação social em inquérito populacional: região metropolitana de São Paulo, 1989/1990. In: III Congresso Brasileiro/ II Congresso Ibero-Americano/ I Latino-Americano de Epidemiologia. Anais. Salvador, Bahia, Brasil; abril 1995, p. 48

39. FOIX-L'HÉLIAS L, BLONDEL B. Changes in risk factors of preterm delivery in France between 1981 and 1995. Paediatric and Perinatal Epidemiology, v. 14, n.4, out. 2000, p. 314-323;

40. FUNDAÇÃO INSTITUTO BRASILEIRO DE GEOGRAFIA E ESTATÍSTICA - IBGE. Sistema SIDRA, 1997. (WWW. Sidra.ibge.gov.br/cgi-bin/prtabl).

41. FUNDAÇAO OSVALDO CRUZ (FIOCRUZ). Mortalidade perinatal e neonatal no Brasil. Boletim TEMA-RADIS, n. 17, fevereiro 1999. P. 6-17

42. FUNDO DAS NAÇÕES UNIDAS PARA A INFÂNCIA. A infância brasileira nos anos 90. UNICEF, 1998. Brasília, p. 169.

43. FUNDO DAS NAÇÕES UNIDAS PARA A INFÂNCIA. Situação Mundial da Infância. UNICEF, 1991. P. 73.

44. GUERRA UA, et al. Mortalidade infantil neonatal e pós-neonatal na área de risco (AR) do Distrito Sanitário (DS) Noroeste de Belo Horizonte. In: III Congresso Brasileiro/ II Congresso IberoAmericano/ I Latino-Americano de Epidemiologia. Anais. Salvador, Bahia, Brasil; abril 1995, p. 5.

45. GUERREIRO JV, et al. Diagnóstico do atendimento obstétrico e perinatal no Estado da Paraiba, 1999 Revista Saúde Para Debate. Série Divulgacão; n. 20, Dez. 2000. Rio de Janeiro. P. 67-76.

46. GUIMARÃES MJ, et al. Fatores de risco associados a mortalidade neonatal: Recife-1994. In: III Congresso Brasileiro/ II Congresso Ibero-Americano/ I Latino-Americano de Epidemiologia. Anais. Salvador, Bahia, Brasil; abril 1995, p. 301

47. HEMMINKI E, GISSLER M. Births by younger and mothers in a population with late and regulated childbearing: Finland, 1991. Acta Obstet. Gynecol., 1996, Jan. v. 75 , n.1. p. 19-27. 
48. HIRVE SS, GANATRA BR. Determination of low birth weight: a comunity based prospective cohort study. Indian. Pediat. 1994, Oct., v.31, n.10, p. 1221-5.

49. HILLE ET, et al. School performance at nine years of age very premature and very low birth weight infants: Perinatal risk factors and predictors at five years of age.

Journal Pediatrics. 1994, Sep., v. 123, n.3, p. 426-34.

50. HOPKINS K. Are Brazilian women really choosing to deliver by cesarian? Social Science \& Medicine. V.51, n.5, september, $2000 ;$ p. 725-740.

51. INSTITUTO DE DESENVOLVIMENTO MUNICIPAL E ESTADUAL DA PARAÍBA IDEME. Anuário Estatístico. 1995. João Pessoa. Editora União.

52. INSTITUTO DE PESQUISA ECONÔMICA APLICADA - IPEA. Relatório sobre o Desenvolvimento humano no Brasil. PNUD, 1996. (www:unap.org.br).

53. KLIEGMAN,R.M. Neonatal technology, perinatal survival, social consequences, and perinatal paradox. Am. J. Public. Health. 1995, Jul. v.85, n.7, p. 909-13.

54. KOIFMAN, S. Social causes of low birth weight. National Center for Health Statistics. Hyattsville, MD; n. 20782. USA. 1995.

55. KRAMER MS et al. Body proportionaly and head and length "sparing" in growth-retarded neonates: a critical reapraisal. Pediatrics $1989 ;$ v. 84, n.4; p. 717-723

56. KUHN TS. A estrutura das revoluções cientificas. Ed. Perspectiva, São Paulo; 1975.

57. LAURELL AC. A saúde-doença como processo social. In: NUNES ED. Medicina Social: aspectos históricos e teóricos. (Textos n.3). Editora Global. São Paulo, 1993. p. 133-158.

58. LAURENTI R et al. Estatísticas de Saúde. São Paulo. EDU/EDUSP, 1985.

59. LAURENTI R et al. Transição demográfica e transição epidemiológica. Congresso Brasileiro de Epidemiologia. Anais, UNICAMP, Campinas/SP, 1990.

60. LIRA L. ISABEL M. Factores de riesgo para el desarrolo psicomotor del lactante de nivel socioeconomico bajo. Revista Chilena de Pediatria. 1994, Ene.-Feb. , v. 65, n.1, p. 21-7.

61. LOMBARDI $\mathrm{C}$ et all. Operacionalização do conceito de classe social em estudos epidemiológicos. Revista de Saúde Pública, São Paulo, v.22, n.2 p.253-265, 1988.

62. MARX C \& ENGELS F. O capital. México. Ed. Fundo de Cultura Econômica. $3^{\text {in }}$ edição, 1978. V.3, p 17-818. Apud: CALDEIRA JRC. Classes sociais e estrutura social. Revista FIPES. São Luís, v.4, n.1, p.91-101; jan.-jun., 1989

63. MENDONÇA HMN. Pobreza e sub-emprego no Nordeste do Brasil. Recife, SUDENE, 1991. 35-49 p. II edição. Série III

64. MENEZES AMB et al. Mortalidade perinatal em duas coortes de base populacional no sul do Brasil: tendências e diferenciais. Cadernos de Saúde Pública, São Paulo. v.12 (supl. 1); p. 33-41 1996.

65. MENEZES AMB et al. Fatores de risco para mortalidade perinatal em Pelotas/RS. In: III Congresso Brasileiro/ II Congresso Ibero-Americano/ I Congresso Latino-Americano de Epidemiologia. Anais. Salvador, Bahia, Brasil, abril 1995, p. 5 
66. MINISTÉRIO DA SAÚDE. Centro Brasileiro de Classificação de Doenças OMS/USP/PAS-OMS) O sistema de informação sobre nascidos vivos - SINASC. Série Divulgação, n.7. São Paulo, 1995

67. MINISTÉRIO DA SAÚDE. Portaria GM n. 2.816 de 28.05.1998. Brasília, 1998.

68. MINISTÉRIO DA SAÚDE. (www:saude.gov.br/datasuslindicadores de saúdel).

69. MONTEIRO CA, et al. A distribuição do peso ao nascer no Município de São Paulo. Revista de Saúde Pública, v.12, n.2, p. 161-172, Jun., 1980.

70. MONTEIRO CA. Velhos e Novos Males da Saúde no Brasil: a evolucão do país e de suas doencas. Editora HUCITEC. NUPENS/USP. 1995. p. 359.

71. MONTEIRO CA, et al. Tendência secular do baixo peso ao nascer na cidade de São Paulo (1984-1996). Revista de Saúde Pública, v. 34, n.6 (supl.), São Paulo, Dez. 2000.

72. MORAIS EN, et al. Momento e frequência das visitas de pré-natal: repercussões sobre os nascimentos pré-termo. Revista Brasileira de Gineco-obstetricia; Jan.-fev. 1998, v.20, n.1; p. 25-32.

73. NARAYAN $\mathrm{H}$, et al. Pregnancy after fifty: profile and pregnancy outcome in a series of elderly multigravidae. Eur. J. Obstet. Gynecol. Reprod. Biol. 1992, Oct., v. 47, n.1, p. 47-51

74. NATIONAL CENTER FOR HEALTH STATISTICS. Center for desease control and prevention, Hyattsville, MD. Journal Reseach Social Medicine. United States, v. 88, n.1, p.611-615, Nov., 1995.

75. NAUFEL HG. Crescimento fetal, peso ao nascer e avaliação clínica da idade gestacional do recém-nascido: estudo crítico da literatura. Dissertação de Mestrado. Faculdade de Saúde Pública - Universidade de São Paulo. 1998, p. 142.

76. NEUMANN NA. Cobertura, qualidade e eqüidade da atenção pré-natal e ao parto, segundo a forma de pagamento destes serviços, em Criciúma/SC. Tese de Doutorado. Faculdade de Saúde Pública/USP. São Paulo, 2000, p. 66.

77. NÓBREGA FJ de. Características antropométricas do recém-nascido e estudo dealgumas variáveis maternas nas Capitais e Regiões Brasileiras. Antropometria do recém-nascido. Serviço de Informação. Nestlé. 1989, p. 197.

78. NOTZON FC. International differences in the use of obstetric intervention. Journal of American Medical Association - JAMA; June 27 1990; v. 263, n. 24; p. 3286-91.

79. NOVAES HMD. Mortalidade neonatal e avaliação da qualidade da atenção ao parto e ao recém-nascido no município de São Paulo. Tese de Livre-docência. Faculdade de medicina da Universidade de São Paulo. p. 118

80. OLINTO MTA. Determinantes da desnutrição infantil em populações de baixa renda: um estudo de análise hierarquizada. Cadernos de Saúde Pública. Rio de Janeiro, 1993, v.9, Supl. 1, p. 7-13.

81. OLIVEIRA F. O elo perdido: classe e identidade de classe. Editora Brasiliense, 1987. p. 134.

82. PALMER BD. Velhas posiç̋̃es/novas necessidades: história, classe e metanarrativa marxista. p. 74-83. In: Wood EM \& FOSTER JB. Em defesa da história: maxismo e pós-modernismo. Editor Jorge Zahar. Rio de Janeiro, 1999. p. 216. 
83. PARKER J, et al. Associations between measures of socioeconomic status and low birth wiegth, small for gestacional age, and premature delivery in the United States. Ann. Epidemiol. 1994, Jul., v.4, n.4, p. 271-8.

84. PECK MN. The importance of childhood socio-economic group for adult health. Soc. Sci. Med. 1994, Aug., v.39, n.4. p. 553-62.

85. PINTO VG. Soluç̃es econômicas para a pobreza. Revista Brasileira Escolar. V. 3; n. 3/4, São Paulo, 1994. p. 99-109.

86. POULANTZAS N. Poder político e classes sociais do estado capitalista. Editora Portucalense; v. 1, 1971. Apud: CALDEIRA JR. Categorias de classes sociais e estrutura social. Revista FIPES. São Luís; v.4, n.1, p. 91-101; jan./jun., 1989.

87. RAMIREZ-ZEDINA $M$ et al. La atención prenatal en la ciudad de Tijuana, México Revista Panamericana de Salud Pública, v.7, n.2; feb. 2000, 97-101 p.

88. RODRIGUEZ, et al. Low birth weight in Spain associated with socioeconomic factors. J. Epidemiol. Community Health. 1995, Feb., v.49, n. 1. p. 38-42.

89. SANTANA PR. Baixo peso ao nascer e alguns dos seus determinantes no Município de João Pessoa/PB. Recife, 1990. Dissertação de Mestrado. Universidade Federal de Pernambuco. 1993, p87.

90. SCHIRMER J et al. Assistência pré-natal: manual técnico. $3^{a}$ Edição. Brasil: Ministério da Saúde Secretaria de Políticas Públicas. Brasília/DF, 2000, 66 p.

91. SCHLAEPFER L, INFANTE C. Bajo peso al nacer en México: evidencias a partir de una encuesta retrospectiva a nivel nacional. Bol. Med. Hospital Infant. 1995, Mar., v.52, n.3, p. 168-79

92. SECRETARIA MUNICIPAL DE SAÚDE DE JOÃO PESSOA - Setor de Planejamento Municipal de Saúde. Setor de Planejamento. João Pessoa/PB, 1997.

93. SEIDMAN DS, et al. The effects of high parity and socio economic status on obstetric and neonatal outcome. Arch. Grnecol. Obstet. 1991, n.249, n.3, p.119-27.

94. SEN A. Desigualdade reexaminada. Editora Record. Rio de janeiro/São Paulo, 2001, p. 301

95. SILVA AAM, et al. Associação entre idade, classe social e hábito de fumar maternos com peso ao nascer. Revista de Saúde Pública, São Paulo, v.26, n.3, p. 150-154, 1992.

96. SILVA RA O lugar do biológico e do social na mortalidade perinatal. Tese. Doutorado. Faculdade de Saúde Pública/Universidade de São Paulo. 1991, p 120.

97. SILVA RA, ALVARENGA AT. Consideraçðes teórico-metodológicas acerca da constituição da perinatologia como área de conhecimento e da morbimortalidade perinatal como objeto de investigação de natureza interdisciplinar. Revista Brasileira de Crescimento e Desenvolvimento Humano. São Paulo, v.5, n.1/2, p. 1- 16, 1995.

98. SILVA AA et al. Tendências do baixo peso ao nascer em Ribeirão Preto/SP. In: V Congresso Brasileiro de Saúde Coletiva/ V Congresso Paulista de Saúde Pública. ABRASCO/APSP/FSP/USP. Anais. Estudos populacionais. 1997, p. 332.

99. SIL VEIRA RMG. 500 anos de uma cidadania excludente. (Resenha apresentada no curso de formação de educadores para os Direitos Humanos. UFPB. João Pessoa, 2000. (s.n.t). 
100. SINGER, P. Globalização e desemprego: diagnóstico e alternativas. Editora Contexto, $4^{*}$ edição. São Paulo, 2000. 139 p.

101. SINGER P. Um mapa da exclusão social no Brasil. In: PASSETE E. Modernidade: globalização e Exclusão. Editora Imaginário. São Paulo, 1996. p.75-113.

102. SLIWIANY R, et al. Qualidade de vida em Curitiba. In: V Congresso Brasileiro de Saúde Coletiva / V Congresso Paulista de Saúde Pública. ABRASCO/ APSP/FSP/USP. Anais. Comunicação Coordenada 1997. p. 7-8.

103. SIQUEIRA AAF, et al. Morbidade e mortalidade maternas, qualidade da assistência e estrutura social: estudo da região sul do município de São Paulo, Brasil. Parte II. Morbidade Materna. São Paulo, 1993. (Relatório final, apresentado à FAPESP).

104. SOCIEDADE CIVIL BEM-ESTAR FAMILIAR NO BRASIL - BENFAM. Pesquisa nacional sobre demografia e saúde, PNDS-1996. Março, 1997, p. 103-124

105. SOLLA JJPS. Problemas e limites da utilização do conceito de classe social em investigação epidemiológica: uma revisão crítica da literatura. Cadernos de Saúde Pública. Rio de Janeiro, v.12, n.2, p. 207-216, Abr-Jun, 1996.

106. SOUSA PO, et al. A desigualdade sócio-espacial da produção da morte por homicídio em Manaus. In: III Congresso Brasileiro/ II Congresso Ibero-Americano/ I Latino-Americano de Epidemiologia. Anais. Salvador, Bahia, Brasil; abril 1995, p. 301

107. SPINILLO A, et al. Perinatal factors and 2 year minor neurodevelopmental impairment in low birth weight infants. Biol. Neonate. 1995, v.67, n. 1, p. 39-46.

108. STRACHAN DP, et al. Incidence and prognosis of asthma and wheezing illness from early childhood to age 33 in a national British cohort. British Journal Medicine.

May, v. 312, n.7041,1996. p. 1195-9.

109. SUNG JF, et al. maternal factors, birthweight, and racial differences in infant mortality: a Georgia population-based study. J. Natl. Med. Assoc. 1994, Jun., v.86, n.6, p. 437-43.

110. TANAKA ACd'A. Maternidade: dilema entre nascimento e morte. HUCITEC-ABRASCO. São Paulo-Rio de Janeiro. 1995, 107 p.

111. TANAKA ACd'A. Estudo da magnitude da mortalidade materna em 15 cidades brasileiras. São Paulo. UNICEF, 1999.

112. TELXEIRA-LIMA R. Estudo comparativo entre fontes primárias e secundárias dos dados de peso e comprimento ao nascer no Município de João Pessoa/PB-1993. Dissertação de Mestrado. Universidade Federal de Pernambuco. Recife, 1995, p. 108.

113. TEIXEIRA-LIMA R, et al. É o baixo peso ao nascer um problema de saúde pública no Brasil?. Revista de Paulista de Pediatria. Março, 1998. P. 35-39.

114. TERUEL J, et al. Investigación interamericana de mortalidad de la niñez; peso ao nacer en la región de Ribeirão Preto, São Paulo, Brasil. Boletin de la Oficina Sanitária Panamericana. Washington, v. 79, n.2, p. $139-145,1995$.

115. VALDEZ T, GOMARIZ S. Brasil - Mulheres Latino-Americanas em dados. Brasil. Madri. Instituto de la mujer. Santiago, Chile. Faculdade latinoamericana de Ciências Sociales. FLACSO, 1993. 
116. VALÉRIO RT, et al. Sobre peso em escolares adolescentes de distintos grupos sócio-econômicos. In: V Congresso Paulista de Saúde Pública. ABRASCO/ APSP/FSP/USP. Anais. Comunicação Coordenada. 1997. p. 7-8.

117. VERAS A, et al. Mortalidade neonatal em hospital - um estudo de fatores de risco. In: III Congresso Brasileiro/ II Congresso Ibero-Americano/I Congresso Latino Americano de Epidemiologia. Anais. Estudos de mortalidade (1161). Salvador/Bahia, Brasil, 24 a 28 de abril, 1995. p. 302.

118. VICTORA A. A pastoral da criança e a saúde materno-infantil em dois municípios do Maranhão. Brasília. UNICEF, 1991, $37 \mathrm{p}$.

119. WALLACE HM, et al. Community study of infant mortality in San Diego County. J. Trop. Pediatric. 1994, Jun. v.40, n.3, p. 172-8.

120. WILCOX MA, et al. The effects of social deprivation on birthweight, excluding physiological and pathological efects. Br. J. Obstet. Gynecol. 1995, Nov. v.102, n.11, p. 918-24.

121. WILDSCHUT HI, et al. Are sociodemografic factors preditive of preterm birth ? A reappraisal of the 1995 British Perinatal Mortality Survey. Britanic Journal Obstectric-Gynecologyc. 1997. Jan, n. 104 , v.1. p. $57-63$.

122. YANAKIEW, M. América Latina pode passar por novo teste. FOLHA de SÃO PAULO/Conjuntura. Domingo, 21 de maio de 2000. P. B3.

123. ZISMAN, M. Nordeste pigmeu: uma geração ameaçada. Recife: CEDIP, 1987. 68 p.; p. 123-131. 
8. ANEXOS 
Anexo 1- Instrumento de coleta de dados.

Anexo 2- Esquema de operacionalização de nova pequena burguesia, pequena burguesia tradicional, proletariado típico e sub-proletariado.

Anexo 3- Esquema de operacionalização da nova pequena burguesia, proletariado não típico, proletariado típico e subproletariado.

Anexo 4- Esquema de operacionalização da burguesia, nova pequena burguesia e pequena burguesia tradicional.

Anexo 5 - Testes estatísticos referentes à caracterização sócio-demográfica familiar. (Tópico 4.1, tabelas 4 a 9).

Anexo 6 - Testes estatísticos referentes à assistência pré-natal. (Tópico 4.2, tabelas 10 a 11)

Anexo 7 - Testes estatísticos referentes à assistência ao parto e ao recém-nascido. (Tópico 4.3, tabelas 12 a 18;

Anexo 8 - Testes estatísticos referentes às relações existentes entre As condições de nascimento e desigualdade social. (Tópico 4.3, tabelas 19, 21 e 22) 
Anexo 1 - Instrumento de coleta de dados.

UNIVERSIDADE FEDERAL DA PARAÍBA

CENTRO DE CIÊNCIAS DA SAÚDE

NÚCLEO DE ESTUDOS EM SAÚdE COLETIVA
UNIVERSIDADE DE SÃO PAULO

FACULDADE DE SAÚdE PÚBLICA

DEPT $^{\circ}$ SAÚDE MATERNO-INFANTIL

\title{
CONDIÇÕES DE NASCIMENTO E DESIGUALDADE SOCIAL
}

\author{
F O R M U L Á R I O

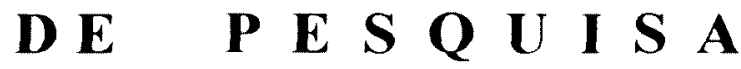

Nome do Entrevistador:

P.S.: Informações confidenciais. Sigilo pessoal garantido. Divulgação em dados globais 


\section{PARTE A - CARACTERIZAÇÃO SÓCIO-ECONÔMICO-DEMOGRÁFICA:}

1. $N^{\circ}$ de ordem:

1. Data:<smiles>[CH]1[CH]C[CH]1</smiles>

$\mathrm{N}^{\circ}$ do prontuário:

3. [MATERN ] Maternidade:

1 = Cândida Vargas

()$\left.^{2}\right)$

$4=$ Edson Ramalho

$7=$ H. Guarnição

2 = São Vicente

$5=$ Santa Maria

$8=$ Lady Center.

$$
\begin{aligned}
& 3=\text { Frei Damião } \\
& 6=H . \text { Universitário }
\end{aligned}
$$

4. [SETOR]: ( ) 1 = Público. 2 = Conveniado/Privado.

Nome da parturiente:

Endereço:

Bairro: Área:

5- [MAEIDAD] Idade: ( ) anos completos.

6- [ESTCIV] Estado civil no momento do parto: ( ).

1= solteira $\quad 2$ = casada 3 = viúva $\quad 4=$ desquitada $\quad 5=$ divorciada.

7- [TPUNIAO ] Tipo de União Conjugal no momento do parto: ( ).

$1=$ legal $\quad 2=$ livre $\quad 3=$ sem união conj. $\quad 4=$ ignora

8- [TMOUNI ] Tempo de união: ( ) [anos completos].

DETALHAR CASOS ESPECIAIS EM RELAÇÃO AOS ITENS 5, 6 e 7.

(Obs.: Destacar no registro da fala da mãe como se definiu aquela situação matrimonial).

9- [CHEFEF ] Chefe de familia: ( ) 1=Homem 2=Mulher 3=Outros.

10- [ SUSTAF ] Principal responsável pelo "sustento" da familia: ( ) $1=$ Homem $\quad 2=$ Mulher $3=$ Outros. 
Caso $\mathrm{n}^{\circ}$

CASO A PARTURIENTE NÃO SEJA A PRÓPRIA RESPONSÁVEL PELO "SUSTENTO" DA FAMILIA OU POR SI MESMA INDAGAR SE:

11- [PARTUR] A parturiente é: ( ).

$1=$ co-responsável pelo sustento da familia

$2=$ dependente

$3=$ outro (especificar)

4= não se aplica (Part. = Resp.)

Composição e caracterização da familia ou grupo de convivência no momento do parto:

\begin{tabular}{|c|c|c|c|c|c|c|c|c|}
\hline$N^{*}$ & Nome & $\begin{array}{c}\text { Rel. c/ } \\
\text { Resp. }\end{array}$ & $\begin{array}{c}\text { ldade } \\
\text { Anos/ } \\
\text { Meses }\end{array}$ & $\begin{array}{c}\text { Sexo } \\
1-M \\
2-\text { F }\end{array}$ & $\begin{array}{c}\text { Escolaridade } \\
\text { Série } \\
\text { Completada + } \\
\text { Tipo Curso (*) }\end{array}$ & $\begin{array}{c}\text { C/Ocu } \\
\text { p } \\
\text { Rem. } \\
\text { 1-Sim } \\
\text { 2-Não } \\
\text { 3-lgn. }\end{array}$ & $\begin{array}{c}\text { Renda } \\
\text { (Ocup./Outros } \\
\text { R\$) }\end{array}$ & Obs.(***) \\
\hline 1 & & $\begin{array}{c}\left({ }^{*}\right) \\
\text { Resp. }\end{array}$ & & & & & & \\
\hline 2 & & Part./Resp. & & & & & & \\
\hline 3 & & RN & & & & & & \\
\hline 4 & & & & & & & & \\
\hline 5 & & & & & & & & \\
\hline 6 & & & & & & & & \\
\hline 7 & & & & & & & & \\
\hline 8 & & & & & & & & \\
\hline 9 & & & & & & & & \\
\hline 10 & & & & & & & & \\
\hline 11 & & & & & & & & \\
\hline 12 & & & & & & & & \\
\hline
\end{tabular}

( " ) NO CASO DA PARTURIENTE SER O RESPONSAVEL PELO 'SUSTENTO" DA FAMILIA OU POR SI MESMA ANOTAR SOMENTE A PARTIR DA LINHA

2 REGISTRANDO ESSA CONDIÇÃO NA COLUNA 'RELAÇÃO COM O RESPONSÁVEL' COM O TERMO "RESP'

(*) ESPECIFICAR TIPO DE CURSO QUANDO SE TRATAR DE CURSO TÉCNICO UNIVERSITARIO OU ASSEMELHADO

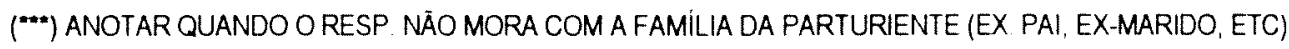

12- [SEGURO] Tipo de seguro social declarado pela parturiente: ( )

$1=$ SUS

4= Convênio Empresa

$6=$ Outro (esp.):
2= Particular

$3=$ IPEP

$5=$ Tem seguro social, mas ignora o tipo. 
Caso no

13- [SEGURO]Tipo de seguro social usado na presente internação: $(\quad)$
$1=$ SUS
$2=$ Particular
$3=$ IPEP
4= Convênio Empresa
$5=$ Não sabe informar.
$6=$ Outro (esp.):

OCUPAÇĀO PRINCIPAL DA PARTURIENTE E DO RESPONSÁVEL PELO "SUSTENTO DA FAMILIA" :

Descrever detalhadamente a OCUPAÇÃO PRINCIPAL (remunerada) no momento do parto ou a última, nos casos de desemprego, aposentadoria, licença, afastamento:

14. [ OCUPPP ] DA PARTURIENTE: ( ).

$\begin{array}{lll}1=\text { Dona de casa. } & 2=\text { Doméstica. } & 3=\text { Pequena comerciante. } \\ 4=\text { Servente. } & 5=\text { Copeira. } & 6=\text { Funcionária pública. } \\ 7=\text { Operária. } & 8=\text { Professora. } & 9=\text { Agricultora. } \\ 10=\text { Caixa Executiva. } & 11=\text { Serviços Gerais } & 12=\text { Nunca trabalhou. } \quad 13=\text { Outras } .\end{array}$

15. [OCUPPR ] DO RESPONSÁVEL pela familia: ( ).

$\begin{array}{lll}1=\text { Comerciante. } & 2=\text { Professor. } & 3=\text { Agricultor } \\ 4=\text { Servente } & 5=\text { Mestre de obras. } & 6=\text { Funcionário público. } \\ 7=\text { Vendedor. } & 8=\text { Gerente de loja. } & 9=\text { Operário. } \\ 10=\text { Taxista } & 12=\text { Serviços Gerais. } & 13=\text { Nunca trabalhou. } \\ 14=\text { Outras } & 15=\text { Ignora. } & \end{array}$

DESCREVER CASOS DE TRABALHO PRECÁRIO ("BICOS") /ATIVIDADES "MARGINAIS"/ E ASSEMELHADOS. Assinalar se regular, esporádica ou não desenvolve

a. DA PARTUTIENTE:（） regular （）esporádica （） não desenvolve

b) DO RESP.FAM.: ( ) regular ( ) esporádica ( ) não desenvolve

Possui Carteira Assinada ou Contrato de Trabalho?

16. [CATRABP] PARTURIENTE: ( ) 1=Sim 2= Não $3=$ não trabalha

Se 1 (sim): especificar: a) para atividade principal ( ).

b) para trabalho precário/marginal ( ).

17. [CATRABR] RESPONSÁVEL: ( ) 1=Sim 2=Não 3=Não trabalha $4=P=R \quad 5=$ Ignora.

Se sim (especificar): a) para atividade principal ( ).

b) para trabalho precário/marginal ( ).

Caso no 
Para o desempenho da ocupação (em relação à atividade principal) foi exigido algum CURSO ESPECIAL do tipo técnico, universitário, de especialização, pós-graduação, etc ?

18. [CURSOP] PARTURIENTE: $(\quad) . \quad 1=\operatorname{sim} \quad 2=$ não $\quad 3=$ não trabalha.

Se $1(\operatorname{sim})$, esp.:

19. [ CURSOR] RESP. FAM.:（） 1=sim $2=$ não $3=$ não trabalha $4=$ n.a. $(P=R) \quad 5=$ ignora.

Se 1 (sim) , esp.:

Qual o NOME do estabelecimento em que trabalha(va), o RAMO de atividade (agric., pecuária, extração, ind., com., serviços, etc. ) e o LOCAL de instalação da unidade econômica:

20. [RAMOCP ] PARTURIENTE: $(\quad)$.

1=Agricultura. 2=Pecuária. 3=Extração. $\quad 4=$ =ndústria. $\quad$ 5=Comércio. 6=Serviços. Nome estabelecimento:

21. [ LOCALP] Local: domicilio ? ( ). $\quad 1=\operatorname{sim} \quad 2=$ não $\quad 3=$ não trabalha.

Se $1(\operatorname{sim})$, esp.:

22. [RAMOCR] RESP. FAM.:( ).

1=Agricultura. 2=Pecuária. 3=Extração. 4=Indústria. 5=Comércio. 6=Serviços. Nome estabelecimento:

23. [ LOCALR] Local: domicilio ?（） 1=sim 2=não $3=$ não trabalha $\quad 4=n$. a.(P=R) $5=$ ignora. Se 1 (sim), esp. : 
Caso no

SOBRE A SITUAÇÃO DE TRABALHO da parturiente e do resp. pela familia:

(CIRCULAR O NÚMERO DA CATEGORIA MENCIONADA)

24. [ SITTRP ]

25. [ SITTRR]

\begin{tabular}{|c|c|c|}
\hline & PART. & RESP.FAM. \\
\hline -Trabalho por conta própria, sem empregado & 1 & 1 \\
\hline $\begin{array}{l}\text {-Trabalho por conta propria, com empregado } \\
\text { (remunerado) }\end{array}$ & 2 & 2 \\
\hline $\begin{array}{l}\text {-Trabalho por conta própria, com "empregado" (não } \\
\text { remunerado) }\end{array}$ & 3 & 3 \\
\hline $\begin{array}{l}\text {-Trabalho por conta propria, com empregado } \\
\text { remunerado e não remunerado }\end{array}$ & 4 & 4 \\
\hline $\begin{array}{l}\text {-Sócio ou dono de firma: } \\
\begin{array}{l}\text { ( )comercial; ( ) industrial; ( )bancária; } \\
\left.\text { ( ) serviços; ( ) outra ( }{ }^{*}\right)\end{array}\end{array}$ & 5 & 5 \\
\hline $\begin{array}{l}\text {-Empregado de firma: ( )comercial; ( )industrial; } \\
\text { ( )bancária; ( ) serviços; ( )outra (*) }\end{array}$ & 6 & 6 \\
\hline $\begin{array}{l}\text {-Funcionário gov., instituto ou outra organização } \\
\text { para-estatal. }\end{array}$ & 7 & 7 \\
\hline -Outra, (esp.) & 8 & 8 \\
\hline -Não se aplica ( Part. = Resp) & $-\cdots$ & 9 \\
\hline - Ignora & 10 & 10 \\
\hline
\end{tabular}


Caso no

OBSERVAÇŌES ESPECIFICAS EM RELAÇÃO AS CATEGORIAS DO ITEM ANTERIOR. PARA QUALQUER DAS CATEGORIAS (PROPRIETÁRIOS EIOU EMPREGADOS) : esSa situação de trabalho é permanente (estável) ou variável (instável) ? Especificar o tempo e demais detalhes relevantes:

26. [ TIPSITP ]. PARTURIENTE: ( ) 1= permanente $2=$ variável $3=n a ̃ o$ trabalha.

27. [TEMPOP ]. Tempo: ( ) EM ANOS.

Detalhes relevantes:

28. [TIPSITR]. RESP. FAM.: ( ) 1= permanente $2=$ variável $3=$ não trab. $4=P=R \quad$ 5=ignora. 29. [TEMPOR ]Tempo: ( ) EM ANOS.

Detalhes relevantes:

SOMENTE PARA AS CATEGORIAS 1, 2, 3, 4 e 5 (PROPRIETÁRIOS) : "emprega" ou não trabalhadores familiares ou agregados ? Especificar o $n^{\circ} \mathrm{e}$ demais detalhes relevantes:

30. [ PEMPRG ]. PARTURIENTE: ( ).

1= "emprega" $2=$ não "emprega" $3=$ não trab. $4=$ n. a. (não prop.)

31. [ NEMPASL] ] № de assalariados : ( ） 32. [NEMPNAS ] № de não assal. : ( ).

Especificar detalhes relevantes :

33. [REMPRG]. RESP. FAM:: ( )

1= "emprega" $2=$ não "emprega" $3=$ não trab. $4=$ n. a. (P=R) 5=n.a.(não prop.) 6=Ignora.

34. [ NEMPASL ]. No de assalariados : ( ). 35. [NEMPNAS ]. № de não assal. ( ). Especificar detalhes relevantes : 
SOMENTE PARA AS CATEGORIAS 2, 3,4 e 5 (PROPRIETÁRIOS COM EMPREGADOS) : só administra ou também auxilia os empregados nas tarefas para as quais foram contratados e remunerados?:

\section{6. [ SADMITP]. PARTURIENTE: ( ).}

$1=$ só $\mathrm{adm} . \quad 2=$ aux. tarefas $3=$ não trab. $4=$ n. a. (não empregadora)

Por que?

Se auxilia, como?

37. [SADMITR]. RESP. FAM:: ( ).

1= só adm. $2=$ aux. Tarefas $3=$ não trab. $\quad 4=$ n. a. $(\tilde{N}$ emp. $) \quad 5=(P=R) \quad 6=$ ignora.

Por que?

Se auxilia, como?

SOMENTE NAS CATEGORIAS 1, 2, 3, 4 e 5 (PROPRIETÁRIOS): possui ou è locador de bens, tais como: local da unidade económica (não residência), maquinas, veiculos, etc.?

38. [BENSP]. PARTURIENTE: $(\quad) . \quad 1=\operatorname{sim} 2=$ não $3=$ não trab. $4=$ n. a. (não prop.) Especificar do que è proprietário ou locador :

39. [ [BENSR ]. RESP. FAM. :( ) 1 $1=\operatorname{sim} 2=$ não $3=$ não trab. $4=$ n.a.(não prop.) $5=(P=R) \quad 6=$ ignora

Por que?

Especificar do que è proprietário ou locador: 
Caso no

OBS: APLICA-SE PARA TODAS AS CATEGORIAS PROPRIETÁRIOS + EMPREGADOS + PROFISSIONAIS LIBERAIS.

Número de pessoas trabalhando PARA ou SOB suas ordens:

\begin{tabular}{|l|c|c|}
\multicolumn{2}{|c|}{$40 .[$ PORDP] ( ) 41.[PORDR]( ) } \\
\hline - nenhuma & PARTUR. & RESP. FAM. \\
\hline - sim, 1 & 01 & 01 \\
\hline - sim, 2 a 5 & 02 & 02 \\
\hline - sim, 6 a 10 & 03 & 03 \\
\hline - sim, 11 a 20 & 04 & 04 \\
\hline - sim, 21 a 49 & 05 & 05 \\
\hline - sim, 50 a 99 & 06 & 06 \\
\hline - sim, 100 ou mais & 07 & 07 \\
\hline - não exercia nenhum tipo de atividade econômica & 09 & 08 \\
\hline $\begin{array}{l}\text { (assinalar a que tipo de atividade se refere): } \\
\text { ( ) regular ( ) precária ( ) marginal ( ) não trabalha }\end{array}$ & & 09 \\
\hline - não se aplica (P = Resp.) & -- & 10 \\
\hline - Ignora & $\cdots$ & 11 \\
\hline
\end{tabular}

OBSERVAÇŐES ESPECÍFICAS PARA CATEGORIAS ACIMA : Especificar se essa situação de ter, ou não, esse no. de pessoas trabalhando no momento do parto é permanente ou instável:

42. [ SITUAP ]. PARTURIENTE: ( ).

1=permanente $2=$ =instável $3=$ não trabalha $\quad 4=n$. a. (não tem subordinados)

43. [TEMPP ]. Precise em tempo: ( ) EM ANOS.

Descreva detalhes relevantes

44. [ SITUAR]. RESP. FAM : ( ).

1=permanente $2=$ instável $3=$ não trabalha $\quad 4=(P=R) \quad 5=n$. a. (não tem sub.) $6=$ Ignora.

45. [ TEMPR ]. Precise o tempo: ( ) EM ANOS.

Descreva detalhes relevantes: 
CONDIÇÃO DE ATIVIDADE da parturiente e do responsável, por ocasião do parto, em relação às diferentes formas de ocupação:

46. [CATIVP]（） 47. [CATIVR]（）

\begin{tabular}{|l|c|c|}
\hline & PARTUR. & RESP. FAM. \\
\hline - trabalhando de "forma regular" & 1 & 1 \\
\hline - em licença & 2 & 3 \\
\hline - afastada (0) & 3 & 4 \\
\hline - desempregada (0) & 5 & 5 \\
\hline - subempregada (0) & 6 & 6 \\
\hline - aposentada (0) senso lato & 7 & 7 \\
\hline - aposentada (0) por doença & 8 & 8 \\
\hline - na caixa & 9 & 9 \\
\hline - incapacitada (0) para o trabalho & 10 & 10 \\
\hline - inativa (0) & 11 & 11 \\
\hline - desocupada (0) & 12 & 12 \\
\hline - com atividade "marginal" & 13 & 13 \\
\hline - estudante & 14 & 14 \\
\hline - dona de casa & 15 & 15 \\
\hline - outra & -- & 17 \\
\hline - (Part. = Resp.) & 17 & 2 \\
\hline - ignora & & 17 \\
\hline
\end{tabular}

OBSERVAÇÕES ESPECÍFICAS PARA CATEGORIAS DA QUESTÃO ACIMA.

48. [ TEMPOP ].Tempo da presente condição (PARTURIENTE) : ( ) EM MESESIANOS.

- OBS: TIPO/MOTIVO dessa condição :

49. [ TEMPOR ]Tempo da presente condição (RESP. FAMILIA): ( ） EM MESESIANOS.

- OBS: TIPO/MOTIVO dessa condição 
NOS CASOS DE: DESEMPREGO/SUBEMPREGO/DESOCUPAÇÃO/AFASTAMENTO DO EMPREGO SEM REMUNERAÇÃO DA PARTURIENTE E/OU RESPONSÁVEL PELA FAMILIA (QUESTÃO NO 14) "SONDAR" COMO SOBREVIVE NESTA CONDIÇÃO:

50. [SOBREVP]A PARTURIENTE: ( ).

$1=$ Depende do marido

4=Recebe ajuda de outros familiares

$6=$ Dependente do padrasto.
2=Depende dos pais $3=$ Recebe ajuda do sogro/(a) 5=Recebe ajuda de outros.

$7=$ Não de aplica. (trab.)

51. [SOBREVR]: O RESP. FAM.: ( ).

$1=$ Depende da mulher

4=Recebe ajuda de outros familiares 6=Não se aplica (trab.).
2=Depende dos pais $3=$ Recebe ajuda do sogro/(a) $5=$ Recebe ajuda de outros.

7=Dependente da mãe.

52. [ SOBREVF] A FAMILIA COMO UM TODO: ( ).

$1=$ Ajuda dos irmãos.

4=Recebe ajuda do sogro(a).

$7=$ Casal + Sogro(a) .
2=Ajuda da mãe. $3=$ Trabalho do casal.

$5=$ Sogra + irmãos. $6=$ Todos trabalham.

8=Mãe + irmãos. $\quad 9=$ Depende do padrasto.

\begin{tabular}{|l|}
\hline OBSERVAÇÕES EM RELAÇÃO AOS DADOS DE RENDANOCUPAÇÃO \\
\hline 1) Grau de confiabilidade ("precisão") das informações prestadas: \\
\hline \\
\hline 2) Outras obs. adicionais relevantes: \\
\hline \\
\hline
\end{tabular}




\section{PARTE B - CARACTERIZAÇÃO CLÍNICO-OBSTÉTRICO- EPIDEMIOLÓGICA DA PARTURIENTE.}

1. [ NGRAV ].Quantas vezes a Sra. ficou grávida? $\mathrm{N}^{\circ}:(\quad)$.

NO CASO DA PRESENTE GESTAÇÃO SER A ÚNICA PASSAR DIRETO PI QUESTÃO 19. CASO CONTRÁRIO PREENCHER QUADRO ABAIXO.

História das gestações :

\begin{tabular}{|c|c|c|c|c|c|c|c|c|c|c|}
\hline$N^{0}$ & $\begin{array}{l}\text { Data do } \\
\text { Término }\end{array}$ & $\begin{array}{l}\text { Nascido: } \\
1=\text { vivo } \\
2=\text { morto }\end{array}$ & $\begin{array}{l}\text { Peso } \\
\text { (g) }\end{array}$ & $\begin{array}{l}\text { Aborto } \\
\text { 1. AE } \\
\text { 2. } A P \\
\text { 3. AT } \\
\text { 4. n.inf }\end{array}$ & $\begin{array}{l}\text { Duração } \\
\text { de } \\
\text { Gravid. } \\
\left(^{\star}\right)\end{array}$ & $\begin{array}{l}\text { Tipo } \\
\text { de Parto }\end{array}$ & $\begin{array}{l}\text { Se ainda } \\
\text { vivo, } \\
\text { Idade }\end{array}$ & $\begin{array}{l}\text { Se já } \\
\text { morreu, } \\
\text { Idade }\end{array}$ & $\begin{array}{l}\text { Local } \\
\text { de } \\
\text { Nasc. }\end{array}$ & $\begin{array}{l}\text { Sexo } \\
\text { 1. M. } \\
\text { 2. F. }\end{array}$ \\
\hline 1 & & & & & & & & & & \\
\hline 2 & & & & & & & & & & \\
\hline 3 & & & & & & & & & & \\
\hline 4 & & & & & & & & & & \\
\hline 5 & & & & & & & & & & \\
\hline 6 & & & & & & & & & & \\
\hline 7 & & & & & & & & & & \\
\hline 8 & & & & & & & & & & \\
\hline 9 & & & & & & & & & & \\
\hline 10 & & & & & & & & & & \\
\hline & & & & & & & & & & \\
\hline
\end{tabular}

(*) Referir em semanas ou meses a gravidez/ aborto. 
Caso $n^{\circ}$

Atividade Sexual ( especificar a idade em anos completos).

2. [IDMEN]. Idade da menarca:

3. [ ATIVSX]. Inicio de relação sexual:

4. [1GEST ] . Idade da primeira gestação: ( )

5. [FPNATAL]. Fez pré-natal durante essa ultima gestação?（） 1= sim 2=não

6. [MOTIVO ]. Se não fez pré-natal descrever o motivo: ( ).

$1=$ Não quis fazer $\quad 2=0$ pinião de $3^{\circ} \mathrm{s} . \quad 3=$ Não sabia que existia

4=Morava longe $\quad 5=$ Não tinha dinheiro/transporte. $6=$ Considerava desnecessário.

COMO NÃO FEZ PRÉ-NATAL PASSAR PARA A Q. 13.

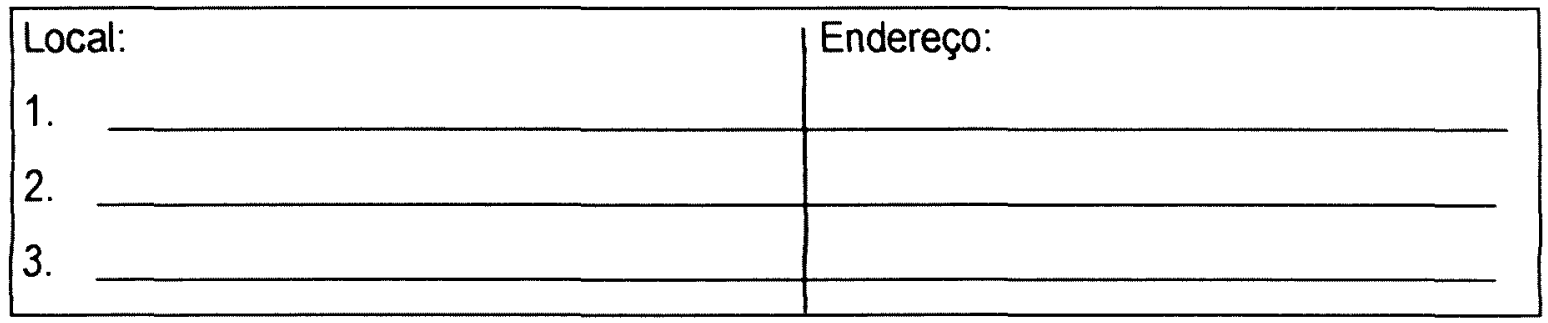

Se fez, especificar número de consultas no pré-natal por mês/ trimestre:

7. [CONS1TR]（） 8. [CONS2TR]（） 9.[CONS3TR]（）

\begin{tabular}{|ccc|}
\hline $1^{\circ}$ Trimestre & $2^{\circ}$ Trimestre & $3^{\circ}$ Trimestre \\
\hline $1^{\circ}$ mês: & $1^{\circ}$ mês: & $1^{\circ}$ mês: \\
\hline $2^{\circ}$ mês: & $2^{\circ}$ mês: & $2^{\circ}$ mês: \\
\hline $3^{\circ}$ mês: & $3^{\circ}$ mês: & $3^{\circ}$ mês: \\
\hline
\end{tabular}

CASO NÃO SAIBA INFORMAR POR TRIMESTRE, ESPECIFICAR N TOTAL DE CONSULTAS DE PRÉ-NATAL:

10. [TTCONS ] Número: ( ) $0=$ Ignora.

11. [ 1MESCPN]Especificar o mês da 1a. consulta: ( ) $0=$ Ignora.

12. [ UMESCPN ]. Especificar o último mês da consulta do pré-natal: ( ） 0 =Ignora.

13. [PESOPGT]. Peso pré- gestacional (g): ( . ) ).

14. [ESTAT]. Estatura $(\mathrm{Cm}):($ )

15. [ GANPESO ]. Ganho de peso durante a gestação $(\mathrm{Kg}):($. ) 
Caso $n^{\circ}$

16. [ INTERC ]. Houve intercorrências durante a gravidez ? ( ) 1=sim 2= não.

Se 1 (sim), descrever tipo e orientação médica.

17. [TIPO]. ( )

$1=$ Anemia

4=Mialgia

$7=$ Infencção urinária.
2=Infecção respiratória.

$5=$ Sifilis

8=Pressão alta.
3=Ameaça de aborto.

$6=$ Hemorragia.

$9=$ Outras.

$1^{\circ}$ tipo:

Orientação:

$2^{\circ}$ Tipo:

Orientação:

$3^{\circ}$ Tipo:

Orientação:

(no caso de maior $\mathrm{n}^{\circ}$ de intercorrências, usar o verso da folha)

18. [ FUMAG ]. Fumou durante a gravidez ? ( ）. 1=sim 2=não Se 1 (sim).

19. [NCGRR]. Quantos cigarros/dia:（） 20. [TEMPO] Por quanto tempo ?（） dias. OBS.: descrever casos de variação do uso de fumo durante a gravidez:

21. [FPASS ] . Existiu fumantes com os quais manteve contato diário durante a gravidez (fumante passiva)? ( ). $1=\operatorname{sim} \quad 2=$ não $\quad 3=$ ignora.

Se 1 ( Sim)

22. [NPESS ]. $N^{\circ}$ de pessoas: $(\quad)$

23. [NCIGRR]. Total aproximado de cigarros/dia: ( ) $0=$ Ignora.

Na sua opinião, o hábito de fumar durante a gravidez pode prejudicar a saúde da mãe e da criança?

24. [FPREJM]. Da mãe: $(\quad) \quad 1=\operatorname{Sim} \quad 2=$ Não $\quad 3=$ ignora.

Por que?

25. [FPREJC]. Da criança: $(\quad) \quad 1=\operatorname{Sim} 2=$ Não $3=$ Ignora.

Por que? 
Caso $n^{\circ}$

SE A MULHER NÃO É FUMANTE PASSAR PARA QUESTÃO 28.

E no seu caso, a Sra. acha que o cigarro chegou a ser prejudicial, nessa gestação, para a sua saúde e a de seu filho?

26. [ PREJGP]. Da parturiente: ( ～～$\quad 1=\operatorname{Sim} \quad 2=$ Não $\quad 3=\operatorname{Ignora} \quad 4=n$. a. (não fuma) Por que:

27. [ PREJGR ]. Do recém-nascido: ( ， 1=Sim $2=$ Não $3=$ ignora $\quad 4=n$. a. (não fuma) Por que:

28. [BEBEU] . Ingeriu alguma bebida alcoólica durante esta gestação ? $1=\operatorname{Sim} 2=$ Não.

29. [ SFREQ]. Se 1 (sim), em que freqüência bebeu: ( ).

1=Diariamente $\quad 2=$ Freqüentemente $\quad 3=$ Ocasionalmente $\quad 3=$ Não se aplica

30. [ QUANT]. A quantidade que bebeu é, na sua opinião: ( ).
$1=$ pequena
$2=$ moderada $3=$ grande
$4=$ não se aplica

31. [TIPOS ] .Tipos de bebidas consumidas durante esta gravidez: ( ).
$1=$ Cerveja
$2=$ Alcool
$3=$ Vinho
$5=$ Cerveja + Álcool
$6=$ Vinho + Cerveja $\quad 7=$ Refrigerante + Cerveja
$8=$ Outras.

4=Refrigerante

Na sua opinião a bebida alcoólica durante a gravidez pode prejudicar a saúde da mãe e da criança?

32. [ BPPREJG]. Da mãe: ( ） 1=sim 2=não 3=ignora

Por que:

33. [ BPPREJC]. Da criança: ( ) 1=sim $2=$ não $3=$ ignora

Por que: 


\section{PARTE D - INFORMAÇÕES CLÍNICO-EPIDEMIOLÓGICAS DO NEONATO: (PRONTUÁRIO MÉDICO HOSPITALAR)}

55. [ CONDNA]. Condição ao nascer:

( ) 1= natimorto $2=$ vivo

56. [SEXO ]. Sexo:

( ) 1= Masculino 2= Feminino

57. [ PESON]. Peso ao nascer (g):

58. [ CCOMPN]. Comprimento ao nascer $(\mathrm{Cm})$ :

59. [ PRCEF ]. Perímetro cefálico (Cm):

60. [PRTOR]. Perimetro torácico $(\mathrm{Cm})$ :

61. [ APGAR1]. Apgar no $1^{\circ}$ minuto:

62. [ APGAR5]. Apgar no $5^{\circ}$ minuto:

63. [ CAPURR]. Idade gestacional, em samansas. (CAPURRO): ( )

64. [ ADEQUA]. Adequação peso/ idade gestacional: ( ). 1= Adequado 2= Pequeno 3=Grande.

65. [ CINTER]. A criança permaneceu internada: ( ) $1=\operatorname{sim} 2=$ não

66. [DOENC]. Doenças do recém-nascido durante a internação hospitalar (até $07^{\circ}$ dia de vida): (CLAP)

$1=$ Nenhuma

2= Membrana hialina

$3=$ Síndrome aspirativa

4= Outras sindromes respiratórias

$5=$ Apneas

6= Trauma mecânico
$7=$ Hemorragia

$8=$ Hiperbilirrubinemia

$9=$ Anomalias congênitas

$10=$ Sindromes neurológicas

$11=$ Infecções

$12=$ Outras:(especificar): 
Caso $n^{\circ}$

Sumário descritivo das doenças do recém-nascido e condição clinica, enquanto estiver internado no hospital nos sete primeiros dias:

\begin{tabular}{|l|l|}
\hline $1^{\circ}$ Dia & \\
\hline & \\
\hline & \\
\hline $2^{\circ} \mathrm{Dia}$ & \\
\hline & \\
\hline & \\
\hline $3^{\circ} \mathrm{Dia}$ & \\
\hline & \\
\hline & \\
\hline $4^{\circ} \mathrm{Dia}$ & \\
\hline & \\
\hline & \\
\hline & \\
\hline $5^{\circ} \mathrm{Dia}$ & \\
\hline & \\
\hline & \\
\hline & \\
\hline $6^{\circ} \mathrm{Dia}$ & \\
\hline & \\
\hline & \\
\hline & \\
\hline $7^{\circ} \mathrm{Dia}$ & \\
\hline & \\
\hline & \\
\hline
\end{tabular}


67. [EXAMESC]. Principais exames complementares: $(\quad)$

$\begin{array}{lll}1=\text { V.D.R.L. } & 2=\text { Tipagem sangüinea } & 3=\text { Hemograma } \\ 4=\text { Urina } & 5=\text { Sorológico } & 6=\text { E.C.G. } \quad 7=\text { Outros } .\end{array}$

\begin{tabular}{|c|c|c|c|c|}
\hline & Doenças & Tipo de exame & Data & Resultados \\
\hline \multicolumn{5}{|l|}{$1^{\circ}$ Diaf } \\
\hline & & & & \\
\hline \multirow{2}{*}{\multicolumn{5}{|c|}{$2^{\circ}$ Dia }} \\
\hline & & & & \\
\hline & & & & \\
\hline & & & & \\
\hline \multicolumn{5}{|l|}{$3^{\circ}$ Diaf } \\
\hline & & & & \\
\hline & & & & \\
\hline \multicolumn{5}{|l|}{$4^{\circ} \mathrm{Dia}$} \\
\hline & & & & \\
\hline \multirow{2}{*}{\multicolumn{5}{|c|}{$5^{\circ}$ Dia }} \\
\hline & & & & \\
\hline & & & & \\
\hline & & & & \\
\hline \multicolumn{5}{|l|}{$6^{\circ} \mathrm{Dia}$} \\
\hline & & & & \\
\hline \multirow{2}{*}{\multicolumn{5}{|c|}{$7^{\circ}$ Dia: }} \\
\hline & & & & \\
\hline & & & & \\
\hline & & & & \\
\hline
\end{tabular}

Conduta médica (em relação às doenças diagnosticadas):

\begin{tabular}{|l|l|}
\hline Doenças: & Condutas: \\
\hline & \\
\hline & \\
\hline & \\
\hline & \\
\hline & \\
\hline & \\
\hline & \\
\hline & \\
\hline
\end{tabular}


68. [ CONDATR]. Condições de alta hospitalar do recém-nascido: ( ).

$1=$ Alta em boas condições:

2= Alta em condições regulares:

$3=$ Alta por óbito:

Horas: Horas: Horas: Dias:

4= Sem informação.

Dias: Dias:

69. [ CONDATP ] .Condições de alta da parturiente: ( ).

1= Alta em boas condições:

$2=$ Alta em condições regulares:

$3=$ Alta por óbito:

Horas: Horas: Dias: 4= Sem informação. Horas: Dias: Dias:

Outras informações consideradas importantes sobre o recém-nascido:

Outras informações consideradas importantes sobre a parturiente:

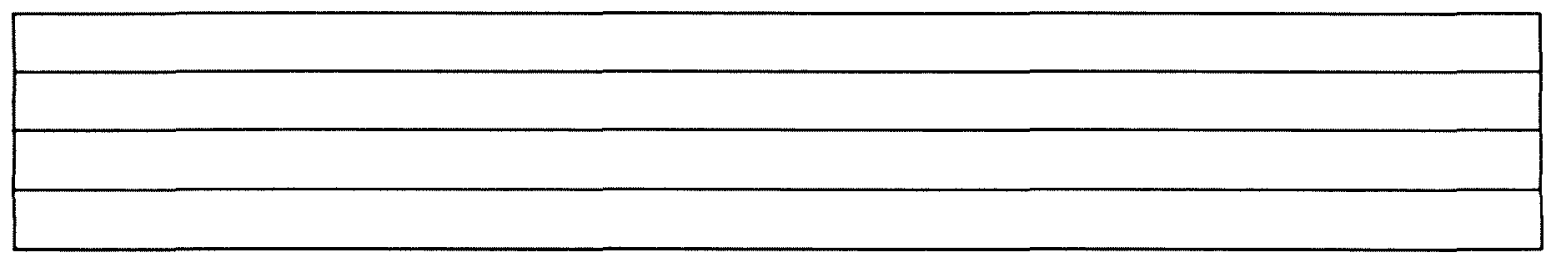


Anexo 2 - Esquema de operacionalização de nova burguesia, pequena burguesia tradicional, proletariado típico e subproletariado.

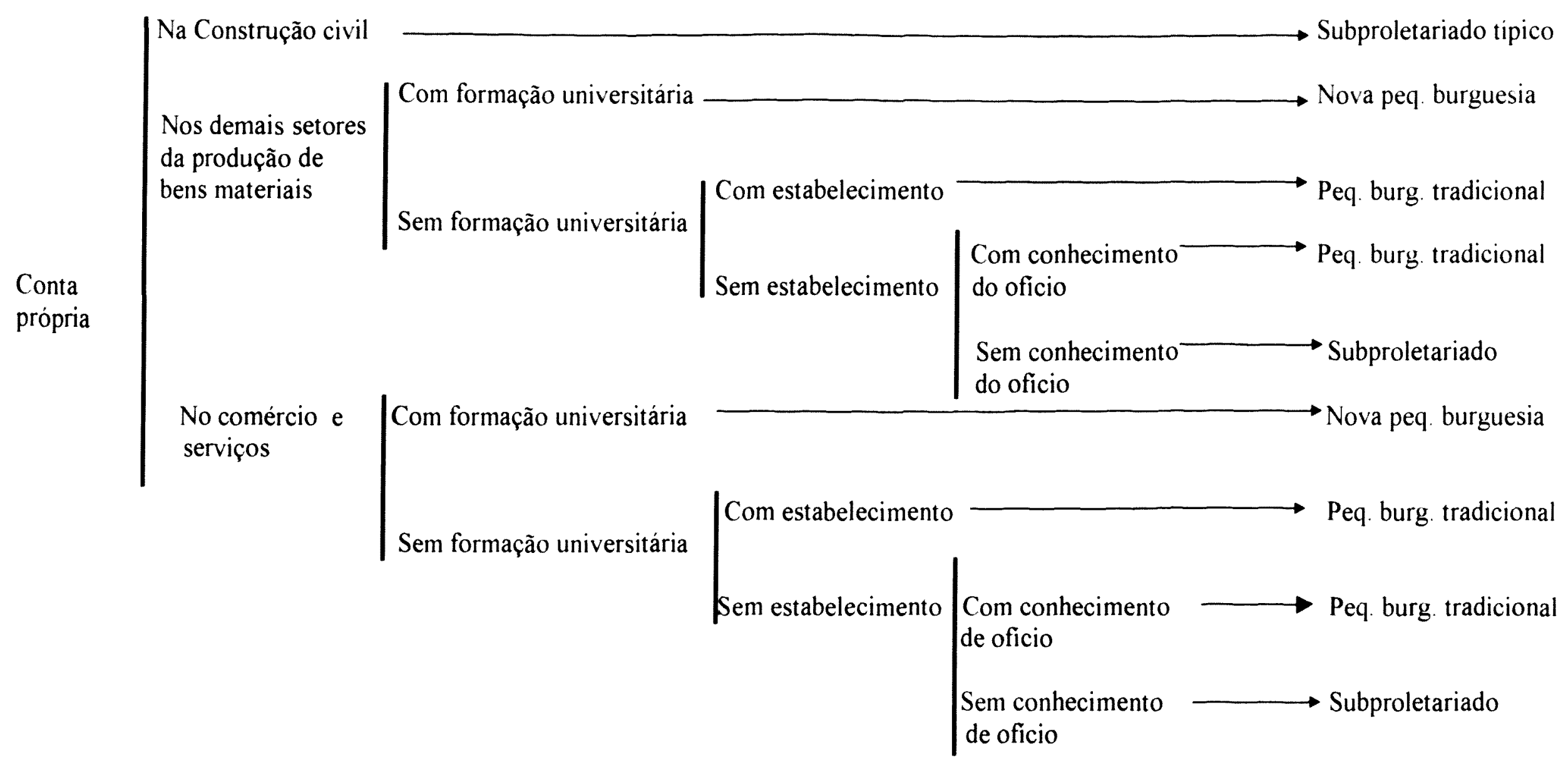


Anexo 3 - Esquema de operacionalização da nova pequena burguesia. proletariado não típico, proletariado tipico e subproletariado

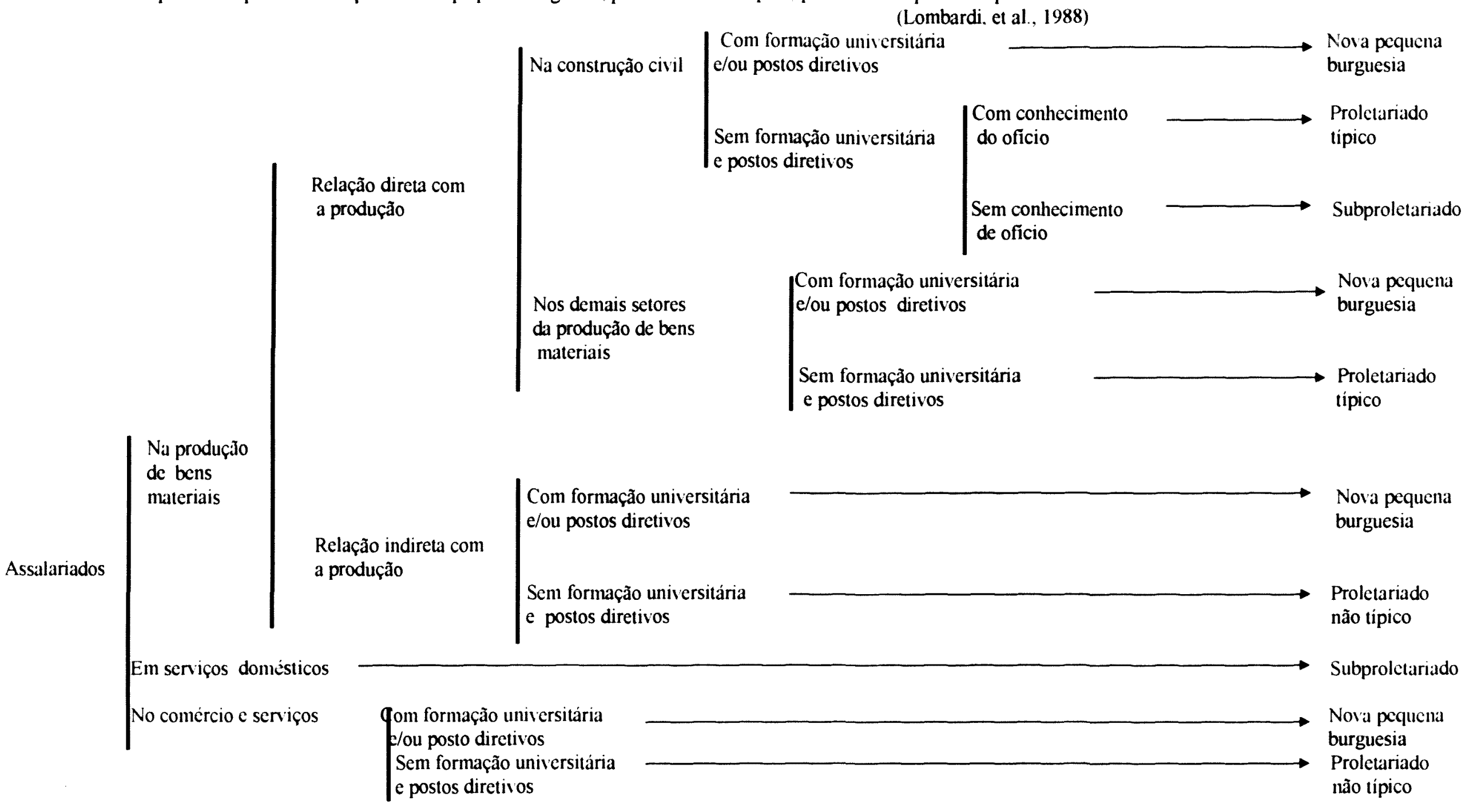


Anexo 4 - Esquema de operacionalização da burguesia, nova pequena burguesia e pequena burguesia tradicional.

(Lombardi, et al., 1988).

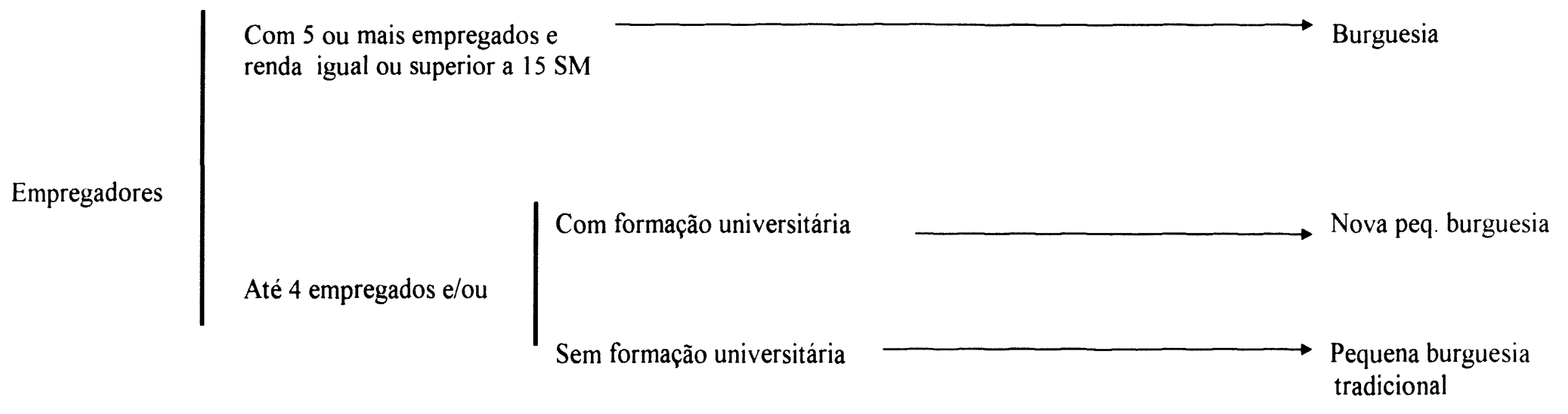


Anexo 5 - Testes estatísticos das tabelas 4 a 9, correspondentes ao item 4.1 - Caracterização da sócio-demográfica familiar

Tabela 4 - Distribuição dos recém-nascidos de baixo peso e não baixo peso, odds ratio, intervalo de confiança, segundo o tipo de famílias. João Pessoa/PB, 2000.

\begin{tabular}{c|c|c|c|c|c|c}
\hline Tipo de famílias & $\begin{array}{c}\text { Baixo } \\
\text { peso }\end{array}$ & $\begin{array}{c}\text { Não baixo } \\
\text { peso }\end{array}$ & OR & $\begin{array}{c}\text { Intervalo de } \\
\text { confiança }\end{array}$ & p & $\mathbf{x}^{\mathbf{2}}$ \\
\hline $\begin{array}{c}\text { Nuclear atípica } \\
\text { e vive só }\end{array}$ & 35 & 93 & 1,43 & $0,66-3,04$ & 0,4222 & 0,64 \\
\hline Nuclear típica & 42 & 142 & 1 & & & \\
\hline $\begin{array}{c}\text { Nuclear atípica } \\
\text { composta }\end{array}$ & 60 & 136 & 0,95 & $0,38-2,32$ & 0,9232 & 0,01 \\
\hline $\begin{array}{c}\text { Extensa típica } \\
\text { e atípica }\end{array}$ & 25 & 62 & 1,15 & $0,66-2,00$ & 0,5953 & 0,28 \\
\hline Total & 137 & $\mathbf{3 7 2}$ & & & & \\
\hline
\end{tabular}

Tabela 5 - Distribuição dos recém-nascidos de baixo peso e não baixo peso, odds ratio, intervalo de confiança, segundo o tipo de união conjugal das parturientes. João Pessoa/PB, 2000.

\begin{tabular}{c|c|c|c|c|c|c}
\hline $\begin{array}{c}\text { Tipo de união } \\
\text { conjugal }\end{array}$ & $\begin{array}{c}\text { Baixo } \\
\text { peso }\end{array}$ & $\begin{array}{c}\text { Não baixo } \\
\text { peso }\end{array}$ & OR & $\begin{array}{c}\text { Intervalo de } \\
\text { confiança }\end{array}$ & $\mathbf{p}$ & $\mathbf{x}^{\mathbf{2}}$ \\
\hline $\begin{array}{c}\text { Solteira/separada/ } \\
\text { viúva/desquitada* }\end{array}$ & 35 & 93 & 0,85 & $0,51-1,44$ & 0,5281 & 0,40 \\
\hline União Livre & 42 & 142 & 0,67 & $0,41-1,09$ & 0,0873 & 2,92 \\
\hline União legal & 60 & 136 & 1 & & & \\
\hline Total & 137 & 372 & & & & \\
\hline
\end{tabular}

(*) vivem sós. 
Tabela 6 - Distribuição dos recém-nascidos de baixo peso e não baixo peso, odds ratio, intervalo de confiança, segundo os responsáveis pelas famílias. João Pessoa/PB, 2000.

\begin{tabular}{|c|c|c|c|c|c|c|}
\hline $\begin{array}{l}\text { Responsável } \\
\text { Pela família }\end{array}$ & $\begin{array}{l}\text { Baixo } \\
\text { peso }\end{array}$ & $\begin{array}{c}\text { Nấ baixo } \\
\text { peso }\end{array}$ & OR & $\begin{array}{l}\text { Intervalo de } \\
\text { confianca }\end{array}$ & p & $x^{2}$ \\
\hline $\begin{array}{c}\text { Parturiente ou } \\
\text { parentes } \\
\text { assemelhados do sexo } \\
\text { feminino }\end{array}$ & 12 & 32 & 1,04 & $0,49-2,20$ & 0,9048 & 0,01 \\
\hline $\begin{array}{l}\text { Pai da parturiente ou } \\
\text { parentes } \\
\text { assemelhados do sexo } \\
\text { masculino }\end{array}$ & 20 & 55 & 0,99 & $0,54-1,79$ & 0,9114 & 0,01 \\
\hline $\begin{array}{l}\text { Marido ou } \\
\text { companheiro da } \\
\text { parturiente }\end{array}$ & 102 & 278 & 1 & & & \\
\hline $\begin{array}{c}\text { Outros familiares } \\
\text { da parturiente }\end{array}$ & 3 & 7 & 1,19 & $0,24-5,23$ & 0,8010 & 0,06 \\
\hline Total & 137 & 372 & & & & \\
\hline
\end{tabular}

Tabela 7 - Distribuição dos recém-nascidos de baixo peso e não baixo peso, odds ratio, intervalo de confiança, segundo a idade das parturientes no momento do parto. João Pessoa/PB, 2000.

\begin{tabular}{|c|c|c|c|c|c|c|}
\hline $\begin{array}{l}\text { Idade materna } \\
\text { (Em anos completos) }\end{array}$ & $\begin{array}{l}\text { Baixo } \\
\text { peso }\end{array}$ & \begin{tabular}{|c|} 
Não \\
Baixo peso \\
\end{tabular} & OR & $\begin{array}{c}\text { Intervalo de } \\
\text { confiança }\end{array}$ & p & $x^{2}$ \\
\hline $\begin{array}{r}<15 \\
15 \text { a } 19\end{array}$ & $\begin{array}{c}1 \\
42\end{array}$ & $\begin{array}{c}2 \\
93\end{array}$ & 1,24 & $0,78-1,97$ & 0,3382 & 0,92 \\
\hline$\frac{20 \times 24}{25 \times 29}$ & $\frac{45}{36}$ & 97 & 1 & & & \\
\hline 30 a 34 & 8 & 38 & 0,58 & $0,24-1,36$ & 0,1762 & 1,83 \\
\hline $\begin{array}{l}35 \text { a } 39 \\
40 e+\end{array}$ & $\begin{array}{l}4 \\
1\end{array}$ & $\begin{array}{r}14 \\
3\end{array}$ & 0,81 & $0,25-2,42$ & 0,6813 & 0,17 \\
\hline Total & 137 & 372 & & & & \\
\hline
\end{tabular}


Tabela 8 - Distribuição dos recém-nascidos de baixo peso e não baixo peso, odds ratio, intervalo de confiança, segundo a idade na primeira relação sexual. João Pessoa/PB, 2000.

\begin{tabular}{|c|c|c|c|c|c|c|}
\hline $\begin{array}{c}\text { Faixa Etária } \\
\text { (Em anos completos) }\end{array}$ & $\begin{array}{l}\text { Baixo } \\
\text { peso }\end{array}$ & \begin{tabular}{|c|}
$\begin{array}{c}\text { Não baixo } \\
\text { peso }\end{array}$ \\
\end{tabular} & OR & $\begin{array}{c}\text { Intervalo de } \\
\text { confianca }\end{array}$ & $\mathbf{p}$ & $x^{2}$ \\
\hline$<15$ & 14 & 54 & 0,83 & $0,35-1,95$ & 0,6462 & 0,21 \\
\hline 15 a 19 & 95 & 235 & 1,30 & $0,71-2,38$ & 0,3674 & 0,81 \\
\hline 20 a 24 & 19 & 61 & 1 & 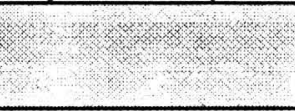 & 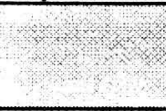 & 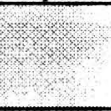 \\
\hline $25 e+$ & 9 & 22 & 1,31 & $0,47-3,65$ & 0,5671 & 0,33 \\
\hline Total & 137 & 372 & & & & \\
\hline
\end{tabular}

Tabela 9 - Distribuição dos recém-nascidos de baixo peso e não baixo peso, odds ratio, intervalo de confiança, segundo a paridade da mulher. João Pessoa/PB, 2000.

\begin{tabular}{|c|c|c|c|c|c|c|}
\hline $\begin{array}{l}\text { Faixa Etária } \\
\text { (Em anos completos) }\end{array}$ & $\begin{array}{l}\text { Baixo } \\
\text { peso }\end{array}$ & $\begin{array}{c}\text { Não baixo } \\
\text { peso }\end{array}$ & OR & $\begin{array}{c}\text { Intervalo de } \\
\text { confianca }\end{array}$ & $\mathbf{p}$ & $x^{2}$ \\
\hline Primipara & 74 & 161 & 1,53 & $1,00-2,35$ & 0,0382 & 4,29 \\
\hline Secundípara & 56 & 187 & 1 & (i. & & . \\
\hline Tercípara & 4 & 22 & 0,61 & $0,17-1,97$ & 0,3733 & 0,79 \\
\hline Grande multípara & 3 & 2 & 5,01 & $0,66-44,08$ & 0,0552 & 3,68 \\
\hline Total & 137 & 372 & & & & \\
\hline
\end{tabular}


Anexo 6 - Testes estatísticos das tabelas 10 a 11, correspondentes ao item 4.2 - Caracterização da assistência pré-natal

Tabela 10 - Distribuição dos recém-nascidos de baixo peso e não baixo peso, odds ratio, intervalo de confiança, segundo o número de consultas de pré-natal. João Pessoa/PB, 2000.

\begin{tabular}{c|c|c|c|c|c|c}
\hline $\begin{array}{c}\text { Número de } \\
\text { consultas de } \\
\text { pré-natal }\end{array}$ & $\begin{array}{c}\text { Baixo } \\
\text { peso }\end{array}$ & $\begin{array}{c}\text { Näo baixo } \\
\text { peso }\end{array}$ & OR & $\begin{array}{c}\text { Intervalo de } \\
\text { confianca }\end{array}$ & $\mathbf{p}$ & $x^{2}$ \\
\hline 1 a 4 & 21 & 51 & 1,07 & $0,58-1,97$ & 0,8103 & 0,06 \\
\hline $5 \mathrm{a} 8$ & 76 & 198 & 1 & & & \\
\hline $9 \mathrm{e}+$ & 18 & 78 & 0,60 & $0,32-1,11$ & 0,0821 & 3,02 \\
\hline $\begin{array}{c}\text { Nãa fez } \\
\text { Pré-natal }\end{array}$ & 22 & 45 & 1,27 & $0,69-2,35$ & 0,4091 & 0,68 \\
\hline Total & 137 & 372 & & & & \\
\hline
\end{tabular}

Tabela 11 - Distribuição dos recém-nascidos de baixo peso e não baixo peso segundo o número de consultas em relação ao trimestre de início do pré-natal. João Pessoa/PB, 2000.

\begin{tabular}{|c|c|c|c|c|c|c|c|c|}
\hline \multirow{2}{*}{$\begin{array}{c}\text { Grupos } \\
\text { estudados }\end{array}$} & \multirow{2}{*}{$\begin{array}{l}\text { Número de } \\
\text { consultas }\end{array}$} & \multicolumn{3}{|c|}{ Período da gravidez } & \multirow[b]{2}{*}{ OR } & \multirow{2}{*}{$\begin{array}{c}\text { Intervalo de } \\
\text { confianca }\end{array}$} & \multirow[b]{2}{*}{$\mathbf{p}$} & \multirow[b]{2}{*}{$x^{2}$} \\
\hline & & $\begin{array}{c}10 \\
\text { Trim } \\
\end{array}$ & $\begin{array}{l}2^{\circ} \\
\text { Irim }\end{array}$ & $\begin{array}{c}3^{\circ} \\
\text { Trim } \\
\end{array}$ & & & & \\
\hline \multirow{3}{*}{$\begin{array}{l}\text { Baixo } \\
\text { Peso }\end{array}$} & $1-4$ & 9 & 5 & 7 & 1,21 & $0,66-2,19$ & 0,5061 & 0,44 \\
\hline & $5-8$ & 46 & 13 & 17 & & & & \\
\hline & $9 \mathrm{e}+$ & 14 & 2 & 2 & & & & \\
\hline \multicolumn{2}{|c|}{ Sub-total } & 69 & 20 & 26 & & & & \\
\hline \multirow{4}{*}{$\begin{array}{l}\text { Não baixo } \\
\text { peso }\end{array}$} & $1-4$ & 9 & 20 & 22 & & & & \\
\hline & $5-8$ & 123 & 35 & 40 & 1 & & & \\
\hline & $9 e+$ & 76 & - & 2 & & & & \\
\hline & -total & 208 & 55 & 64 & & & & \\
\hline
\end{tabular}


Anexo 7 - Testes estatísticos das tabelas 12 a 18, correspondentes ao item 4.3 - Caracterização da assistência ao parto e ao recém-nascido.

Tabela 12 - Distribuição dos recém-nascidos de baixo peso e não baixo peso, odds ratio, intervalo de confiança, segundo o sexo. João Pessoa/PB, 2000.

\begin{tabular}{c|c|c|c|c|c|c}
\hline $\begin{array}{c}\text { Sexo do } \\
\text { Recém-nascido }\end{array}$ & $\begin{array}{c}\text { Baixo } \\
\text { peso }\end{array}$ & $\begin{array}{c}\text { Não baixo } \\
\text { peso }\end{array}$ & OR & $\begin{array}{c}\text { Intervalo de } \\
\text { confiança }\end{array}$ & $\mathbf{P}$ & $\boldsymbol{x}^{2}$ \\
\hline Masculino & 67 & 213 & 1 & & & \\
\hline Feminino & 70 & 159 & 0,71 & $0,47-1,08$ & 0,0932 & 2,82 \\
\hline Total & 137 & 372 & & & & \\
\hline
\end{tabular}

Tabela 13 - Distribuição dos recém-nascidos de baixo peso e não baixo peso, odds ratio, intervalo de confiança, segundo a condição de sobrevida. João Pessoa/PB, 2000.

\begin{tabular}{c|c|c|c|c|c|c}
\hline $\begin{array}{c}\text { Condição de } \\
\text { Sobrevida }\end{array}$ & $\begin{array}{c}\text { Baixo } \\
\text { peso }\end{array}$ & $\begin{array}{c}\text { Não baixo } \\
\text { peso }\end{array}$ & OR & $\begin{array}{c}\text { Intervalo de } \\
\text { confiança }\end{array}$ & $\mathbf{p}$ & $\mathbf{x}^{2}$ \\
\hline Óbito & 3 & 11 & 0,73 & $0,16-2,89$ & 0,6391 & 0,22 \\
\hline Sobrevida & 134 & 361 & 1 & & & \\
\hline Total & 137 & 372 & & & & \\
\hline
\end{tabular}

Tabela 14 - Distribuição dos recém-nascidos de baixo peso e não baixo peso segundo o tipo de serviço utilizado e tipo de parto das mulheres. João Pessoa/PB, 2000.

\begin{tabular}{|c|c|c|c|c|c|c|c|}
\hline \multirow{2}{*}{$\begin{array}{l}\text { Grupos } \\
\text { estudados }\end{array}$} & \multirow{2}{*}{$\begin{array}{l}\text { Tipos de } \\
\text { servigos }\end{array}$} & \multicolumn{2}{|c|}{ Tipo de parto } & \multirow[b]{2}{*}{ OR } & \multirow{2}{*}{$\begin{array}{l}\text { Intervalo de } \\
\text { confianga }\end{array}$} & \multirow[b]{2}{*}{ p } & \multirow[b]{2}{*}{$x^{2}$} \\
\hline & & Vaginal & Cescíreo & & & & \\
\hline $\begin{array}{l}\text { Baixo } \\
\text { Peso }\end{array}$ & \multirow[t]{2}{*}{ Público } & 70 & 58 & \multirow[t]{2}{*}{5,83} & \multirow[t]{2}{*}{$0,95-38,87$} & \multirow[t]{2}{*}{0,0590} & \multirow[t]{2}{*}{3,57} \\
\hline $\begin{array}{c}\text { Não baixo } \\
\text { peso }\end{array}$ & & 183 & 155 & & & & \\
\hline \multicolumn{2}{|c|}{ Sub-total } & 253 & 213 & & & & \\
\hline $\begin{array}{l}\text { Baixo } \\
\text { Peso } \\
\end{array}$ & \multirow[t]{2}{*}{ Privado* } & 5 & 4 & \multirow[t]{2}{*}{1} & & & \\
\hline $\begin{array}{c}\text { Não baixo } \\
\text { Peso }\end{array}$ & & 6 & 28 & & & & \\
\hline \multicolumn{2}{|c|}{ Sub-total } & 11 & 32 & & & & \\
\hline
\end{tabular}

${ }^{*}$ ) Incluídos nesta categoria os privado/conveniados. 
Tabela 17 - Distribuição dos recém-nascidos de baixo peso e não baixo peso, odds ratio, intervalo de confiança, segundo a adequação peso/idade gestacional. João Pessoa/PB, 2000.

\begin{tabular}{|c|c|c|c|c|c|c|}
\hline Adequação & $\begin{array}{l}\text { Baixo } \\
\text { peso }\end{array}$ & $\begin{array}{c}\text { Não baixo } \\
\text { peso }\end{array}$ & OR & $\begin{array}{c}\text { Intervalo de } \\
\text { confianca }\end{array}$ & $\mathbf{p}$ & $x^{2}$ \\
\hline PIG & 41 & 11 & 25,35 & $11,43-57,35$ & 0,000 & 108,52 \\
\hline Não PIG & 40 & 272 & 1 & & & \\
\hline Total & 137 & 372 & & & & \\
\hline
\end{tabular}

Tabela 18 - Distribuição dos recém-nascidos de baixo peso e não baixo peso, odds ratio, intervalo de confiança, segundo a internação hospitalar. João Pessoa/PB, 2000.

\begin{tabular}{|c|c|c|c|c|c|c|}
\hline Internaç̃o & $\begin{array}{l}\text { Baixo } \\
\text { peso }\end{array}$ & $\begin{array}{c}\text { Não baixo } \\
\text { peso }\end{array}$ & OR & $\begin{array}{c}\text { Intervalo de } \\
\text { confianca }\end{array}$ & p & $x^{2}$ \\
\hline $\mathrm{Sim}$ & 18 & 16 & 3,37 & $1,57-7,25$ & 0,0007 & 12,52 \\
\hline Năo & 119 & 356 & 1 & (x) & & \\
\hline Total & 137 & 372 & & & & \\
\hline
\end{tabular}


Anexo 8 - Testes estatísticos referentes às relações existentes entre As condições de nascimento e desigualdade social. (Tópico 4.4, tabelas 19, 21 e 22)

Tabela 19 - Distribuição dos recém-nascidos de baixo peso e não baixo peso, odds ratio, intervalo de confiança, segundo as categorias de classes sociais. João Pessoa/PB, 2000.

\begin{tabular}{c|c|c|c|c|c|c}
\hline $\begin{array}{c}\text { Categorias de } \\
\text { classes sociais }\end{array}$ & $\begin{array}{c}\text { Baixo } \\
\text { peso }\end{array}$ & $\begin{array}{c}\text { Não baixo } \\
\text { peso }\end{array}$ & OR & $\begin{array}{c}\text { Intervalo de } \\
\text { confianca }\end{array}$ & p & $x^{2}$ \\
\hline Proletariado & 118 & 306 & 1,34 & $0,75-2,42$ & 0,3653 & 0,82 \\
\hline Burguesia & 19 & 66 & 1 & & & \\
\hline Total & 137 & 372 & & & & \\
\hline
\end{tabular}

Tabela 21 - Distribuição dos recém-nascidos de baixo peso e não baixo peso, odds ratio, intervalo de confiança, segundo a renda per capita. João Pessoa/PB, 2000.

\begin{tabular}{c|c|c|c|c|c|c}
\hline $\begin{array}{c}\text { Renda } \\
\text { per capita } \\
\text { (em salśrio mínimos) }\end{array}$ & $\begin{array}{c}\text { Baixo } \\
\text { peso }\end{array}$ & $\begin{array}{c}\text { Năo baixo } \\
\text { peso }\end{array}$ & OR & $\begin{array}{c}\text { Intervalo de } \\
\text { confiança }\end{array}$ & p & $x^{2}$ \\
\hline $\begin{array}{c}\text { Pobre } \\
(<0,5)\end{array}$ & 26 & 72 & 1,12 & $0,64-1,94$ & 0,7741 & 0,08 \\
\hline $\begin{array}{c}\text { Não pobre } \\
(>0,51)\end{array}$ & 71 & 220 & 1 & & & \\
\hline Total & $97 *$ & $292 *$ & & & & \\
\hline
\end{tabular}

$\left(^{*}\right)$ foram excluidos 40 casos e 80 controles sem informaçào da renda. 
Tabela 22 - Distribuição dos recém-nascidos de baixo peso e não baixo peso, odds ratio, intervalo de confiança, segundo a escolaridade materna no momento do parto. João Pessoa/PB, 2000.

\begin{tabular}{|c|c|c|c|c|c|c|}
\hline $\begin{array}{c}\text { Nível de } \\
\text { escolaridade }\end{array}$ & $\begin{array}{l}\text { Baixo } \\
\text { peso }\end{array}$ & $\begin{array}{l}\text { Não baixo } \\
\text { peso }\end{array}$ & OR & $\begin{array}{c}\text { Intervalo de } \\
\text { confianca }\end{array}$ & $\mathbf{p}$ & $x^{2}$ \\
\hline $\begin{array}{c}\text { Analfabeto + } \\
\text { básico incompleto }\end{array}$ & 23 & 72 & 0,78 & $0,38-1,59$ & 0,5680 & 0,33 \\
\hline $\begin{array}{l}\text { Básico completo + } \\
\text { fund. Incompleto }\end{array}$ & 64 & 164 & 0,95 & $0,53-1,71$ & 0,9721 & 0,00 \\
\hline $\begin{array}{l}\text { Fundamental comp. } \\
+ \text { Médio incompleto }\end{array}$ & 25 & 75 & 0,81 & $0,40-1,64$ & 0,5336 & 0,39 \\
\hline $\begin{array}{l}\text { Médio completo + } \\
\text { superior incompleto } \\
\text { Superior completo }\end{array}$ & 25 & 61 & 1 & & & \\
\hline Total & 137 & 372 & & & & \\
\hline
\end{tabular}

